$x^{2}$

$\stackrel{8}{2}$

Q

is

$\frac{\underline{H}}{5}$

¿ิ

嵌

\title{
THE PHOTOCHEMISTRY AND BIOCHEMISTRY \\ OF AROMATIC N-OXIDES
}

Algimantas Augustinas Alkaitis (Ph.D. Thesis)

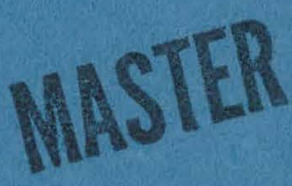

September 1970

AEC Contract No. W-7405-eng -48
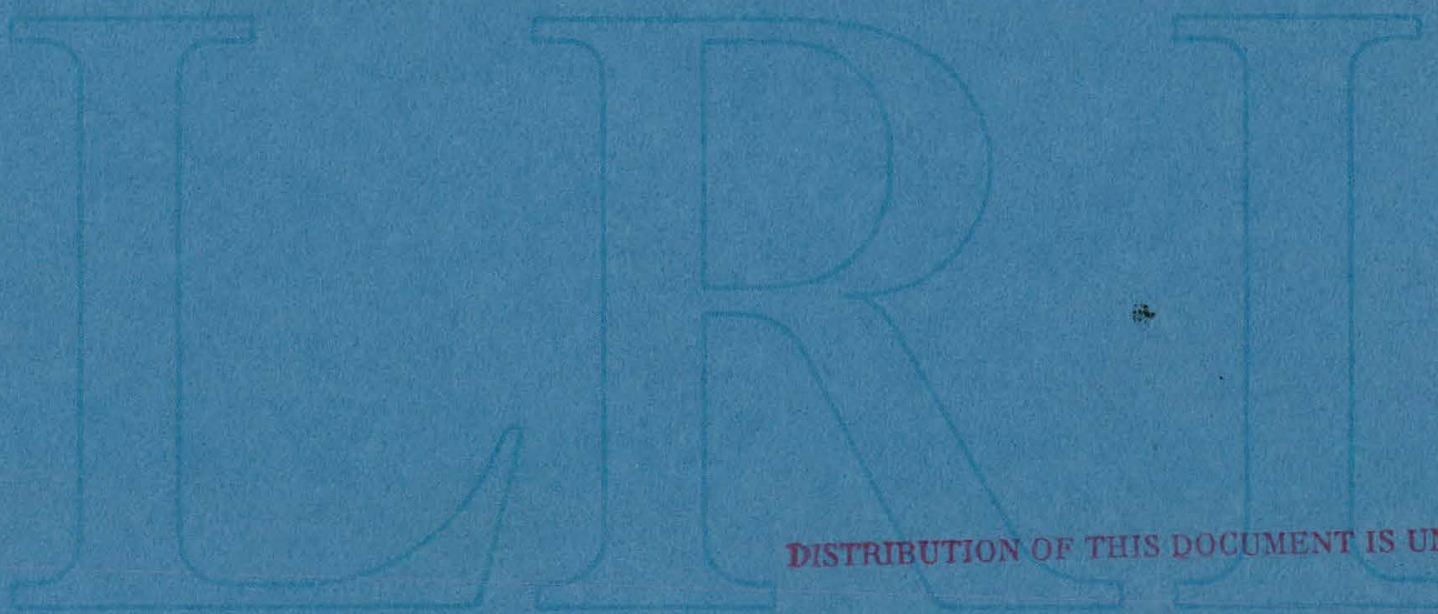

DISTRIBUTHON OF THIS DOCUMENT IS UNLIMITED 


\section{DISCLAIMER}

This report was prepared as an account of work sponsored by an agency of the United States Government. Neither the United States Government nor any agency Thereof, nor any of their employees, makes any warranty, express or implied, or assumes any legal liability or responsibility for the accuracy, completeness, or usefulness of any information, apparatus, product, or process disclosed, or represents that its use would not infringe privately owned rights. Reference herein to any specific commercial product, process, or service by trade name, trademark, manufacturer, or otherwise does not necessarily constitute or imply its endorsement, recommendation, or favoring by the United States Government or any agency thereof. The views and opinions of authors expressed herein do not necessarily state or reflect those of the United States Government or any agency thereof. 


\section{DISCLAIMER}

Portions of this document may be illegible in electronic image products. Images are produced from the best available original document. 
On the seventh day God rested

And God put man on the Earth and said to him -- you are the ruler of all this

Oh, God, let me be guided correctly

I look at the universe and I am in awe. A gift that I may even see what my eyes see, hear what my ears hear, feel what my body feels. And all that I see submits to me even the far reaches of space -but though I can examine and change and mold, yet all is creation and the basic nature does not change.

Your universe is vast -- I can see but a small piece of it. And I can understand but a little of it. May I submit and be guided correctly. And as I grasp the nature of things and use them, I see that all must answer to the God. For, indeed, this Earth is ruled by man, and man must answer to God for his uses. The burden of a ruler is vast, as vast as the subjects. For, if the ruler is unjust and goes contrary to the nature of his subjects, $h$ is kingdom will be torn apart. 0, Lord, forgive us for our pride and selfishness.

I came to Berkeley, and I shall leave it to itself.

Oh, Lord, may I use my intellect so that some of the problems of living here can be solved. May I do my work without jealousy, nor put it to unjust use. Guide me so that my people shall be free.

\section{LEGAL NOTICE}

This report was prepared as an account of Government sponsored work. Nelther the United

A nor the Commission, nor any person acting on behalf of the Comates racy, completeny waranty or representation, expressed or implied, win respect

of any information of the information contalned in this report, the accuprivately ormation, apparatus, method, or process disclosed in the report, or that the use vately owned rights; or

les with respect to the bis or,

As As used in the above, "person acting on behalf diclosed in this report.

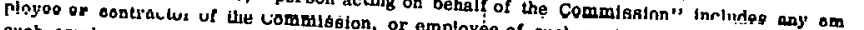
such employee or contractor of the Commigape of such contractor, to the extent that

disseminates, or provides access to any inform, or employee of such contractor prepares

with the Commission, or bisess to, any information pursuant to his employment or contes 
THIS PAGE

\section{WAS INTENTIONALLY \\ LEFT BLANK}




\section{TABLE OF CONTENTS}

Page

ABSTRACT

$-v-$

GENERAL INTRODUCTION

PART I: THE PHOTOCHEMISTRY OF AROMATIC N-OXIDES

1. Introduction 5

2. Photochemistry of Pyridine $\mathrm{N}$-Oxide $\ldots \quad . . \quad 9$

3. Photochemistry of Nicotinamide $\mathrm{N}$-0xide 27

4. Photochemical Oxygen Transfer from Pyridine $\mathrm{N}-$ Oxide to Cyclohexene

5. Photolytic 0xygen Transfer as a Model for Microsomal Hydroxylase

PART II: THE BIOCHEMISTRY OF AROMATIC N-OXIDES

1. Introduction

Mechanisms of oxidase systems

Role of nicotinamide in hydroxylases

Deliniation of thesis question

2. Nicotinamide $\mathrm{N}$-Oxidase

A. Enzymatic formation of nicotinamide $\mathrm{N}$-oxide 60

B. Reduction of nicotinamide $\mathrm{N}$-oxide $\quad 72$

3. Squalene Oxidase 77

4. Laurate Hydroxylase 97

5. Parahydroxybenzoate Hydroxylase 101 


$$
-i v-
$$

TABLE OF CONTENTS (continued)

PART III: CONCLUSION

ACKNOWLEDGEMENTS

REFERENCES 
THE PHOTOCHEMISTRY AND BIOCHEMISTRY OF AROMATIC N-OXIDES

\author{
Algimantas Augustinas Alkaitis \\ Laboratory of Chemical Biodynamics \\ Lawrence Radiation Laboratory \\ University of Cal ifornia \\ Berkeley
}

September 1970

\title{
ABSTRACT
}

The photochemistry of pyridine $\mathrm{N}$-oxide and nicotinamide $\mathrm{N}$-oxide was studied in various solvents. It was found that pyridine $\mathrm{N}$-oxide reacts in two ways when irradiated: 1) rearrangement and 2) loss of oxygen: Irradiation of pyridine $\mathrm{N}$-oxide in cyclohexene gave, besides the rearranged products; oxygenated cyclohexene compounds (cyclohexene oxide, cyclohexanol, and cyclohexanone). This oxygen transfer reaction scrved as a good model for the activation of molecular oxygen by mixed function oxidases.

The possibility that an aromatic $\mathrm{N}$-oxide, nicotinamide $\mathrm{N}$-oxide, might act as a discrete intermediate in the activation of molecular oxygen by mixed function oxidases was explored. The enzyme systems studied were the squalene epoxidase, laurate hydroxylase, and p-hydroxj̧benzoate hydroxylase. Nicotinamide $N$-oxide does not act as an oxygen source for these mixed function oxidases. 
GENERAL INTRODUCTION 


\section{General Introduction}

Since the discovery of oxygenase systems, the least understood step has been the incorporation of an oxygen atom into a substrate from molecular oxygen. This step has been referred to as the "oxygen activation" step. The topic of this thes is is the investigation of cofactors involved in oxygen activation. The particular possible cofactor studied is nicotinamide $\mathrm{N}$-oxide. Such a cofactor would fit into the following general scheme for "mixed function" oxidases:

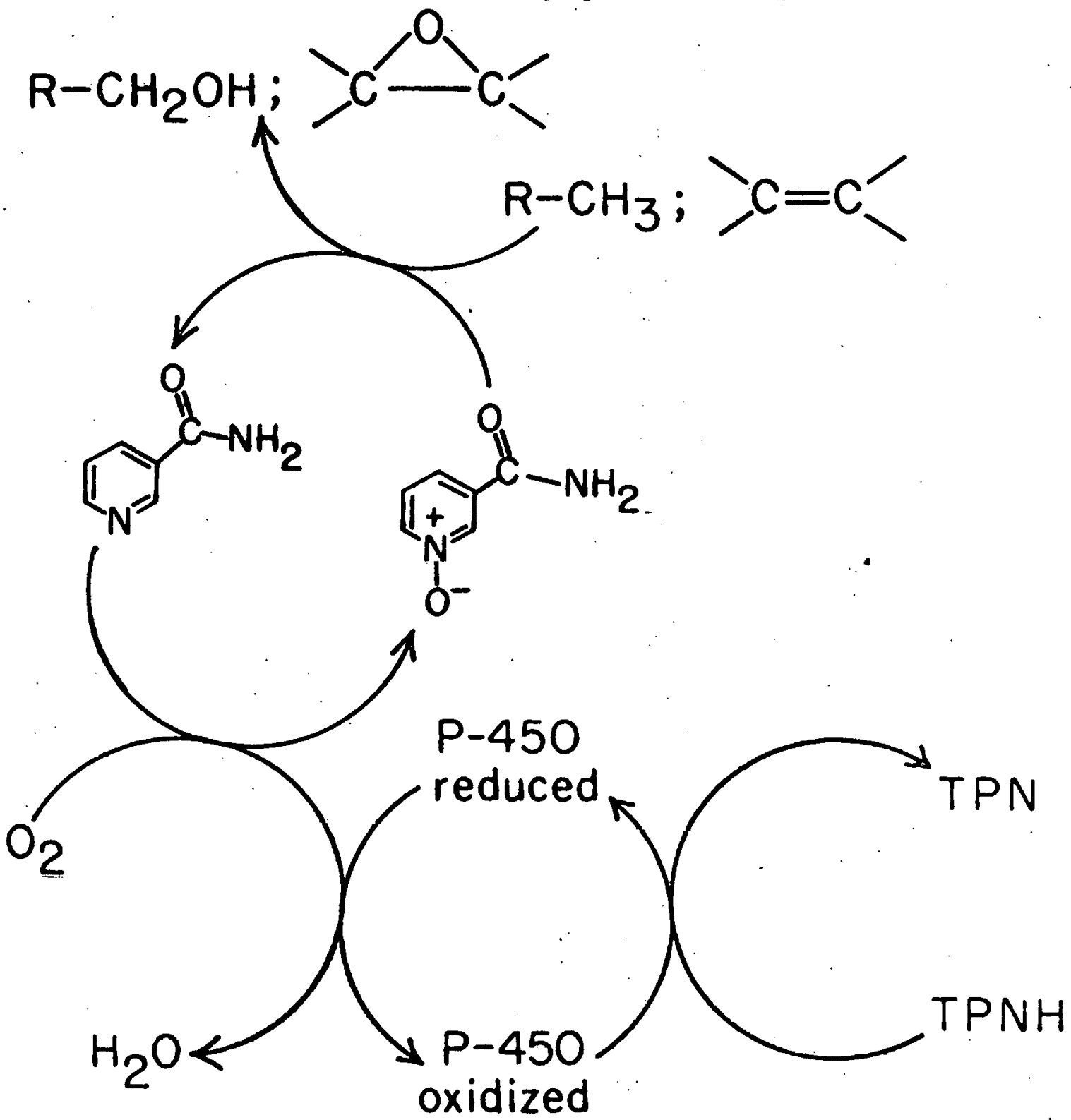


Several lines of evidence suggest nicotinamide $\mathrm{N}$-oxide as a cofactor in oxygen activation.

1. Direct oxygen transfer (determined by isotopic labeling) from nicotinamide $\mathrm{N}$-oxide to xanthine by xanthine oxidase:
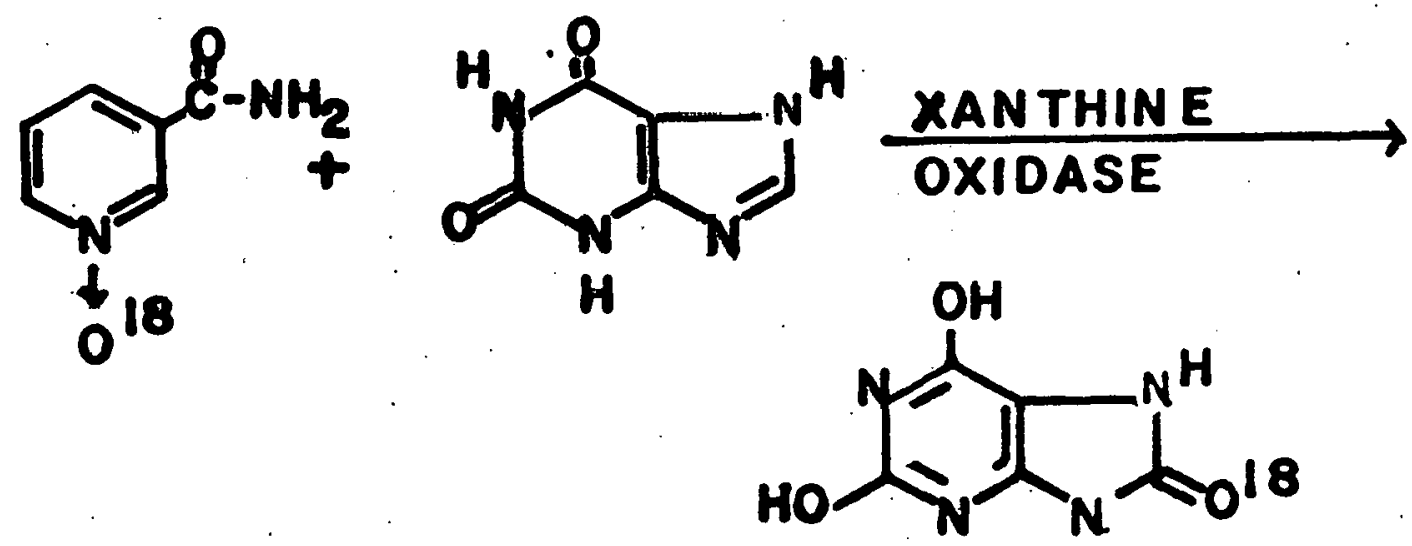

H

2. Increase in activity of enzyme systems (such as hydroxylation and oxidative dealkylation) in liver mlerosomes with the addition of nicotinamide. (These reactions also require TPNH and $0_{2}$.)

3. Experimentally determined production of nicotinamide $\mathrm{N}$-oxide from nicotinamide by rat liver homogenates.

4. By analogy to a model system: the photochemical transfer of oxygen from pyridine $\mathrm{N}$-oxide to cyclohexene. The photochemical trans fer from pyridine $\mathrm{N}$-oxide to aromatic substrates has reproduced the "NIH shift". (The NIH shift is a property of hydroxylase systems.) The postulated photochemical intermediate in the transfer of oxygen could be the same intermediate produced by hydroxylase. 

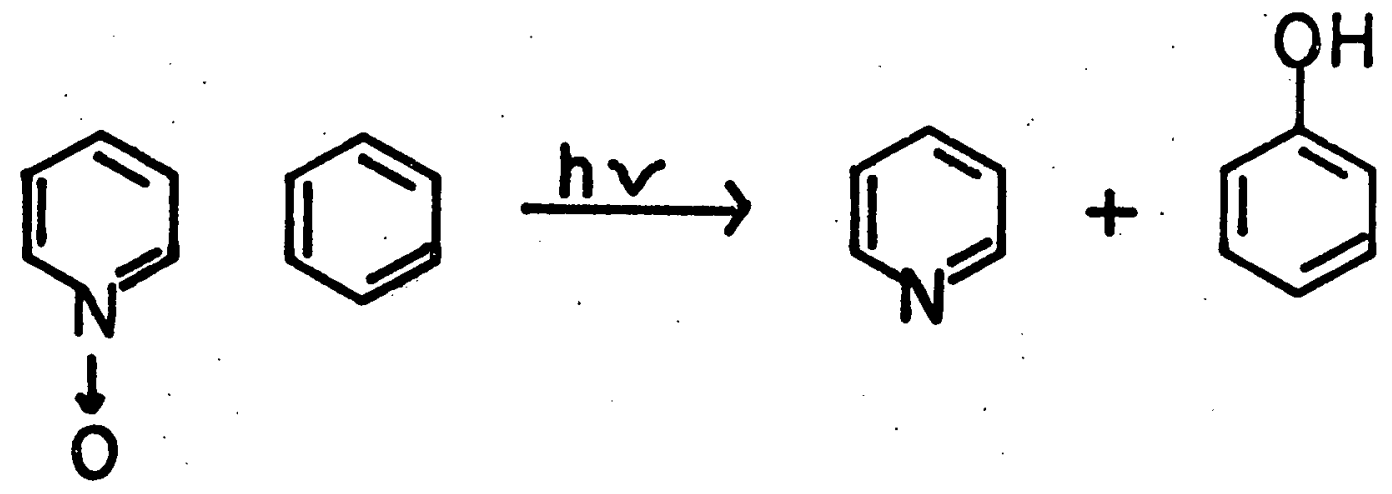

The experimental approach employed in testing the hypothesis that nicotinamide $\mathrm{N}$-oxide could act as a general cofactor in mixed function oxidase systems was as follows: Under anaerobic conditions, nicotinamide $\mathrm{N}$-oxide was introduced into the enzyme system instead of oxygen. The presence or absence of oxygenated substrate was then determined. Three enzyme systems were used-squalene oxidase and fatty acid hydroxylase in rat liver homogenates, and purified p-hydroxy benzoic acid hydroxylase from pseudomonas. In each case nitotinamide $\mathrm{N}$-oxide did not act as an oxygen donor. Therefore the transfer of oxygen from nitotinamide $\mathrm{N}$-oxide in the xanthine oxidase system cannot be generalized to mixed-function oxidase systems. However, the function of nicotinamide in microsoma? oxidations remains uncertain.

This thes is will be divided into two parts: The first will deal with the photochemis try of aromatic $\mathrm{N}$-oxides (a photochemical model for hydroxylase systems is developed); and the second will deal with the biochemistry of nicotinamide and nicotinamide $\mathrm{N}$-oxide. Failure of the nicotinamide $\mathrm{N}$-oxide to act as a general oxygen transfer agent is demonstrated. 


\section{Instrumentation}

The various instruments used throughout my thes is work are described below.

Infrared spectra ( $t R)$ were taken on a Perkin Elmer 257 instrument. Ultraviolet absorption spectra (UV) were taken on a Cary 14. Nuclear magnetic resonance (NMR) spectra were taken on a Varian $220 \mathrm{MHz}$ instrument and on a Varian A-60. Thanks is given to $\mathrm{Dr}$. Melvin Klein for assistance in operating these instruments. Gas liquid chromatography (GLC) was done on a Varian Aerograph 204 instrument equipped with a thermal conductivity detector. When a flame ionization instrument was needed, a F $8 M 5750$ was used. Mass spectra were taken on AEI MS 12 by Jerry Han. Scintillation counting was done on a P.ackard Model 3375 liquid scintillation counter. The scintillation fluid consisted of 4.5 grams 2,5-diphenyl oxazole and 0.5 grams p-bis-2-(5-phenyl oxazole)-benzene per liter of toluene. If aqueous solutions were counted, Beckman "Bio-Solv" solubilizers were added along with the aqueous solution to the scintillation fluid. Autoradiography was done with a Geiger tube built in this laboratory. 
Introduction

As with any exploratory scientific inquiry, the original questions asked lead to many different questions.

This is the evolution of my thesis problem. I started looking at the photochemical behavior of aromatic $\mathrm{N}$-oxides in solution.

There was a report that oxygen could be produced by the gas phase photolysis of pyridine N-oxide (Hata and Tanaka, 1962) (Fig. 1). This was a curious result and brought up speculations concerning the nature of the nitrogen-oxygen bond in such chemical systems. There had been some work done on similar structures in aliphatic compounds. Such a structure, (I), was found by J. Splitter and M. Calvin (1965) to produce an oxaziridine, (II), under photolytic conditions:
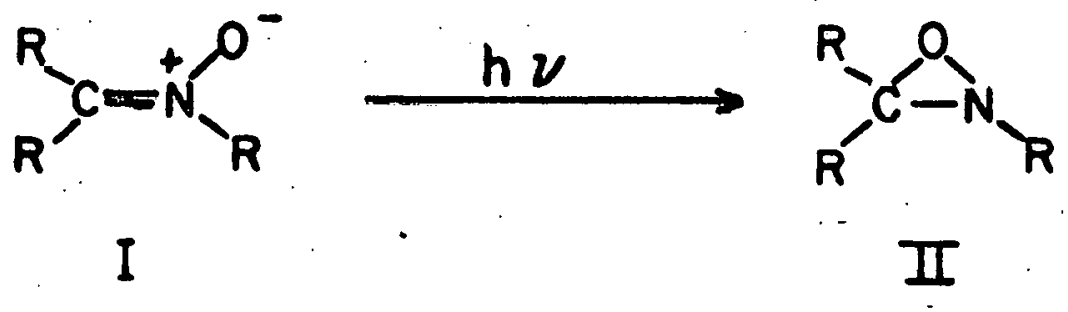

These oxaziridines, described chemical ly by Emmons (1957), proved to be good oxidants. This brought up the possibility that the primary product in the photolys is of pyridine $\mathrm{N}$-oxide was such an oxaziridine which then produced oxygen, possibly by a bimolecular mechanism. So I started by looking at the solution photochemistry of pyridine $\mathrm{N}$-oxide, since it was the simplest of the aromatic $\mathrm{N}$-oxides.

The photochemistry of pyridine $\mathrm{N}$-oxide turned out to be quite 


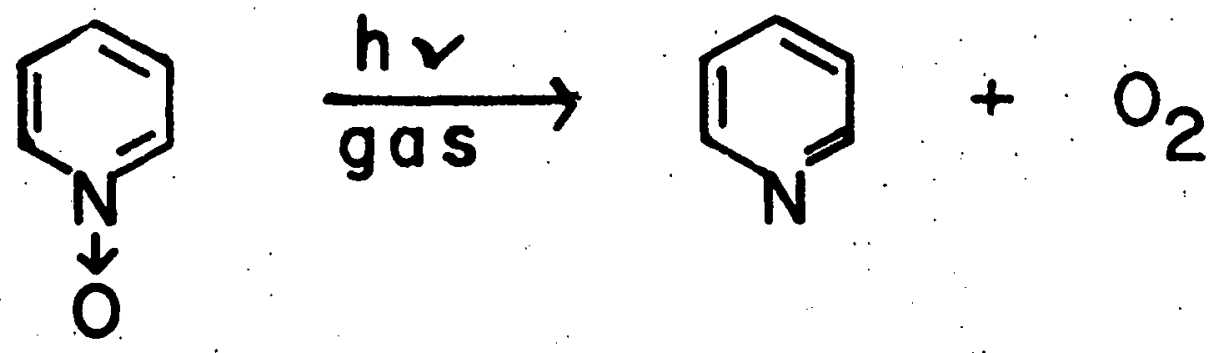

HATA \& TANAKA (1962)

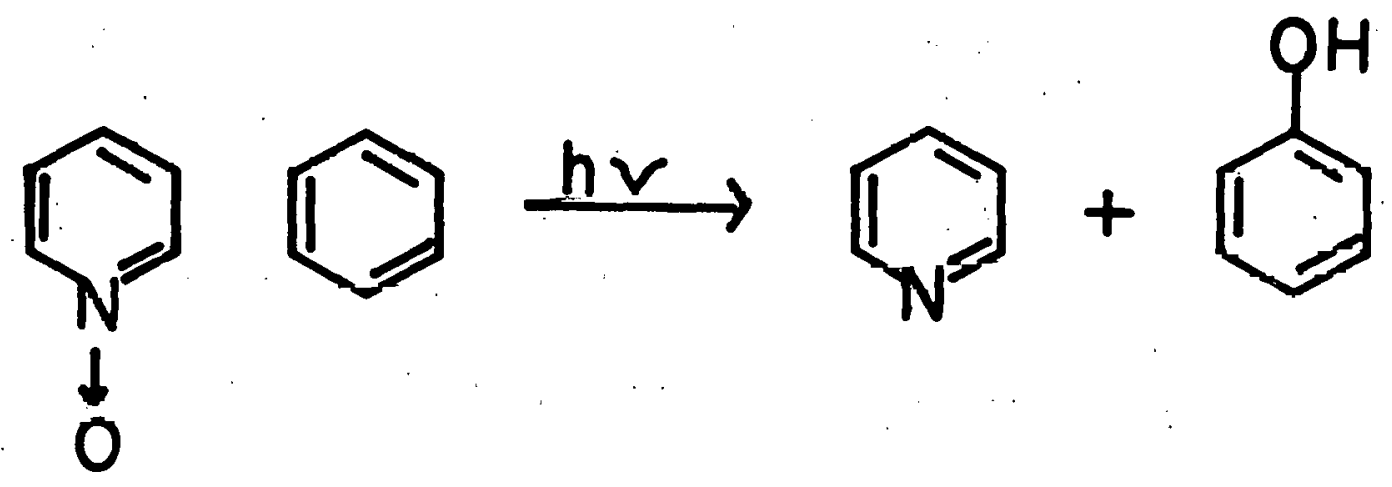

STREITH et al. (1967)

Figure 1. Photochemical reactions of pyridine $\mathrm{N}$-oxide. 
complicated. By analyzing the products, I found that the solvent was being oxidized during the phọtochemical reaction-i.i.e., acetaldehyde was produced from ethanol. This oxidation was very intriguing, bringing up the question of where the oxygen was going since pyridine was also a product of the photolysis. A very interesting question arose: Could the oxygen be transferred to another molecule? At this time a paper came out by Chaykin (1966) describing oxygen transfer from nicotinamide $\mathrm{N}$-oxide to xanthine catalyzed by xanthine oxidase. With this information, the problem became one of more general nature than exploring interesting chemistry. The possibility became apparent that these aromatic $\mathrm{N}$-oxides could act as oxygen sources in biological sys tems. Thus I embarked on the biochemical aspects of these aromatic $\mathrm{N}$-oxides.

At the same time, in investigating the photochemical oxygen transfer, the substrate I chose was cyclohexene: I hoped to produce the epoxide by transfer of oxygen from pyridine $\mathrm{N}$-oxide. At first the experiment failed due to difficulties in the experimental procedures. Then Streith and Sigwald (1967) (Fig. 1) published a paper describing the photochemical transfer of oxygen from pyridine $\mathrm{N}$-oxide to benzene to produce phenol. With renewed efforts, I was able to find the correct conditions to produce the cyclohexene oxide from cyel ohexene and pyridine $\mathrm{N}$-oxide.

With this reaction established, the biological aspects were pursued. These experiments and the results are reported in the second part of the thesis. 
Since my experiments, several key papers appeared substantiating the oxygen transfer reaction and relating this reaction to possible biological systems. In 1969, T. Tsuchiya et à . reported the production of cyclohexene oxide from pyridazine $\mathrm{N}$-oxides and cyclohexene; using the same photolytic conditions that I used. Also, very soon afterwards, there appeared a paper by Jerina, Boyd et af: (1970) showing that pyridine $\mathrm{N}$-oxide transferred its oxygen to a variety of aromatic and aliphatic substrates. The oxygen transfer paralleled the action of hydroxylase enzyme systems. Most exciting was their discovery that this photochemical model system reproduced the enzymatic "NIH shift". Thus the photochemical transfer of oxygen seems to be the best model system for studying the "activated" oxygen which hydroxylates substrates catalyzed by the oxygenase enzymcs.

In this first section. I would like to describe the photocliemical experiments which lead up to the development of such a model system for hydroxy lases. 
I-2 THE PHOTOCHEMISTRY OF PYRIDINE N-OXIDE 


\section{The Photochemistry of Pyridine $\mathrm{N}$-oxide}

\section{Introduction}

The main thrust of the experiments presented in this and the subsequent sections is to develop the photolytic reactions of aromatic $\mathrm{N}$-oxides as a model for biological oxidations. In particular, the photochemical transfer of oxygen from pyridine $\mathrm{N}$-oxide to a substrate may provide a key to the intermediate in oxygen activation by enzymes.

In this section, the products of the photolys is of pyridine $\mathrm{N}$-oxide will be described. These results have been published (A. Alkaitis and M. Calvin, 1967). There is an excellent review which is quite extensive and complete which includes the photochemistry of various aromatic N-oxides (G. Spence, E. Taylor, 0. Buchardt, 1970). This review puts these results which I will report into perspective regarding the chemical and photochemical behavior of aromatic $\mathrm{N}$-oxides. The chemistry of amine oxides is very well reviewed in Ochiai's book (1967).

\section{Experimental}

The synthes is of pyridine $\mathrm{N}$-oxide and other compounds described in this section will be discussed in the synthetic section. Acetaldehyde was purchased from Aldrich Chemical Company. Spectroquality pyridine was purchased from Hathesion, Ealeman and:Be11. GLC colum packing materials were obtained from Applied Sctences Lab.

The photolys is were carried out in a quartz water cooled immersion apparatus equipped with a Hanovia $450 \mathrm{~W}$ high pressure mercury lamp. The emitted light was filtered by means of various glass 
sleeves which surrounded the light. The solutions were stirred by means of a magnetic stirrer. thogen was bubbled through the solution through a sintered glass tube built into the solution chamber.

The pyridine $\mathrm{N}$-oxide was distilled, then purified by sublimation. The sublimator was opened in a dry box and the pyridine $\mathrm{N}$ oxide was transferred immediately into a volumetric flask, welghed, and dry solvent added. The above manipulation was needed since pyridine $\mathrm{N}$-oxide is extremely hydroscopic. A typical photolys is solution consisted of approximately 1 gram pyridine $\mathrm{N}$-oxide/100 ml solvent.

At the end of the photolysis, the reaction mixture was analyzed by gas-liquid chromatography (GLC). A stainless steel column (6 ft. $x 1 / 8$ inch), packed with a $2.5 \%$ FFAP on Chrom $G$ column material, was used extensively. A Porapak Q ( $3 \mathrm{ft} . \times 1 / 8 \mathrm{inch})$ column was used to separate acetaldehyde from ethanol. In order to identify the products and assign the GLC peaks properly, the volume of the photolys is mixture was reduœed in vacuo and the resulting concentrated solution was separated by means of a preparative GLC. An $8 \mathrm{ft}$. $x 1 / 4^{\prime}$ inch colum was used for this purpose. A 10:1 effluent splitter was used with one part of the effluent gas going to the flame detector and the other 9 parts going to a collection port. The quantities of products formed were determined by measuring areas under the peaks and comparing these to areas from standard solutions of the compounds. 


\section{Résults}

Fig. 1 shows the results of a typical run (photolysis of $1 \mathrm{~g} /$ $100 \mathrm{ml} \mathrm{RCH}{ }_{2} \mathrm{OH}$, 10 mole). With the pyrex filter, $50 \%$ of the starting material was recovered after 6 hours of photolysis. Using an all quartz system, $10 \%$ of the starting material was recovered after 10 min of photolysis.

Structure Determination of Products

The structure of I, II, IV, and V was proved by comparison of the GLC retention times, the IR spectra, the UV spectra, the NMR spectra, and the mass spectra to those of authentic samples (I and II were available commercially; IV and $V$ were synthesized).

The structure of III is believed to be as shown from the following evidence: the IR spectrum shows no N-H stretch at $3400 \mathrm{~cm}^{-1}$ and no carbonyl stretch. there is a strong absorption pattern at 1000 to $1550 \mathrm{~cm}^{-1}$ indicative of an acetal function. The NMR spectrum of III $(R=H)$ shows a sharp singlet at $3.2 \delta(6 \mathrm{H})$ and broad singlets at $5.7 \delta(1 \mathrm{H}), 6.05 \delta(2 \mathrm{H}), 6.75 \delta(2 \mathrm{H})$. The NMR spectrum of III $\left(\mathrm{R}=\mathrm{CH}_{3}\right)$ shows a triplet at $1.2 \delta(6 \mathrm{H})$, a quarter at $3.5 \delta(4 \mathrm{H})$, and broad singlets at $5.9 \delta(1 \mathrm{H}), 6.08 \delta(2 \mathrm{H}), 6.8 \delta(2 \mathrm{H})$.

The UV spectrum in EtOH of both $\mathrm{R}=\mathrm{H}$ and $\mathrm{R}=\mathrm{CH}_{3}$ shows $a \cdot \lambda_{\max }$ at

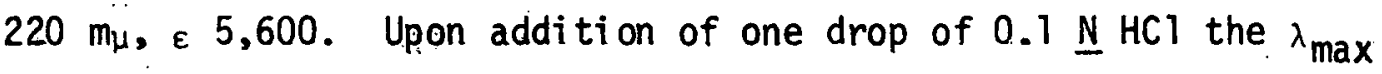
shifted to $235 \mathrm{mi}$ with an increase in $\varepsilon$. Upon addition of 3 drops of $0.1 \underline{\mathrm{N}} \mathrm{NaOH}$ the $\lambda_{\max }$ shifted to $210 \mathrm{~m} \mu$. Upon reacidification, there

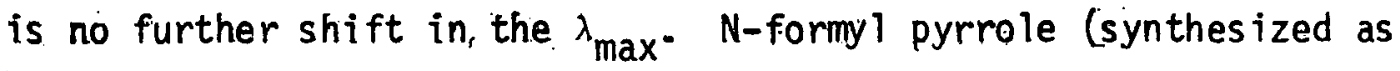
a standard for proof of V) shows a $\lambda_{\max }$ in $\mathrm{EtOH}$ at $235 \mathrm{m \mu}, \varepsilon 11,200$, 


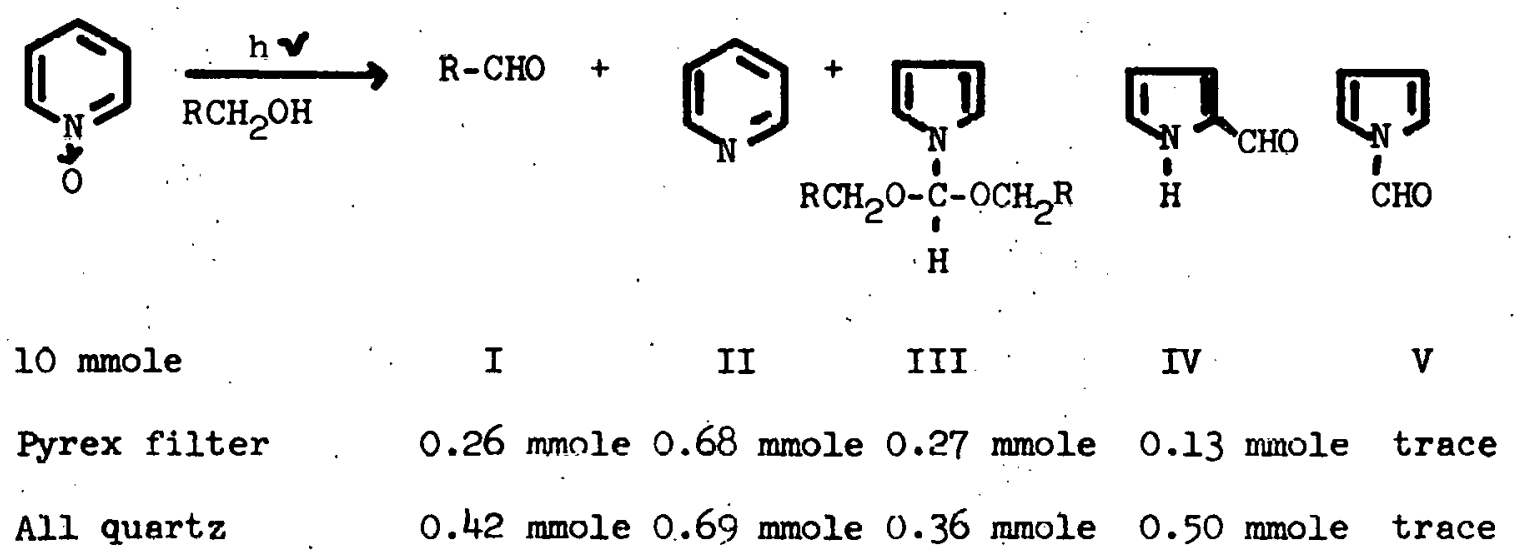

Figure 1. Photolysis of pyridine $\mathrm{N}$-oxide in ethanol and methanol. (See text for experimental details.) 
in the UV. Upon addition of 2 drops of $0.1 \mathrm{~N} \mathrm{NaOH}$, there is a shift of the $\lambda_{\max }$ to $210 \mathrm{mu}$. A parallel experiment was performed on a more concentrated solution of III and the reaction with acid or base was followed by GLC. The product of each of the reactions was collected and the UV taken of the fractions. The following reaction is consistent with the results. (It was found that III slowly hydrolyzed to $\mathrm{N}$-formyl pyrrole upon standing in ethanol solution.)
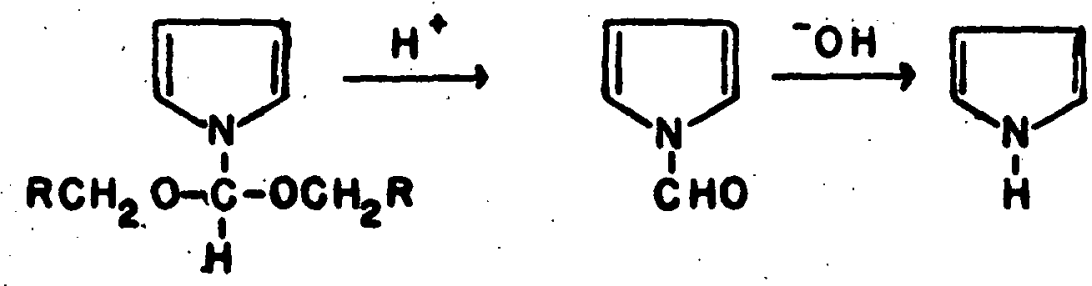

Elemental analysis of III, $\mathrm{R}=\mathrm{CH}_{3}$, agreed with the formul a $\mathrm{CgH}_{15} \mathrm{NO}_{2}$. A high resolution mass spectrum was taken of III $(R=H)$. (Thanks to Dr. H. Schnoess.) The base peak was $\mathrm{m} / \mathrm{e} 75\left(\mathrm{C}_{3} \mathrm{H}_{7} \mathrm{O}_{2}\right)$. The other major peaks were: parent peak ( $18 \%$ of base peak) at $\left.141\left(\mathrm{C}_{7} \mathrm{H}_{1} 1^{\mathrm{NO}}\right)_{2}\right)$; $\mathrm{m}-31, \mathrm{C}_{6} \mathrm{H}_{8} \mathrm{NO}$ (32\% base); $\mathrm{m}-46, \mathrm{C}_{5} \mathrm{H}_{5} \mathrm{NO}$ (30\% base); $\mathrm{m}-74, \mathrm{C}_{4} \mathrm{H}_{5} \mathrm{~N}$ (40\% base). The following scheme gives the formulation to the fragmentation pattern. 

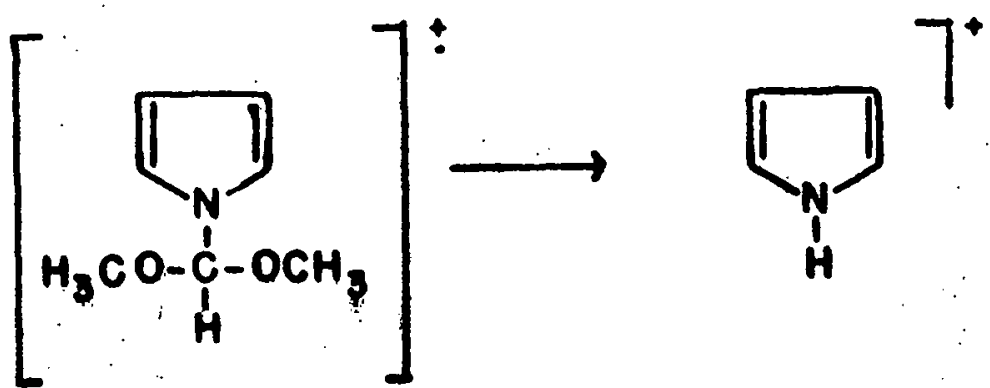

$\mathrm{m} / 67$

$$
m p 141
$$

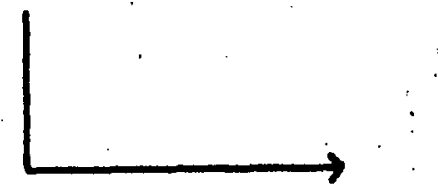

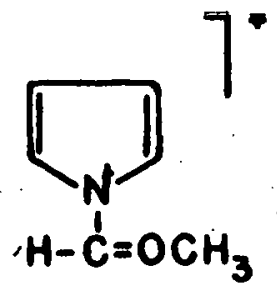

$m / e 110$<smiles>COCCCCOC</smiles>

$m / 875$<smiles>O=Cn1cccc1</smiles>

$\mathrm{m} / \mathrm{e} 95$

\section{Discyssion}

The photochemistry of the aromatic $\mathrm{N}$-oxides is interpreted in the light of the photochemistry of the nitrones since both have the same atomic arrangement around the nitrogen atom. The primany product of nitrone irradiation is the oxaziridine. Figure 2 gives the chemical formation of the oxaziridine and the identification of the oxaziridine structure (from H. Ono's thesis, 1969). Figure J shows some of the general reactions of the oxaziridines. Note the oxidation of iodide and the thermal rearrangement to the amide.

In the photochemistry of the aromatic $\mathrm{N}$-oxides, the most extensively studied series was the quinoline N-oxides. Figure 4 shows the primary rearranged photoproducts. The parent quinoline compounds 


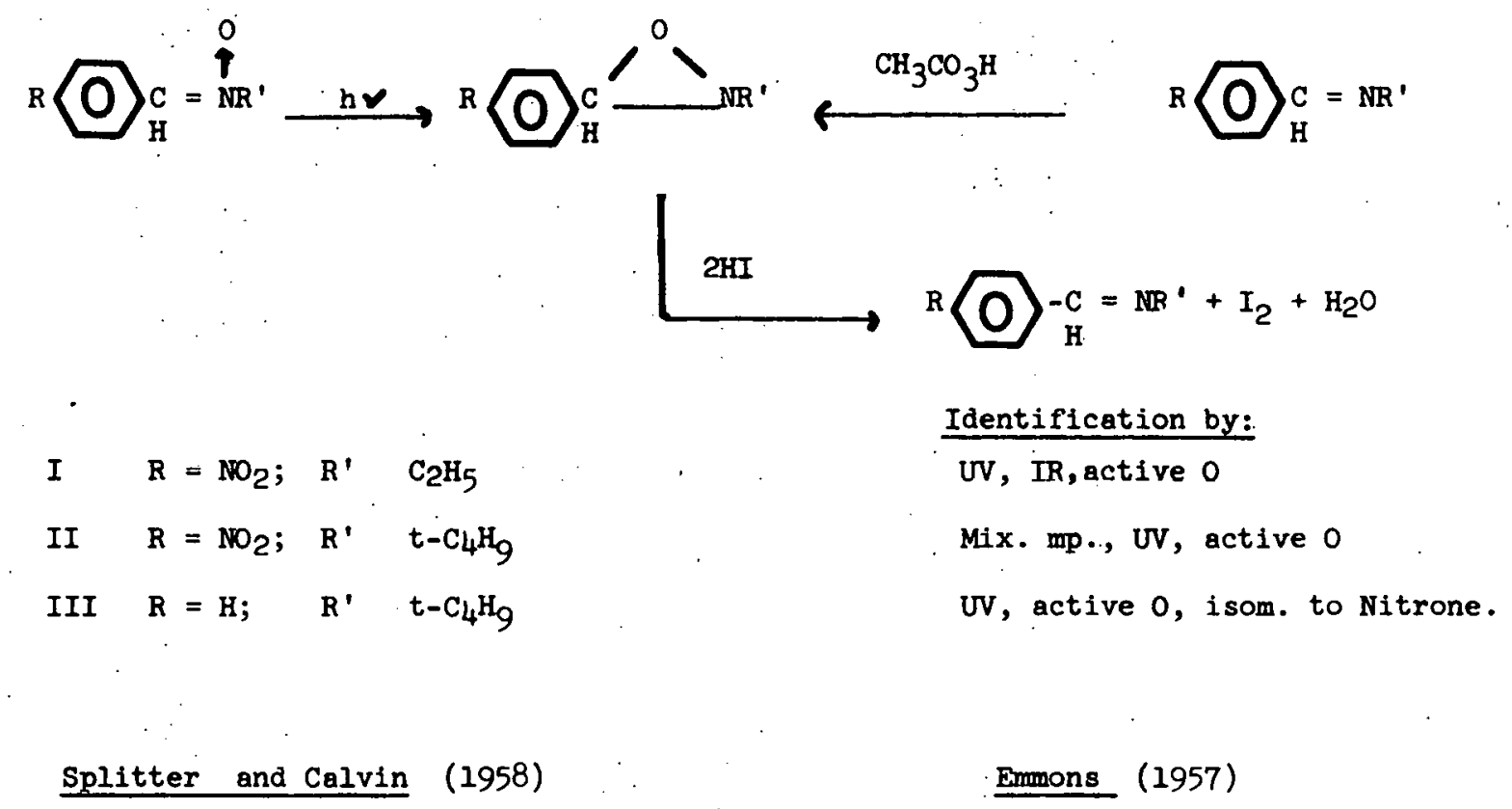

XBL 684-4167

Figure 2. Photochemical and chemical formation of the oxaziridine structure (from H. Ono, Ph.D. Thesis, University of California, 1969). 


\section{GENERAL REACTIONS OF OXAZIRIDINES}

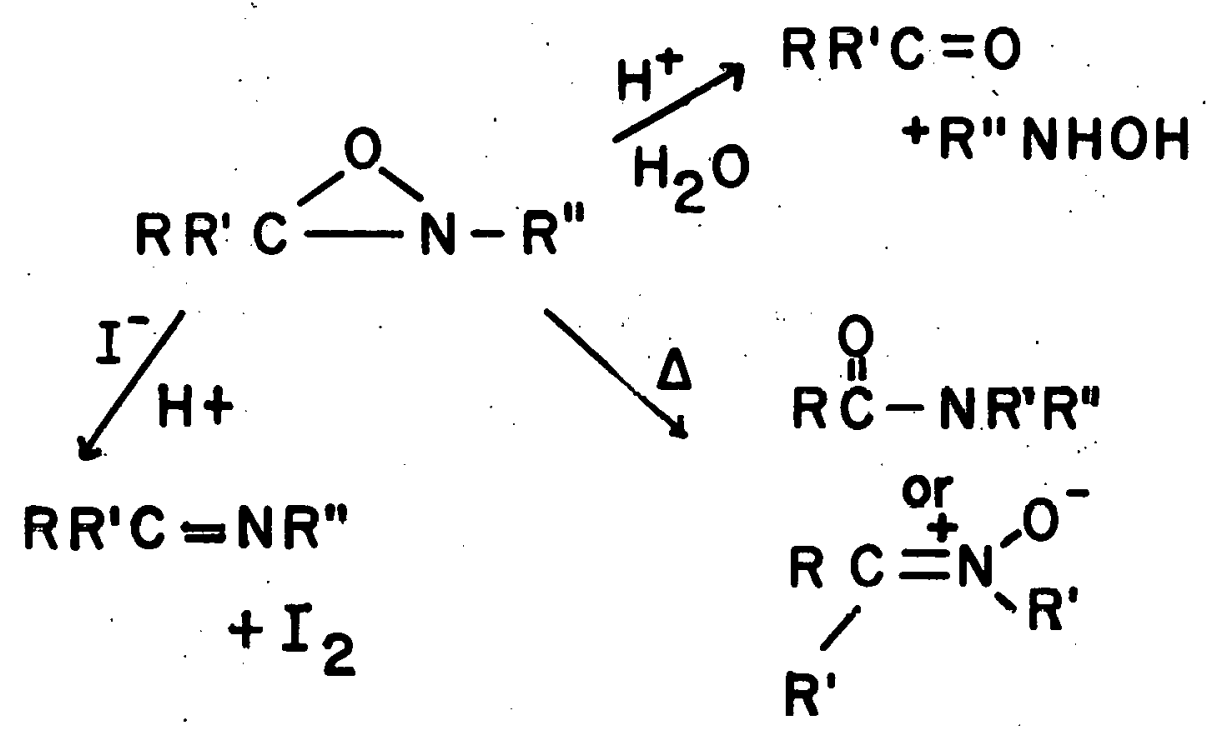

XBL 684-4159

Figure 3. General reactions of oxaziridines: solvolysis, rearrangement, and reduction of the oxaziridine. 


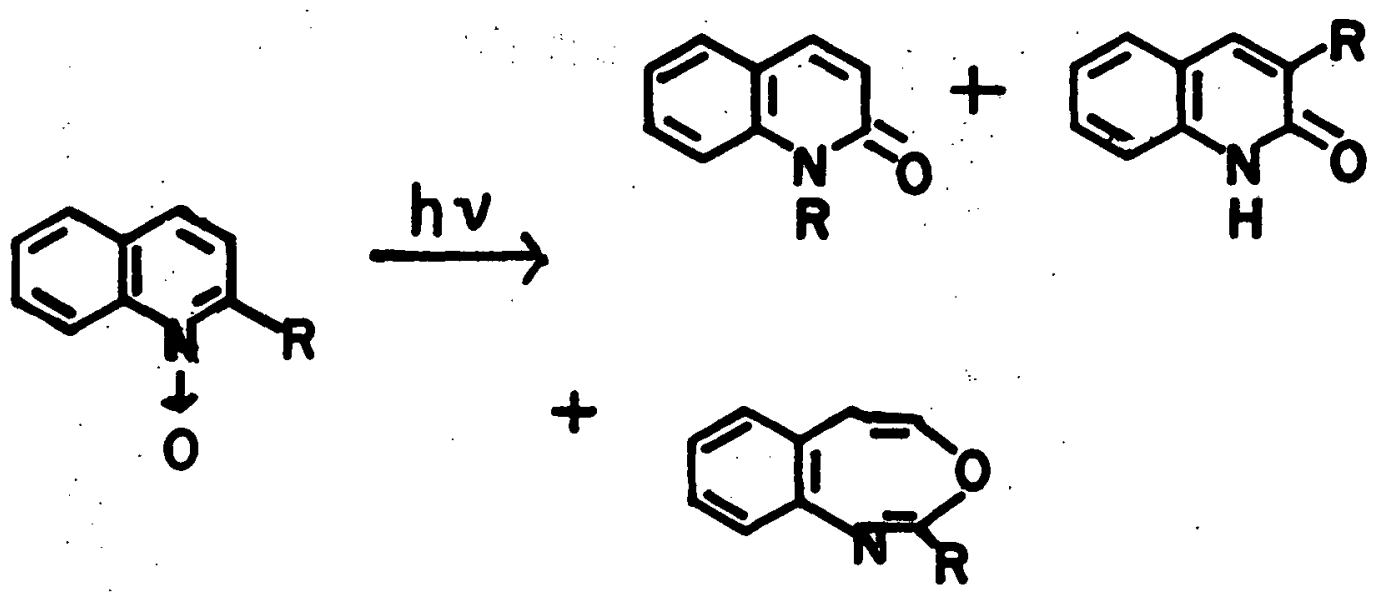

\section{BUCHARDT (1966) \\ KANEKO (1966)}

XBL $684-4190$

Figure 4. Primary products of the photolysis of substituted quinoline $\mathrm{N}$-oxide. 
were also formed in varying yields. A discussion of these and minor. sideproducts is given completely in the review cited (G. Spence et al., 1970). Although the pyridone derivatives were reported as products of the phtolysis of quinoline $\mathrm{N}$-oxides, no pyridone could be detected in the pyridine $\mathrm{N}$-oxide photolysis. Figure 5 shows some of the other products isolated as coming from secondary reaction of the primary formed 1,3-benzoxazepine. These products were only identified by means of an NMR. Very likely, III comes from such an intermediate oxazepine. However, the oxazepine from pyridine $\mathrm{N}$-oxide must be completely unstable, since there is no spectral evidence for such an intermediate in all the photolys is experiments with pyridine $\mathrm{N}$-oxide. (The UV of the oxazepines has an absorption band around $340 \mathrm{~nm}$.

Pyridine N-oxide, upon irradiation, showed no shift in the UV absorption band to longer wavelengths.) The photochemistry of pyridine $\mathrm{N}$-oxide did correspond to that of the quinoline $\mathrm{N}$-oxides.

It is generally postulated by analogy to the nitrone photochemistry (Fig. 2) that the first step in the photochemical reaction of the aromatic $\mathrm{N}$-oxide is the formation of the non-isolatable, unstable oxaziridine, with subsequent rearrangement.

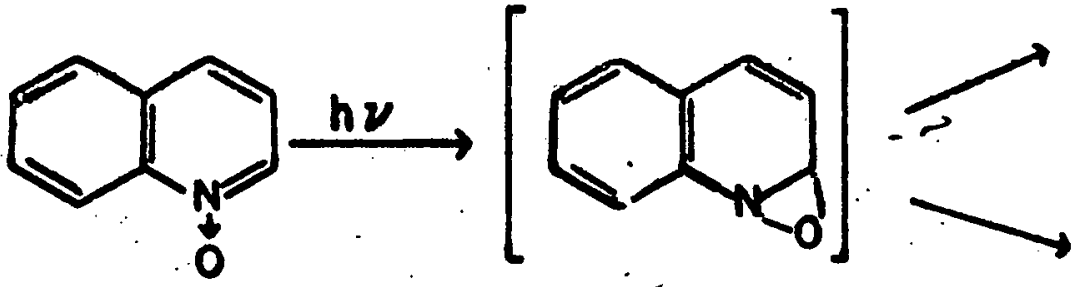<smiles>O=c1ccc2ccccc2[nH]1</smiles> 

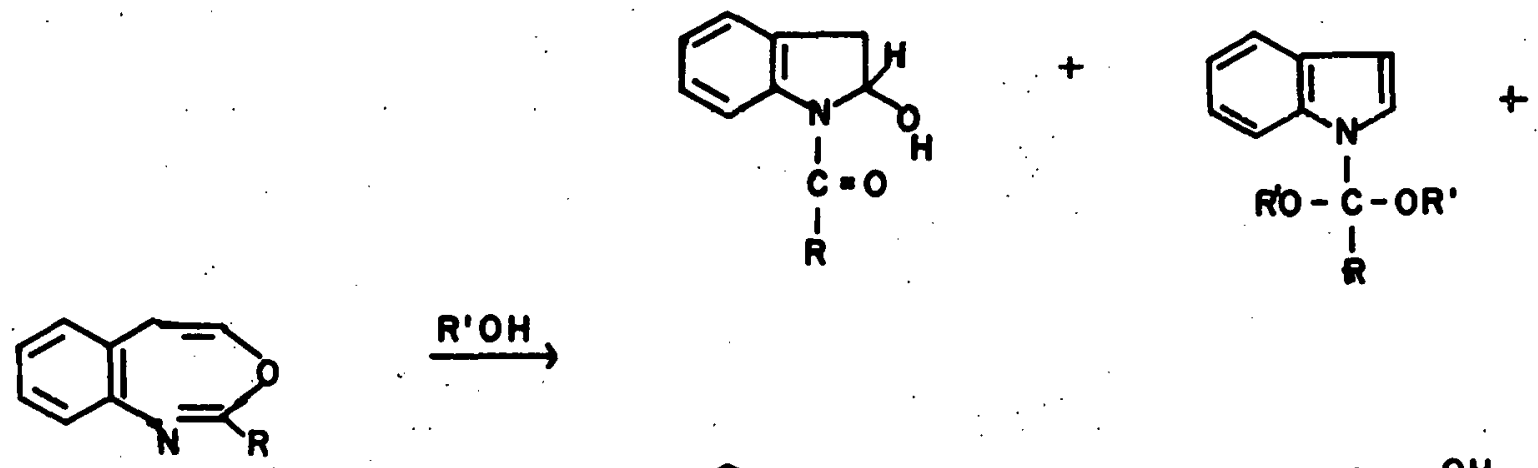

$\stackrel{\text { R'OH }^{\prime}}{\longrightarrow}$
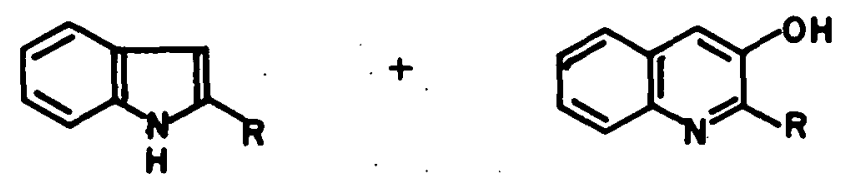

XBL $684-4192$

Figure 5. Reactions of benz-1,3 oxazepine with alcoholic solvents (Kabeko et al. (1966). 
The ifinding of the previously unreported oxidation product of the solvent (acetaldehyde from ethanol) is evidence for the more powerful oxidant, an oxaziridine, as an intermediate. It is known that an oxaziridine will oxidize iodide to fodine. Oxazepines, on the contrary, will reduce iodine to lodide (0. Buchardt, 1966). Since, in the oxidation of iodide by an oxaziridine the parent imine is formed as a product, the presence of the deoxygenated heternatomic compound may also be explained by the following reaction:

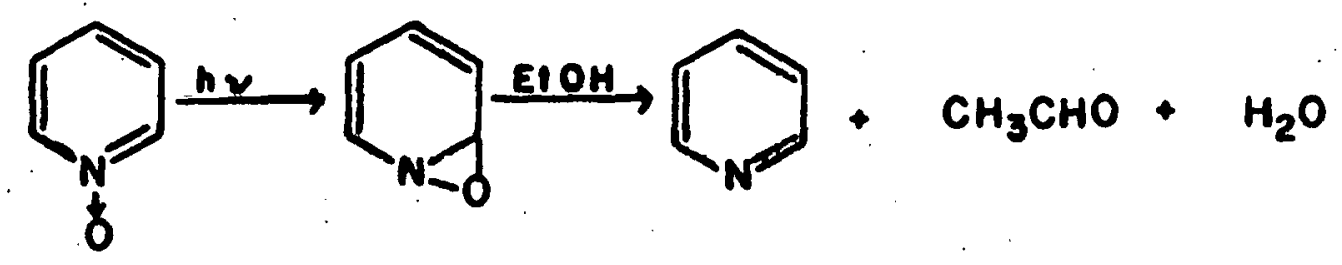

\section{$\ldots: \mathbf{V} \mathbf{I}$}

If the solvent is susceptible to oxidation by some photochemical intermediate, it may be possible to oxidize carbon-carbon double bond and obtain an oxygen transfer (perhaps to an epoxide) instead of a hydrogen abstraction as in the case of ethanol. Photochemical transfer of oxygen from pyridine $\mathrm{N}$-oxide to cyclohexene is discussed in Section 4.

\section{Synthesis of Pyridine $\mathrm{N}$-oxide}

The method described by E. Ochiai (1953) was employed. To a solution of $40 \mathrm{~g}$ pyridine in $300 \mathrm{ml}$ glacial acetic acid, $50 \mathrm{ml}$ of 
$35 \%$ aqueous hydrogen peroxide was added. The mixture was heated on a water bath at $80^{\circ} \mathrm{C}$. After 3 hours an additional $35 \mathrm{ml}$ peroxide (total of 1.7 moles) was added and the mixture was maintained at $80^{\circ} \mathrm{C}$ for an additional 9 hours. The mixture was concentrated to approximately $100 \mathrm{ml}$ in vacuum, diluted with $100 \mathrm{ml}$ water and again concentrated in vacuum as far as possible. The residue was made strongly alkaline with anhydrous sodium carbonate, shaken with $250 \mathrm{ml}$ chloroform and allowed to stand. The solution was filtered, dried with sodium sulfate, and the solvent removed. The residue was vacuum distilled. The yield of pyridine $\mathrm{N}$-oxide was $46 \mathrm{~g}(96 \%$ theoretical). The boiling point at $15 \mathrm{~mm}$ mercury was $138-140^{\circ} \mathrm{C}$. The melting point, taken in a sealed tube, was $66-67.5^{\circ} \mathrm{C}$. The main IR absorption bands in $\mathrm{cm}^{-1}$ are: 3300, 2950, 1700, 1450, 1250, $1185,1160,1015,900,840$. The UV absorption in maxima in methanol (molar extinction coefficients in parenthesis) are at $2630 \mathrm{~A}(12,800)$ and $2110 A(17,800)$.

Synthesis of Pyrrole Aldehyde (Pyrrole-2-carboxaldehyde)

The method used was the same as the one described in Organic Synthesis Coll. Vol. IV, 831 (1963). The UV absorption maxima in al cohol were $278 \mathrm{~nm}(\varepsilon=16,500)$ and $238 \mathrm{~nm}(\varepsilon-6,500)$. The IR maxima are in $\mathrm{cm}^{-1}: 3400,3200,2750,1645,1400,1340,1300,1280$, 1110. 1070, 1060, 1020. The MMR (on Varian A-60) showed multiplets centered at $\delta 6.2,6.8,7.1$ and doublet centered at $\delta 9.3(j=2 \mathrm{cps})$. Each of these absorption bands integrated for 1 proton. (The $\mathrm{N}-\mathrm{H}$ proton is very broad at $\delta 10$.$) The mass spectra (relative intensi-$ ties in parenthesis) showed $\mathrm{m} / \mathrm{e}$ at: $96(8), 95(100), 94(63), 93(2)$, 
$68(3), 67(39), 66(42), 65(1), 42(5), 41(5), 40(13), 39(6), 38(4)$. The mass spectra was taken on an AEI MS12.

Synthesis of $\mathrm{N}$-Formyl Pyrrole

$\mathrm{N}$-formyl pyrrole was able to be synthesized by a modification of the procedure used by N. Putochin (1926). (If the precise procedure is employed as described by Putochin, only pyrrole-2-aldehyde is obtained.) The synthetic route is outlined in the following reaction sequence:

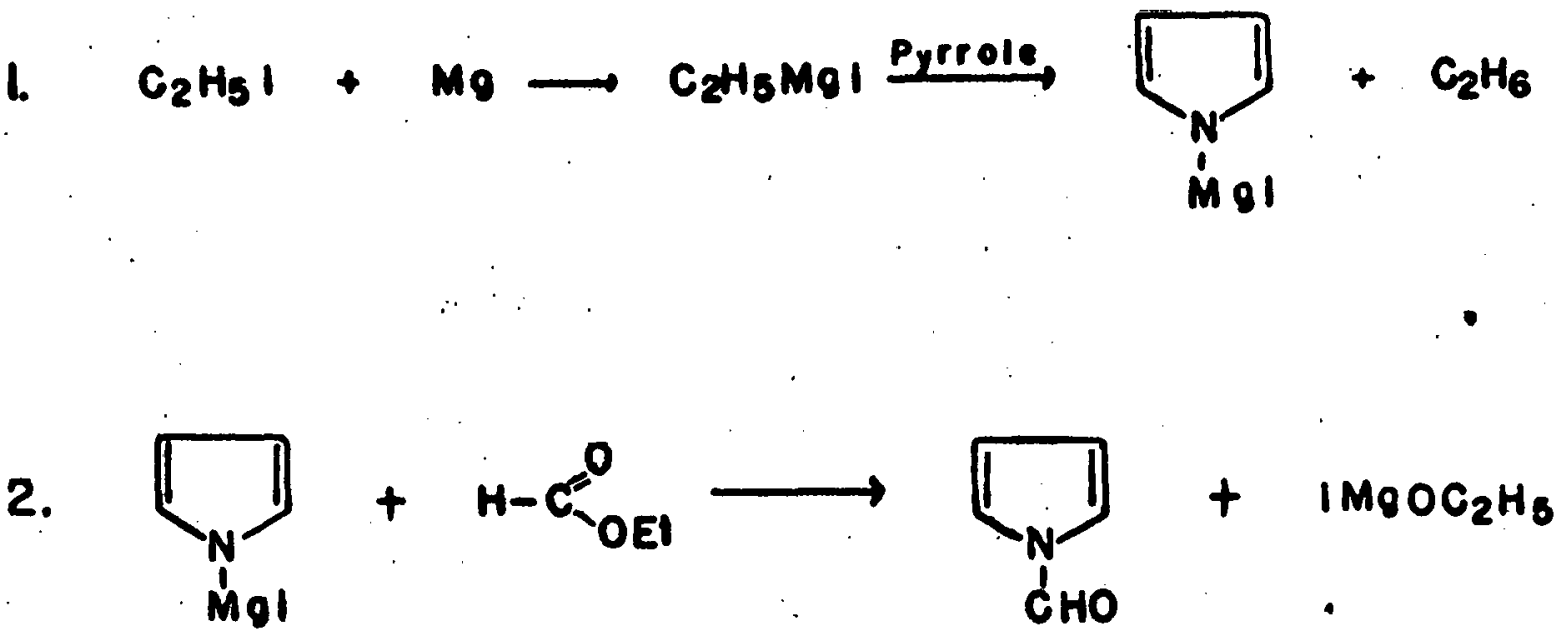

To a $50 \mathrm{ml} 3$-neck round bottom flask, fitted with a dropoing funnel, condensor, and mechanical stirrer with teflon paddle, is added first $2 \mathrm{ml}$ ether and $5.6 \mathrm{~g}$ magnesium and then is added in a $15-$ min interval a solution consisting of $30 \mathrm{~g}$ ethyl iodide in $30 \mathrm{ml}$ ether. The solution is then allowed to stir for an additional hour. To the grey solution is added $13 \mathrm{~g}$ of fresh distilled pyrrole in $8 \mathrm{ml}$ ether. The rate of addition of the pyrrole is adjusted to the 
rate of formation of gas (bubbles in the solutionL. Vigorous bubbling subsided after half of the pyrrole had been added. The grey-green solution is cooled to $-10^{\circ} \mathrm{C}$ by dry ice-acetone bath. To the cool reaction vessel is added very slowly $40 \mathrm{~g}$ of ethyl formate. It is extremely important to add the formate slowly enough and to keep the $\mathrm{flask}$ in a cold bath so that the temperature in the reaction vessel does not exceed approximately $-10^{\circ} \mathrm{C}$. The grey-green solution turns to a reddish-green syrup as the formate is being added. Additional ether was added to keep the viscous mass from solidifying. After the addition of the formate, $30 \mathrm{ml}$ cold water is added. The dark brown mixture is extracted with ether. The ether extracts are distilled under reduced pressure. The fraction boiling over at $40-50^{\circ} \mathrm{C}$ $(22 \mathrm{~mm} \mathrm{Hg}$ ) contained the product. This distilled fraction was then purified by means of preparative GLC $(25 \mathrm{ft} \times 1 / 4$ inch column, $5 \%$ SE 30 on (hrom W). The yield of $\mathrm{N}$-formyl pyrrole was approximately $10 \%$ of the theoretical yield.

The UV absorption maxima was at $235 \mathrm{~nm}(\varepsilon=10,000)$. The IR. spectrum showed the following maxima $\left(\mathrm{cm}^{-1}\right): 2800,1730,1720,1520$, $1460,1390,1320,1280,1230,1060,1040,930$. The NMR (on Varian A-60) spectra showed broad singlet absorption bands at 6.3 (2 protons), 7.3 ( 2 protons), and 8.8 (1 proton).ppm.

The fragmentation pattern from the mass spectrum is shown below: 


\begin{tabular}{cccc}
$\frac{m}{m} / \mathrm{e}$ & $\frac{\text { Relative intensity }}{37}$ & $\frac{\text { Rele }}{2}$ & \multicolumn{2}{c}{ Relative intensity } \\
37 & 21 & 63 & 3 \\
38 & 40 & 64 & 3 \\
39 & 100 & 65 & 2 \\
40 & 71 & 66 & 12 \\
41 & 87 & 67 & 52 \\
42 & 4 & 68 & 4 \\
44 & 14 & 94 & 2 \\
48 & 1 & 95 & 80 \\
49 & 3 & 96 & 7 \\
50 & 8 & & \\
51 & 6 & & \\
52 & 5 & &
\end{tabular}

Chemical behavior of $\mathrm{N}$-formy 1 pyrrole

It was found that $\mathrm{N}$-formyl pyrrole was insensitive to mild acid. There was no change in the UV absorption bands or in the retention times on the GLC upon addition of a few drops of concentrated $\mathrm{HCl}$ to a methanol solution of $\mathrm{N}$-formyl pyrrole. Upon the addition of a few drops of $1 \mathrm{M} \mathrm{NaOH}$ solution, the UV absorption maximum shifted to $210 \mathrm{~nm}$, and the retention times of the product on the GLC corresponded to pyrrole. This behavior is consistent with the behavior of the $\mathrm{N}$-formyl pyrrole produced by the hydrolys is of the product (III) from irradiation of pyridine $\mathrm{N}$-oxide in alcohol. 
IR and Mass Spectra of III

A. $\mathrm{R}=\mathrm{H}$

The IR spectra showed the following absorption maxima in $\mathrm{cm}^{-1}$ : $3000,2920,2870,2760,1700,1470,1430,1370,1310,1270,1240$, $1200,1180,1170,1100,1060,1050,980,950,890$.

The fragmentation pattern of a high resolution mass spectrum taken on a Consolidated Electronics Model 110 mass spectrometer (70 eV, source temp $270^{\circ} \mathrm{C}$ ) is given below:

\begin{tabular}{|c|c|c|}
\hline $\mathrm{m} / \mathrm{e}$ & Formula & Relative intensity \\
\hline & $\mathrm{CHNO}$ & \\
\hline 38 & 3200 & 13 \\
\hline 39 & 3300 & 49 \\
\hline 40 & 3400 & 18 \\
\hline 41 & 2310 & 32 \\
\hline 42 & 2410 & 2 \\
\hline 50 & 4200 & 4 \\
\hline 51 & 4300 & 7 \\
\hline 52 & 4400 & 4 \\
\hline 53 & 450.0 & 4 \\
\hline 66 & 4410 & 8 \\
\hline 67 & 4510 & 40 \\
\hline 75 & 3702 & 100 \\
\hline 76 & 3802 & 5 \\
\hline 80 & 5610 & 7 \\
\hline 81 & 5710 & 6 \\
\hline
\end{tabular}




\begin{tabular}{|c|c|c|}
\hline m/e & Formula & Relative intensity \\
\hline 94 & 5411 & 4 \\
\hline 95 & $\begin{array}{llll}5 & 5 & 1\end{array}$ & 28 \\
\hline 110 & $\begin{array}{llll}6 & 8 & 1 & 1\end{array}$ & 30 \\
\hline 141 & 71112 & 17 \\
\hline
\end{tabular}

B. $\mathrm{R}=\mathrm{CH}_{3}$

The IR spectra showed the following absorption maxima in $\mathrm{cm}^{-1}$ : $3000,2920,2870,2850,1540,1500,1470,1430,1410,1370,1310$, $1270,1240,1100,1060,1050,950,900,830$.

The fragmentation pattern of a low resolution mass spectrum taken on an AEI Model MS 12 mass spectrometer ( $70 \mathrm{eV}$, source temp $200^{\circ} \mathrm{C}$, glass inlet) is given below:

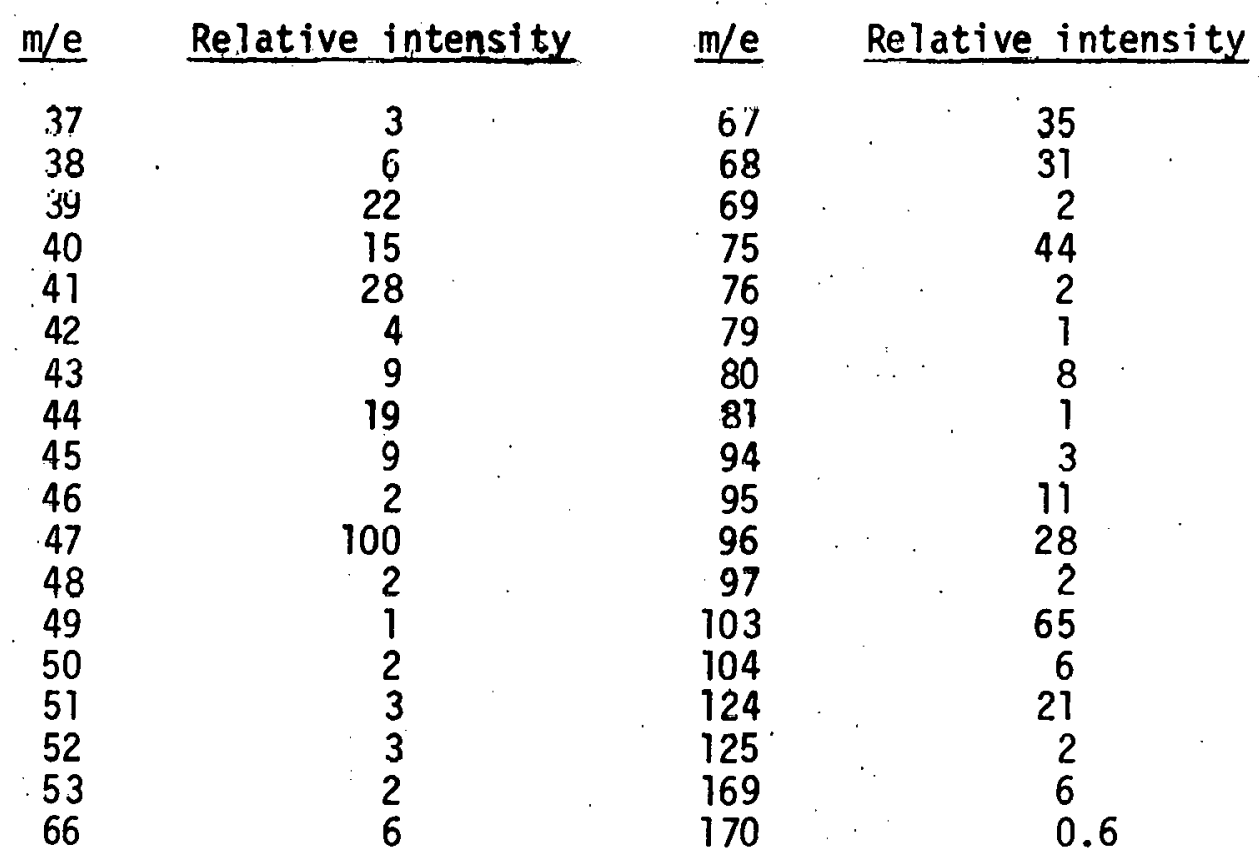


I-3 THE PHOTOCHEMISTRY OF NICOTINAMIDE N-OXIDE 
The Photochemistry of Ni cotinami de $\mathrm{N}$-Oxide

Introduction

Since nicotinamide is the aromatic heterocyclic compound implicated in biological oxidation reactions (see Section II-1), the photochemistry of nicotinamide $\mathrm{N}$-oxjide was studied. The problem with the study of the photochemical properties of nicotinamide $\mathrm{N}$-oxide is that the material is not soluble in many solvents. Ten grams nicotinamide $\mathrm{N}$-oxide dissolve in $1 \mathrm{ml}$ water. It is slightly soluble in methanol and ethanol (about $0.1 \mathrm{~g} / \mathrm{ml}$ ) and essentially insoluble in all the other common organic solvents. Thus it was impossible to test whether nicotinamide $\mathrm{N}$-oxide transferred oxygen to an olefin under photolytic conditions. It was, however, photoreactive in water, ethanol, or methanol. This was determined by the changes in the UV absorption spectrum: the $268 \mathrm{~nm}$ and $222 \mathrm{~nm}$ peaks decreased and a new absorption peak at $355 \mathrm{~nm}$ appeared. Although this particular photochemistry does not directly relate to the model system for biological hydroxylations, it adds to the elucidation of the photochemical behavior of derivatives of pyridine $\mathrm{N}$-oxide. There is certainly a marked change in the photochemical behavior of a pyridine $\mathrm{N}$-oxide when a substituent group is placed in the 3 position.

\section{Experimental}

Nicotinamide $\mathrm{N}$-oxide was synthesized using the procedure of E. Taylor and A. Crovetti (1954). The nicotinamide $\mathrm{N}$-oxide was recrystallized several times from a water-ethanol mixture. The 
characteristics of the product were the same as those reported for nicotinamide $\mathrm{N}$-oxide in the literature. The m.p. was $290-292^{\circ} \mathrm{C}$ (dec.). The UV spectrum showed absorption maxima at $268 \mathrm{~nm}^{\prime}(\varepsilon=11,000)$ and at $222(\varepsilon=20,000)$. The mass spectrum showed a large parent peak. ( $30 \%$ of the base peak) at $\mathrm{m} / \mathrm{e} 138$ and a large peak (base peak) at $\mathrm{m} / \mathrm{e} 122$.

Ni cotinamide $\mathrm{N}$-oxide was first irradiated using the same experimental procedure used in the irradiation of pyridine $\mathrm{N}$-oxide. Approximate ly $50 \mathrm{mg} / 100 \mathrm{ml}$ solvent (methanol, ethanol, water) were irradiated with a high pressure 450W Hanovia mercury lamp. The same results, with only a difference in the time course, were obtained from the irradiation of the nicotinamide $\mathrm{N}$-oxide with or without a pyrex filter. The reaction was monitored by taking a UV absorption spectra of aliquots taken at various times. It was found that initially only one soluble product was formed with an absorption peak at $355 \mathrm{nh}$. Under these conditions (quartz reactor) the initially formed product reached its height after 4 min of irradiation and was subsequently photolyzed. The final photolysis product was not identified. The fact that one soluble product was initially formed is deduced from the fact that there was an initial linear decrease in the UV absorption of nicotinamide at $268 \mathrm{~nm}$ with a concommitant linear increase in the absorption at $355 \mathrm{~nm}$. (An insoluble polymer also seems to form with irradiation.) There was an isoaspectic point at $310 \mathrm{~nm}$. However, the initially formed product, although it was stable in solution, decomposed or rearranged to several unidentified 
products when subjected to chromatographic procedures. Differential extraction with various solvents and attempts to crystallize the product failed.

Therefore, the initially formed product from the irradiation of nicotinamide $\mathrm{N}$-oxide in $\mathrm{D}_{2} \mathrm{O}$ was studied by means of NMR spectroscopy and UV spectros copy.

A solution of $5 \mathrm{mg}$ nicotinamide $\mathrm{N}$-oxide in $1 \mathrm{ml} \mathrm{D}_{2} \mathrm{O}$ was placed in an NMR tube. The NMR spectrum was recorded on a $220 \mathrm{MHz}$ spectrophotometer (Varian Associates). The NMR tube was then placed in a rayonette photolys is apparatus equipped with $2537 \%$ Tahos. After set times $(81,360$, and $577 \mathrm{~min})$ of irradiation, the UV absorption spectrum and the NMR spectrum were recorded. The UV spectrum was determined by removing $15 \lambda$ of the irradiated solution, diluting it with $15 \mathrm{ml} \mathrm{H}_{2} \mathrm{O}$, and recording the UV absorption spectrum.

Results:

The UV absorption spectrum, taken at the indicated times of irradiation, of nicotinamide $\mathrm{N}$-oxide in $\mathrm{D}_{2} \mathrm{O}$ is shown in Figure 1 . The $350 \mathrm{~nm}$ absorption peak increased with time of irradiation, whereas the $265 \mathrm{~nm}$ and the $222 \mathrm{~nm}$ peaks decreased: Despite the length of time that the sample was irradiated, a single soluble product seemed to be formed as evidenced by the simple UV absorption spectra and a very clean NMR spectra (one set of absorption peaks disappear and another set of absorption peaks appear). However, the intensity of the NMR peaks diminished with increased times of irradiation. This is indicative that some insoluble side product, or subsequent 


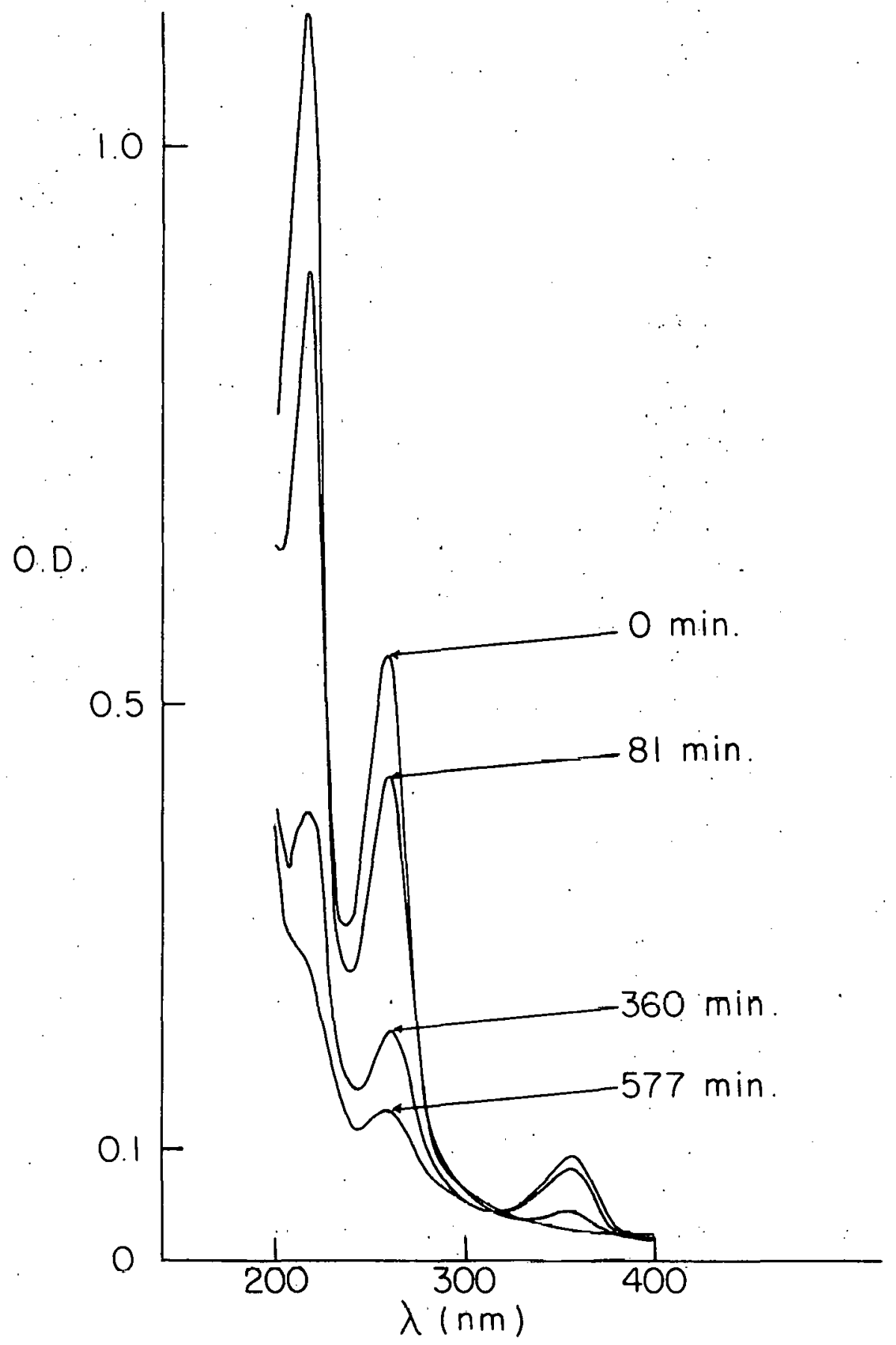

XBL 703-5121

Figure 1. The UV absorption spectra of a solution of nicotinamide $\mathrm{N}$-oxide in $\mathrm{D}_{2} \mathrm{O}$, after irradiation for various lengths of time. See text for details. 


\section{IRRADIATION OF NICOTINAMIDE N-OXIDE ( $5 \mathrm{mg} / / \mathrm{ml} \cdot \mathrm{D}_{2} \mathrm{O}$ in NMR tube)}<smiles>CO[n+]1c(C)c(O)c(P)c(C(N)=O)c1C</smiles><smiles>Cc1nc(C)c(C(N)=O)c([18OH])c1C(N)=O</smiles>

\section{$220 \mathrm{MHz}$ NMR}

$$
\begin{array}{llll}
\nu_{a}=7.75 & J_{a b}=8.0 & \nu_{a}=7.63 & J_{a b}=8.0 \\
\nu_{b}=8.11 & J_{a c}=6.0 & \nu_{b}=8.26 & J_{a c}=4.5 \\
\nu_{c}=8.46 & J_{a d}=0.3 & \nu_{c}=8.70 & J_{a d}=1.2 \\
\nu_{d}=8.72 & J_{b c}=1.8 & \nu_{d}=8.92 & J_{b c}=3.0 \\
J_{b d} & =0.5 & & J_{b d}=1.8 \\
J_{c d} & =1.0 & & J_{c d}=1.2
\end{array}
$$

XBL 703-5120

Figure 2. Assigned structure of the product of irradiation of nicotinamide $\mathrm{N}$-oxide in $\mathrm{D}_{2} \mathrm{O}$. Whether the product is a 1,2 or a 1,3 oxazepine is unable to be determined. The NMR (220 MNz, Varian Associates instrument) of the starting nicotinamide $\mathrm{N}$-oxide and the product of the irradiation is given. The chemical shifts are in del ta units. $J$ is the coupling constant in cps. 
insoluble rearranged product, is being formed. Figure 2 shows the NMR spectrum of the starting nicotinamide $\mathrm{N}$-oxide and of the resultant product after irradiation for $577 \mathrm{~min}$. The possible structures of the photolysis product which are consistent with the data are drawn. This assignment is tentative until the product is isolated and purified.

The NMR spectra, taken at the times of irradiation indicated, showed a very clean conversion to a single soluble product. The nicotinamide $\mathrm{N}$-oxide had absorption peaks in the NMR at $7.75,8.11$, 8.46, and $8.72 \mathrm{ppm}$. Each peak integrated to one proton. After 81 min of irradiation, three of the NMR peaks decreased in height (7.75, $8.11,8.46 \mathrm{ppm})$ and three new peaks appeared $(7.63,8.26,8.92 \mathrm{ppm})$. After 360 min of irradiation, it appeared that approximately haif of the nicotinami de $\mathrm{N}$-oxide had been converted to the product. The NMR spectrum showed 7 absorption bands integrating in a ratio of $1: 2: 1: 1: 1: 1: 1$ at $8.92,8.70,8.46,8.26,8.11,7.75$, and $7.63 \mathrm{ppm}$. After $577 \mathrm{~min}$ of irradiation, the NMR peaks of the original nicotinamide $\mathrm{N}$-oxide had disappeared, and only four peaks remained at $7.63,8.26,8.70$, and 8.92 . These peaks integrated with a ratio of $1: 1: 1: 1$.

Discussion

The product of the photolysis of nicotinamide $\mathrm{N}$-oxide is very different from the products of the photolysis of pyridine $\mathrm{N}$-oxide. The formation of a 7 -member ring when nicotinamide $\mathrm{N}$-oxide is irradiated may indicate that the same type of 7 -member ring is formed on irradiation of pyridine $\mathrm{N}$-oxide. This 7 -member ring, formed from pyridine $\mathrm{N}$-oxide, would not be stabilized by a carboxamide group and would 
rearrange to give the final isolable products as reported in the previous section. Also, the formation of such a 7-member ring as an intermediate in the photolysis of aromatic $\mathrm{N}$-oxides (benzoxazepines have been isolated from the photolys is of quinoline $\mathrm{N}$-oxides) lends support to an initially formed oxaziridine structure. The oxaziridineoxazepine rearrangement is analogous to the benzene oxide-oxepine rearrangement.

The assignment of the oxazepine structure as the soluble product of the irradiation of nicotinamide $\mathrm{N}$-oxilde is consistent with the spectral data presented. The oxazepine structure has been unequivocally identified (by $X$-ray crystallography) as a product in the photolysis of quinoline $\mathrm{N}$-oxides (Buchardt et al., 1970). It is not possible to determine whether the product from irradiation of nicotinami de $\mathrm{N}$-oxide is the 1,2 or the 1,3 oxazepine. The 1,3 oxazepine is the one formed on irradiation of quinoline $\mathrm{N}$-oxides. It would be extremely interesting if the 1,2 oxazepine were the structure formed on irradiation of nicotinamide $\mathrm{N}$-oxide. This would be the first 1,2 oxazepine found. A study of the substituent effects on the photolys is of the pyridine $\mathrm{N}$-oxide could provide insights into the mechanism of the photolytic reaction. 
I -4 PHOTOCHEMICAL OXYGEN TRANSFER FROM PYRIDINE N-OXIDE TO CYCLOHEXENE 


\section{Photochemical Oxygen Transfer from Pyridine $\mathrm{N}$-oxide to Cyclohexene}

Introduction

It was found (Section I-2) that pyridine $\mathrm{N}$-oxide, upon irradiation with ultraviolet light, can be converted to an active intermediate capable of oxidizing an alcohol to an aldehyde. Two questions immediately arise: What is the nature of this active intermediate, and can this active intermediate transfer oxygen to some acceptor molecule? The nature of this active intermediate will be discussed in the next section. In this section the transfer of oxygen under photolytic conditions from pyridine $\mathrm{N}$-oxjide to cyclohexene will be presented. Cyclohexene was chosen as an oxygen acceptor since all of the simple oxygenated products of cyclohexene were readily available.

\section{Experimental}

Cyclohexene, chromatoquality, was purchased from Matheson, Coleman, and Bell. It was found by GLC that this cyclohexene contained appreciable quantities of oxygenated products, particularly cyclohexenol and cyclohexenone. (Purified cyclohexene upon standing in air will rapidly form cyclohexenone and cyclohexenol.) Therefore the cyclohexene was purified by GLC and stored under helium before using. The GLC instrument used was a F \&M Mode 1775 equipped with a $12 \mathrm{ft} \times 3 / 4$ inch column (20\% Carbowax 20M on Chrom W, Applied Science). Pyridine $\mathrm{N}$-oxide was used in the same marmer as described in the provious section (I-2). Cyclohexene oxide, cyclohexanol, and cyclohexanone were purchased from Aldrich Chemical Co. Cyclohexenone and cyclohexenol were a yift of Mr. Bruck Radclift in the Chemistry Department. 
Pyridine $\mathrm{N}$-oxide was not soluble in the cyclohexene to any appreciable amount. It was found that pyridine $\mathrm{N}$-oxide was very soluble in methylene chloride, and was photoreactive in this solvent. Therefore pyridine $\mathrm{N}$-oxide was made soluble in cyclohexene by addition of $20 \%$ methylene chloride. The irradiation $(0.5$ g pyridine $\mathrm{N}$-oxide in $20 \%$ methylene chloride in cyclohexene) was carried out in a quartz, water-cooled immersion apparatus equipped with a Hanovia $450 \mathrm{~W}$ high pressure mercury lamp. A vycor sleeve was used to filter the light. The photolys is solution was flushed with dry nitrogen (scrubbed with basic pyrrogallol) for 45 min before the irradiation was started. After the irradiation was complete, samples of the photolysis mixture were injected into a glc (F\&M Model 5750) equipped with a 2.5\% FFAP column (on Gaschrom Q, Applied Sciences). The quantities of products formed were determined by measuring the area under each peak. Areas were related to quantity by measuring areas under peaks of known concentration of standard compounds.

Results

The results of a typical run are given:in Figure 1. The figure shows a glc trace of the products obtained from an 8-min photolys is of pyridine $\mathrm{N}$-oxide in cyclohexene (20\% methylene chloride). Approximately $1 / 2$ of the pyridine $\mathrm{N}$-oxide remained after $8 \mathrm{~min}$ of photolysis. The quantities of the products formed are given below. (Initial amount of pyridine $\mathrm{N}$-oxide $=5$ mmoles.)

Product

cyclohexene oxide pyridine cyclohexanone cyclohexanol

2 formy 1 Pyrrole mmoles formed

0.1

0.8

0.1

0.01

0.1 


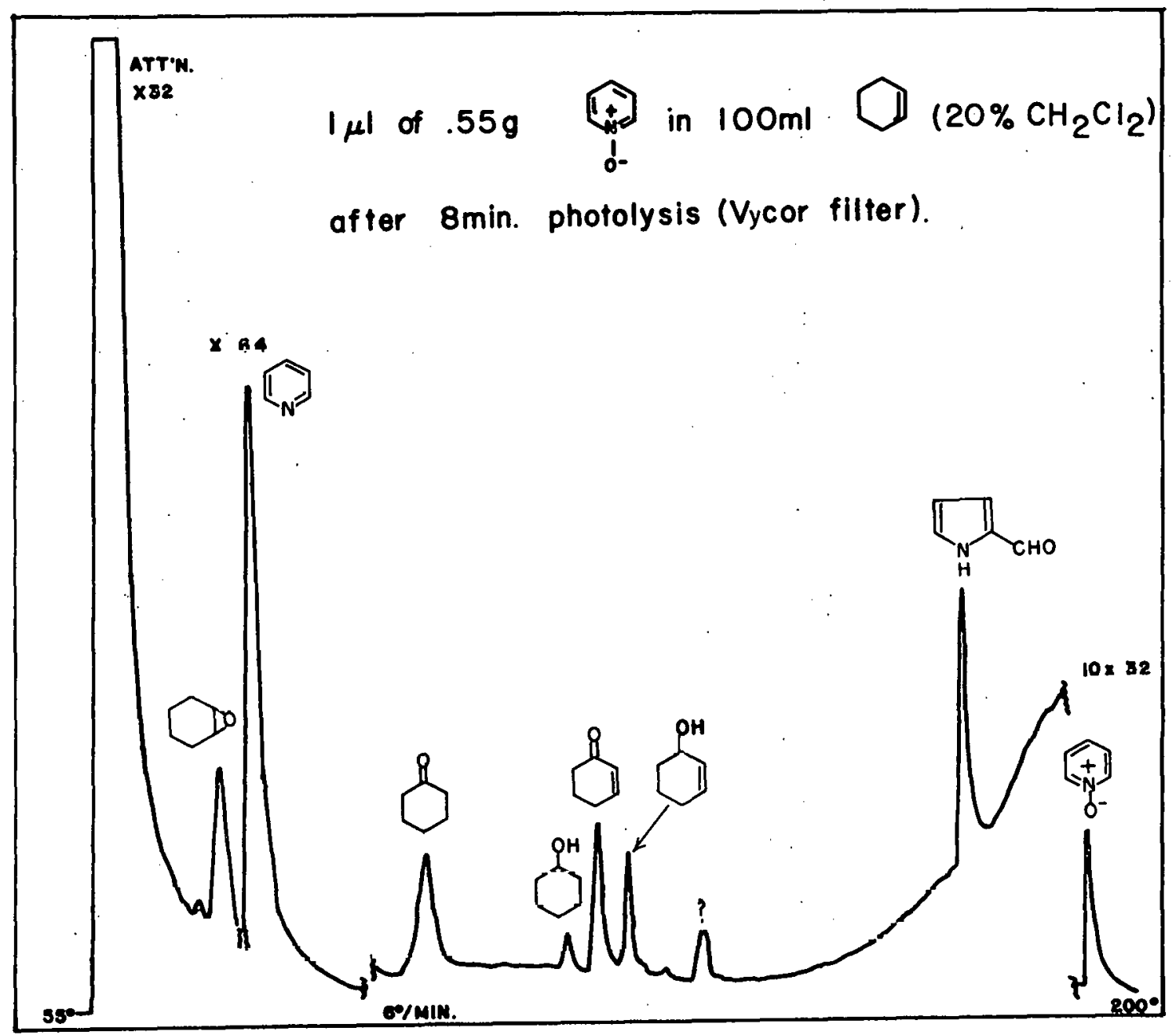

XBL 685-4209

Figure 1. 
The structures of the products were assigned by collecting the products by preparative $\mathrm{glc}$ and comparing the glc retention times by coinjection and their mass spectra with standards: The fragmentation patterns obtained from the mass spectra of the various photolys is products matched perfectly with the fragmentation patterns of the assigned standards. The major peaks from the fragmentation patterns of these products are given in Table I.

Discussion

Cyclohexenol and cyclohexenone do not seem to be products of oxygen transfer from pyridine $\mathrm{N}$-oxide to cyclohexene. In the purification of cyclohexene there remains a small quantity of the peak identified as cyclohexenone and a small peak identified as cyclohexenol. Upon irradiation of pyridine $\mathrm{N}$-oxide in this purified cyclohexene, the peak corresponding to cyclohexenone does not change in height, whereas the peak corresponding to cyclohexenol does raise in height (to about twice $i$ ts original height). This rise could come by the interaction of the cyclohexene with air. In the purified cyclohexene, if allowed to stand in air (also if the photolysis mixture is al lowed to stand in air), cyclohexenol and cyclohexenone will form rapidly. A control photolysis, using only purified cyclohexene (no $\mathrm{N}$-oxide) under the same conditions which gave oxygen transfer from pyridine $\mathrm{N}$-oxide, showed that no oxygenated products formed from the cyclohexene by itself.

In another control experiment using the usual photolys is conditions, the disappearance of pyridine $\mathrm{N}$-oxide was followed with time and the appearance of cyclohexene oxide was followed with time. The 
Table I

Mass Spectra of Products of Photolys is of Pyridine $\mathrm{N}$-oxide in Cyclohexene

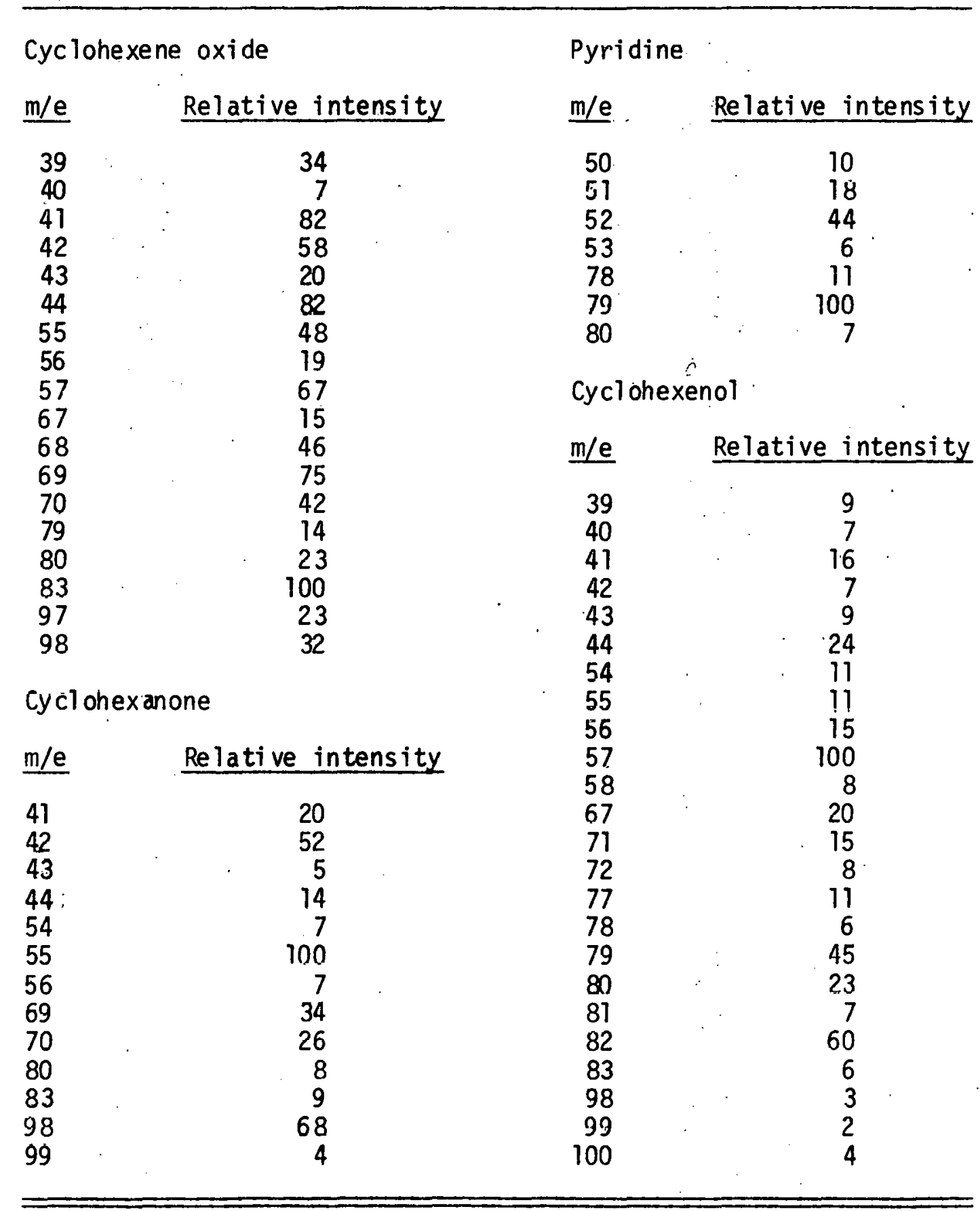


pyridine $\mathrm{N}$-oxide disappearance and the cyclohexene appearance was linear with time for the first 6 min of irradiation.

The material balance is not good. All of the pyridine $\mathrm{N}$-oxide consumed cannot be accounted for by the products isolated. There is considerable polymer formed, which could explain where the rest of the pyridine $\mathrm{N}$-oxide went. The material balance for the oxygen transfer reaction is also not good. There is 0.8 mole of pyridine formed and only 0.2 mmole of oxygenated cyclohexene formed. It is possible that some of the oxygen lost from the pyridine $\mathrm{N}$-oxide could oxygenate the polymer formed (possibly the oxygen could be intimately connected in the production of the polymer). Another possibility is that molecular oxygen is formed in solution, paralleling the finding of Hata and Tanaka (1962), that molecular oxygen is formed in the gas phase photolys is of pyridine $\mathrm{N}$-oxide. This possibility could be checked with difficulty by photolyzing pyridine $\mathrm{N}$-oxide $0^{18}$. The fact that the material balance is not good can be due to polymer formation in the concentrated pyridine $\mathrm{N}$-oxide solution.: When pyridine $\mathrm{N}$-oxide was photolyzed in cyclohexene in a more dilute solution $(0.3 \mathrm{~g} / 100 \mathrm{ml})$, and with a pyrex filter, the material balance was better. After approximately $2 / 3$ of the pyridine $\mathrm{N}$-oxide was photolyzed (approximately 2 mmoles), 0.4 mmole cyclohexene oxide, 1.1 mmoles pyridine, and 0.15 mmole cyclohexenone were formed.

\section{Conclusion}

The photochemical transfer of oxygen from pyridine $\mathrm{N}$-oxide to cyclohexene has been shown. This finding has since been substantiated 
by T. Tsuchiya et al. (1969). The photochemical transfer of oxygen to a substrate from pyridine $\mathrm{N}$-oxide seems to be a general reaction. There is some active intermediate formed, possibly atomic oxygen or the oxaziridine, which acts as a good oxidant. There is some extremely interesting chemistry involving the nature of the nitrogen-oxygen bond which is worthy of study. The particular aspect of this oxygen transfer reaction which interested me was the possibility that this reaction could serve as a model system for the activation of oxygen by oxygenase enzymes. This direction of inquiry will be discussed in the following section. 
I-5 PHOTOLYTIC OXYGEN TRANSFER AS A MODEL FOR MICROSOMAL HYDROXYLASE 
Photolytic Oxygen Transfer as a Model for Microsomal Hydroxylase

With the discovery that pyridine $\mathrm{N}$-oxide, upon irradiation, transfers $i$ ts oxygen to a variety of substrates, the possibility arises that this photochemical transfer reaction may serve as a model system for the activation of molecular oxygen by mixed function oxidases. The number of substrates oxygenated and the products formed from photolytic oxygen transfer parallel the hydroxylation of various substrates by mixed-function oxidase sys tems.

The mixed-function oxidase system hydroxylates a wide variety of substrates: olefins to epoxides, aromatics to phenols, and aliphatics to carbinols. Several important aspects of the hydroxylase system have been elucidated: 1) The reaction is stereospecific. R. McMahon and H. Sullivan (1969) found that on hydroxylation of ethyl benzene by liver microsomes, $86 \%$ of the methy 1 pheny 1 carbinol formed was $R(+)$. 2) In the hydroxylation of aliphatics by microorganisms there is a direct substitution of a hydrogen by a hydroxyl group. The reaction is stereospecific and proceeds with a net retention of configuration (E. Heinz et al., 1969; and D. Jones, 1968). 3) In para hydroxylation by microsomes of aromatic compounds substituted in the para position ( $T, \mathrm{CH}_{3}, \mathrm{Br}$, for example), the phydroxy aromatic compound retains the original para substituent. This is called the NIH shift. The figure below (S. Undenfriend et al., 1969) gives an example of the NIH shift: 

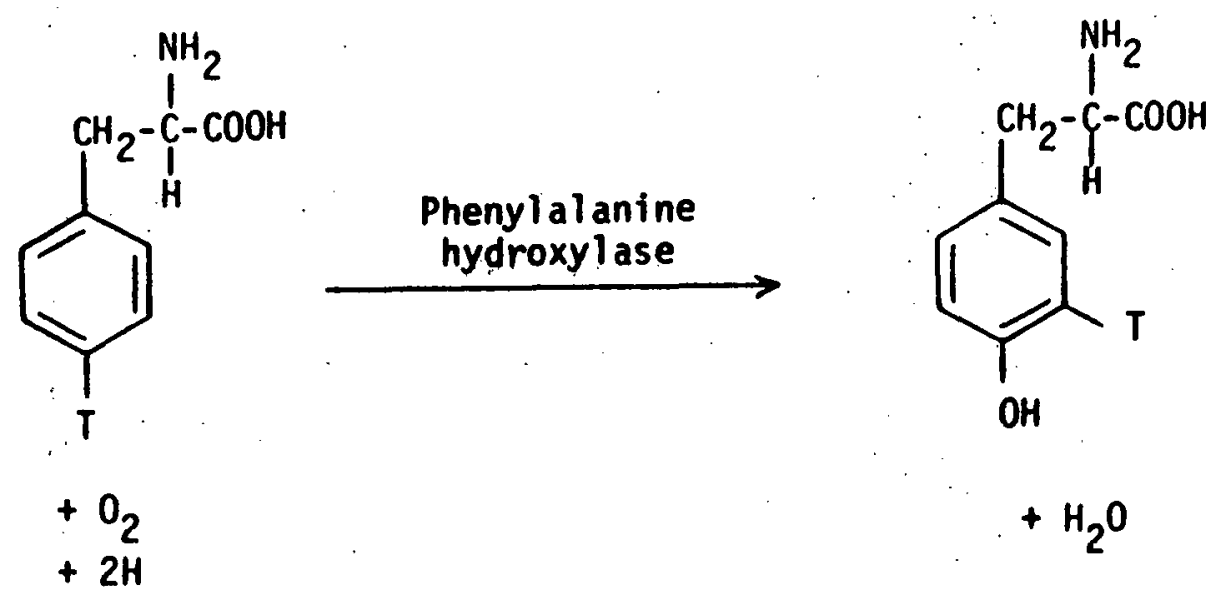

XBL 705-5226

These above observations on the action of microsomal hydroxylase systems, coupled with studies on model systems, provide some clues to the nature of the hydroxylating species which must be formed from molecular oxygen.

There are several chemical systems which will hydrnxylate various substrates. These chemical hydroxylation systems can serve as models in the elucidation of the mechanism of microsomal hydroxylase systems. The major question which can be investigated by using model systems concerns the chemical nature of the hydroxylating species derived from molecular oxygen. The comparison of these various model systems and microsomal hydroxylase systems is presented by $V$. Ulirich and $H$. Staudinger (1969): Previous to the discovery of the photochemical mode 1 system, most of these model hydroxylase systems contained a reduced metal and some form of oxygen (either molecular oxygen or hydrogen peroxide). Comparing the action of these various chemical 
hydroxylating systems on different substrates, the nature of the hydroxylating species (whether it is an $\mathrm{OH}$ radical, and $\mathrm{OH}^{+}$, or an "oxene") can be deduced. Then, comparing the hydroxylation produced by microsome to the various model hydroxylations, it can be concluded ethat the active oxygen species produced by microscomal hydroxylase systems is an electrophilic oxygen (possibly $\mathrm{OH}^{+}$) or an oxene. An oxene is an oxygen nucleus with six electrons around it (analogous to the earbene).

The main reason for invoking an $\mathrm{OH}^{+}$as the hydroxylating species has been the observation of the NIH shift. Recently, with the discovery that arene epoxides are metabolites of aromatic compounds ( $D$. Jerina et al., 1968), the NIH shift may be explained by an initial formation of an epoxide intermediate (D. Jerina, J. Daly, et al., 1970). This epoxide intermediate could possibly be formed by an "oxene" reacting with the aromatic compound, thus eliminating the need for an $\mathrm{OH}^{+}$oxygen. None of the model hydroxylating systems were able to reproduce the NIH shift. Hydroxylation by peroxytrifluoracetic acid did reproduce the NIH shift to a slight degree (D. Jerina, 1969). However, the NIH shift produced by this model, system did not correspond to the NIH shift produced by microsomes when tested with various substrates.

The discovery that the photochemical oxygen transfer could take place made possible another model system. Jerina, Boyd, and Daly (1970) looked at the photochemical transfer of oxygen from pyridine $\mathrm{N}$-oxide to various substrates. These results were compared to 
microsomal hydroxylation of these same substrates. He found that the photochemical oxygen transfer reaction was the best model system to date. It reproduced the NIH shift to a similar degree that the micorsomes produced the NIH shift in all substrates tried. 1,2-naphthalene oxide was also produced under the photochemical oxygen transfer conditions. The photochemical oxygen transfer not only hydroxyldled aromatics, it also hydroxylated aliphatic compounds to carbinols and formed an epoxide from an olefin (see previous section). Thus, the photochemical transfer of oxygen from pyridine $\mathrm{N}$-oxide to a substrate is a good model system for the microsomal hydroxylase system. The question which still remains is what is the nature of the active species of oxygen formed during irradiation of pyridine $\mathrm{N}$-oxide. It is possible that the $\mathrm{N}-\mathrm{O}$ bond breaks directly, forming atomic oxygen which reacts with the substrate; or that an intermediale oxaziridine species is formed which interacts with the substrate with subsequent oxidation of the substrate.

The question which I asked myself was whether the same intermediate, producing oxygen transfer, which is formed on irradiation of pyridine $\mathrm{N}$-oxide, can be formed by the microsomal hydroxylase system. This active intermediate from the $\mathrm{N}$-oxide could then be directed by the enzyme to the substrate (explaining the stereospecificity). The aromatic $\mathrm{N}$-oxide (some unspecified $\mathrm{N}$-oxide*) could be formed from the aromatic heterocyclic compound and oxygen. This possibility is explored in the second part of this thesis.

*The particular aromatic $\mathrm{N}$-oxide studied was nicotinamide $\mathrm{N}$-oxide. The reasons for choosing nicotinamide as the aromatic heterocyclic compound will be discussed in the second part of the thesis. 
In the next short section, a few non-enzymatic, exploratory experiments are described.

Attempts to produce oxygen transfer from aromatic $\mathrm{N}$-oxides by nonphotochemical means.

1. Thermal

The aromatic $\mathrm{N}$-oxide (pyridine $\mathrm{N}$-oxide or nicotinamide $\mathrm{N}$-oxide) was placed in a sealed tube with benzene or cyclohexene (10 $\mathrm{mg} \mathrm{N}$-oxide/ml solvent). The sealed tube was heated in a bomb at $350^{\circ} \mathrm{C}$ from 1 to 5 days. The resultant mixture was analyzed by glc for oxygenated solvent. There was no phenol (from benzene) nor cyclohexene oxide or cyclohexanone (from cyclohexene) formed in any of the tubes. Interestingly, when nicotinamide $\mathrm{N}$-oxide was heated for 3 days, 3-cyanopyridine was formed. This product was identified by coinjection with authentic 3-cyanopyridine on a glc column and by comparison of the IR of the product with that of authentic 3-cyanopyridine.

2. Attempted oxygen transfer from aromatic $\mathrm{N}$-oxides to anisole catalyzed by reduced metals

Ferris et al. (1968) found that tertiary amine oxides will rearrange in the presence of iron, $\mathrm{Fe}(\mathrm{II})$. This reactipn is depicted below:

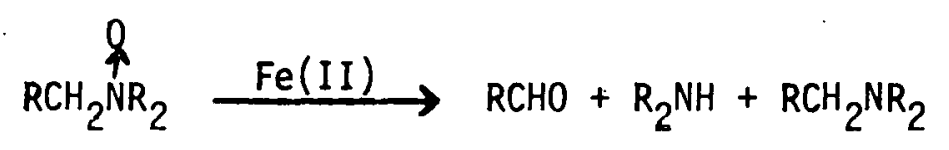

From the above results, the question arose whether reduced metals could catalyze deoxygenation (and thus oxygen transfer) of aromatic $\mathrm{N}$-oxides. Since model hydroxylase systems employ reduced metals as catalysts to 
activate molecular oxygen, the possibility that aromatic $\mathrm{N}$-oxides could act as the oxygen source in these model systems was explored.

Several model hydroxylation systems were tried (see. V. Ullrich and H. Staudinger; 1969, and ref. therein): : (Fe+2/EDTA; $\mathrm{Fe}^{+2} /$ EDTA/ascorbate; $\mathrm{Sn}^{+2} / \mathrm{HPO}_{4}{ }^{-2}$.) The substrate used was anisole. A typical tube contained 5 micromoles reduced metal, 15 micromoles EDTA, $0.6 \mathrm{ml}$ acetate buffer $\left(0.1 \mathrm{M}_{\mathrm{o}} . \mathrm{pH} 5.8\right), 10$ lambda anisole in $0.2 \mathrm{ml}$ acetonitrile. The solutions were deoxygenated by bubbling helium through for an hour. Nicotinamide $\mathrm{N}$-oxide or pyridine $\mathrm{N}$-oxide were then introduced at various concentrations $(5,20$, and $50 \mathrm{mM})$. The solution, after heating for an hour (temp. from 20 to $80^{\circ} \mathrm{C}$ were tried), was extracted with ether; the ether extracts were dried and washed; and the solution was analyzed by glc ( $3 \%$ OV-17 on Gas Chrom Q, Applied Sciences) for oxygenated anisole.

In 211 cases, under anaerobic conditions, whether an arnmatic N-oxide was present or not, no hydroxylated product could be detected. 
II-1 INTRODUCTION 


\section{Introduction}

In this section I would like to first broadly sketch the characteristics of hydroxylase enzymes. I would then like to discuss microsomal hydroxylase systems, first placing these enzymes in the framework of future significant research and then discussing the mechanistic aspects of their action, thus introducing the specific problem of this thesis.

The central question of this thesis is: Can nicotinamide $\mathrm{N}$-oxide act as a general oxygen donor in hydroxylase enzymes? Another way of asking the question would be whether nicotinamide $\mathrm{N}$-oxide acts as a discrete intermediate in the incorporation of molecular oxygen into a substrate by a hydroxylase enzyme? Two major areas are incorporated in this question: 1) the biological role of aromatic $\mathrm{N}$-oxides and 2) the mechanism of hydroxylase enzymes. The area concerning the role of aromatic $\mathrm{N}$-oxides in biological systems has been recently reviewed by $M$. Bickel (1969). (This review also discusses aliphatic N-oxides.) My approach to the question concerning the reTationship between $\mathrm{N}$-oxides and hydroxylase systems is from the view of the mechanism of action of hydroxylases. The two hydroxylase systems looked at were the "microsomal hydroxylases" and microbial hydroxylases.

Hydroxylases

0. Hayaishi (1969) has written an excellent review concerning hydroxylase enzymes. He discusses the broad field of hydroxylases and gives many good leading refererices. I will only discuss a few aspects of hydroxylases, which are necessary for the main question. 
In general, very few hydroxylases, have been purifyed and characterized. However, there seem to be several different mechanisms of introducing a hydroxyl group into substrate.

The hydroxylases systems which will be discussed in this thesis are the microsomal hydroxylases (squalene oxidase and laurate hydroxylase) and microbial hydroxylase ( $p$-hydroxybenzoate hydroxylase). These hydroxylases are a subgroup of the class of oxygenases which are enzymes catalyzing the direct incorporation of molecular oxygen into a substrate. A reduced cofactor (NADPH) is required. One atom of the oxygen molecule is incorporated into the substrate and the other atom goes into water. The general requirements of the reaction are depicted below: $S$ is the substrate, and $E$ is the hydroxylase enzyme:

$$
\mathrm{S}+\mathrm{O}_{2}+\mathrm{NADPH}+\mathrm{E} \longrightarrow \mathrm{S}-\mathrm{OH}+\mathrm{H}_{2} \mathrm{O}+\mathrm{NADP}+\mathrm{E}
$$

(It would be extremely interesting if this reaction were reversible to any measurable degree. There is no evidence reported for the reverse reaction.) These hydroxylations: are "mixed function oxidases" according to the H. Mason (1957) definition or "external monooxygenases" according to the 0. Hayaishi and M. Nozaki (1969) definition.

Microsomal Hydroxylation

The microsomal hydroxylase system (I call it a system since it contains an electron transport chain, see mechanism section) is contained in the microsomes which are vesicular sections of endoplasmic reticulum. These microsomes are formed spontaneously when the cells are disrupted by the process of homogenation. The microsomes 
are isolated by differential centrifugation. It must be stressed that such an enzyme preparation is heterogeneous both enzymatically and physically. (There are "rough" microsomes containing ribosomes and "smooth" microsomes lacking ribosomes. The size and yield of microsomal particles is dependant on the method of homogenation.) It is not known whether there is a single, non-specific enzyme hydroxylating the various substrates or several more specific enzymes. It has proven difficult to characterize the enzyme system since it is integrally bound to the membrane.

The microsomal hydroxylase system is of paramount importance in metabolism of various substrates such as steroids and drugs. The role of these hydroxylases seems to be expanding continually. For example, R. Tenhunen, H. Marver, and R. Schmid (1969) have found that the microsomal hydroxylase system plays an important role in the breakdown of hemoglobin. In the section below, I would like to point up several major areas of research where these microsomal hydroxylase systems play an important role in the breakdown of hemoglobin. In the section below, I would like to point up several major areas of research where these microsomal hydroxylase sys tems may play an essential role. The understanding of these systems may lead to a new understanding of cellular control processes and possibly ability to modify these processes. Stgnificance of Microsomal Hydroxylases

1. It is in the endoplasmic reticulum where substances from the external enviroment (drugs, food, toxic substances) many times first are acted upon. Most foreign substances entering the body are 
"detoxified" in the endoplasmic reticulum by the hydroxylating enzymes. Hydroxylating renders the compounds soluble so that they can be excreated or further metabolized. The various aspects of drug oxidation by microsomes are discussed in "Microsomes and Drug Oxidation" (Gialetite 1969). . It must be noted here that drugs induce the formation of endoplasmic reticulum with a concomitnent increase in hydroxylase activity. This effect may be similar to induction of hepatic tyrosine-a-ketoglutarate transaminase by hydrocortisone (F. Kenney, D. Holten, W. Albritton, 1967). Steroids are implicated in the hydroxylase induction by S. Orrenius et al (1967). A definitive characterization of microsomal hydroxylase systems may provide a key to drug action and lead to modifying. or specifying drug action by manipulating the hydroxylase enzymes or manipulating the structure of the drugs. These hydroxylase systems are of great importance today with the concern about the blological effects of pollution. (It is precisely the failure of microsomal hydroxylase to hydroxylate DDT that creates such problems with this insecticide.)

2. These hydroxylating enzymes metabolize the carcinogenic agents: Possibly, it is this hydroxylation teaction which may produce intermediates which cause the carcinogenic process to begin. It has been found that the carcinogentc process is an electrophilic type, which fits the hydroxylation process. (see sect. II). P. Grover and P. Sims (1968) and G. Gelboin (1969) found that carcinogenic aromatic hydrocarbons were chemically bound to DNA in the presence of microsomes. 
Thus chemical carcinogenesis may be a direct result of the functioning of the microsomal hydroxylases. Specific chemical evidence for the mechanism of this action of the carcinogenic hydrocarbons with microsomes will be published shortly by E. Cavalieri (from this laboratory). I am indebted to E. Cavalieri for discussions on chemical carcinogenesis.

3. Since the microsomal hydroxylase sys tem is so important in "cleaning up any garbage we might ingest," the functioning of these sys tems may play an important role in the aging process. One can imagine that if the functioning of these hydroxylating sys tems were impaired due to some external factors (such as the amount of various foreign materials ingested during a lifetime) or due to inherent changes within the cell (possible due to mistakes in DNA), the organism would not be able to cope with toxic substances and die. There is some evidence presented by W. Mainwaring (1969) suggesting that the endoplasmic reticulum is involved in the aging process in the mouse. He found that several proteins were absent in the endoplasmic reticulum of old mice relative to the proteins present in young mice.

Mechanism of Microsomal Hydroxylation

- P. Strittmatter (1968), in his review on microsomal hydroxylations, provides a thorough discussion of the various components of the microsomal hydroxylase system. The scheme below provides the generally accepted mechanism for hydroxylation by microsomes: 


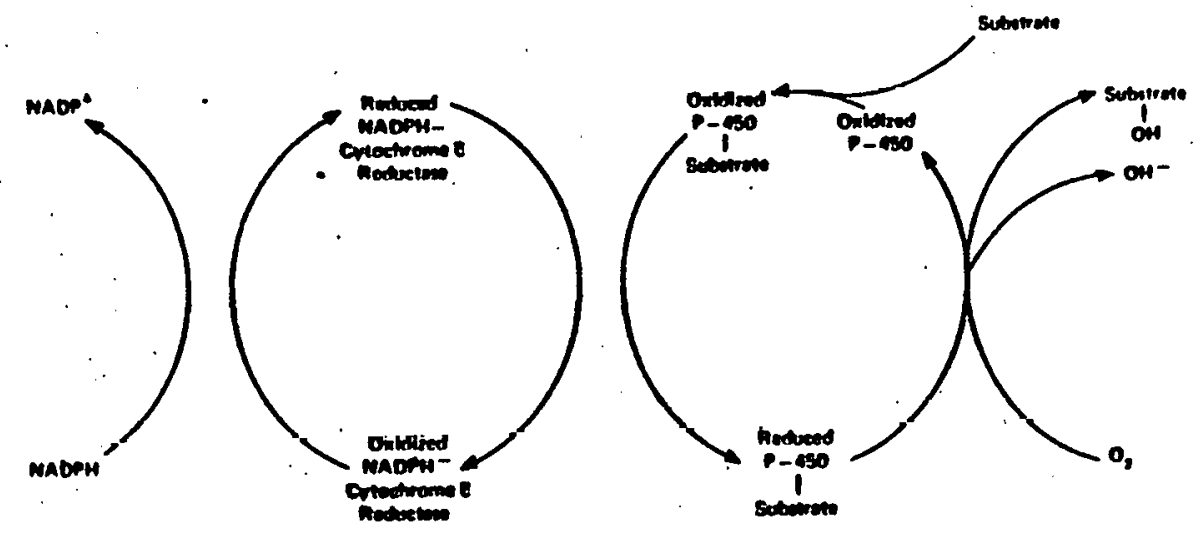

The role of the pigment, cytochrome $P-450$, as the enzyme which interacts with molecular oxygen and substrate to produce the hydroxylated substrate has been definively shown by $T$. Omura, et a1. (1965) The cytochrome P-450 has been characterized by $Y$ Ichikawa and $T$. Yamano (1970). The fact that the electron transport chain is essential to hydroxylase activity (as opposed to the direct reduction of oxygen by NADPH) was shown by $\mathrm{J}$. Holtzman (1970). This general scheme, however, does not hold true in all cases of microsomal hydroxylations (Hayaishi, 1969) (Strittmatter, 1968). Speculation of how the cytochrome $P_{450}$ could activate the oxygen is discussed by H. Hill, A. Roder, and R. J. Williams (1970). The overali reaction (oxidation of substrate by moleçular oxygen) is a two electron oxidation. The iron of the cytochrome P-450 is only a one electron transfer center. H. Hill, et al (1970) suggests that a thiol, a lingand of the iron in the cytochrome, would provide the cytochrome, would provide the other electron in producing an $02-2$ as the hydroxylating spectes. R. J. Williams. (1969) discusses the role of organic side chains in electron transfer centers. The one electron 
transport properties of the iron in cytochrome $P-450$ may provide a key in understanding the carcinogenic properties of aromatic amines. (A carbon radical may be produced by the hydroxylase, E. Arrhenius, 1969).

The Role of Nicotinamide In Oxygen Activation

One of the major questions which is still unanswered is: How is the oxygen "activated" by the enzyme in order to break the $0-0$ double bond? From evidence presented in the section on model systems, some form of electrophilic oxygen is required (possibly $\mathrm{OH}^{+}$). The following evidence suggests the possibility that nicotinamide $\mathrm{N}$-oxide formed from nicotinamide may be involved in the formation of such an electrophilic oxygen in microsomal hydroxylations. The suggestion here is that molecular oxygen is activated by first producing nicotinamide $\mathrm{N}$-oxide which in turn hydroxylates the substrate. The following five lines of evidence point to this possibility: 1. From the photochemical studies of aromatic $\mathrm{N}$-oxides, it seems that there is an intermediate formed from the photochemical reaction which could produce an electrophinitic oxygen species $\left(\mathrm{OH}^{+}\right)$. This same intermediate which should transfer oxygen in the photochemical system could be formed by the enzymatic system. The speculation of what this intermediate is has been discussed in the photochemical section. Particular note must be made that the photochemical hydroxylation of aromatic substrates produced the "NIH shift" to the same degree as microsomal hydroxylations. (D Jerina et al, 1970)

2. There is a direct transfer of oxygen from nicotinamide $\mathrm{N}$-oxide to xanthine catalyzed by xanthine oxidase as shown on the following page. 

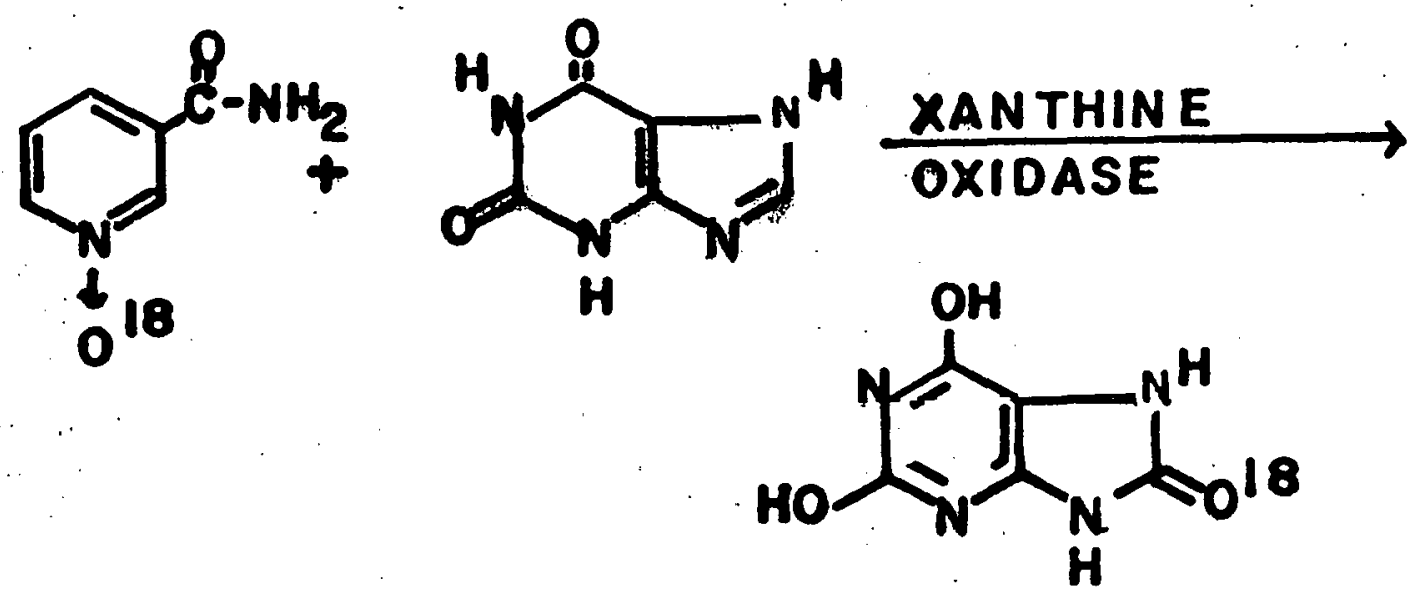

(Murray, K. N. and Chaykin, S., 1966)

It must be noted that the mechanism of xanthine oxidase is not clearly understood. Generally xanthine oxidase acts as a dehydrogenase and does not fall in the catagory of a monoxygenase. Xanthine oxidase has been shown to also reduce a number of purine $\mathrm{N}$-oxides, (G. Stohrer, 1968). Other $\mathrm{N}$-oxides may also act as oxygen donors. 3. There is two to ten fold increase of the hydroxylase activity when nicotinamide is added to the liver homogenates: One example, is a report by B. Brodie et al. (1955). Also see the results reported in the squalene oxidase section of this thesis. These increases in hydroxylase activity may not be general since some inhibition of hydroxlase activity was reported by J. Schenkman, J. Ball and R. Estabrook (1967). (However, these inhibitory results may be due to the particular conditions used).

4. A nitrogen atom in an aromatic ring such as pyridine can act as a site for catalytically transfering electrophilic species. A Fersht and $W$. Jencks (1969) reported evidence for an acetylpyridium ion intermediate in pyridine-catalyzed acyl transfer. The authors studied pyridine 
catalyzed acylation of anisidine by acetic anhydride.

5. Along the same line of reasoning as in point: 4 , Albert Bobst (1968) found that in a cation radical of the pteridine series a substituent on $\mathrm{N}-5$ had a very high group transfer potential. The substituent on $\mathrm{N}-5$ would leave as a cation. Molecular orbital calculationswere consistent with experimental group transfer potentials. An $\mathrm{OH}^{+}$is postulated as a possible group which is transferred. The structures of the pteridine is given below

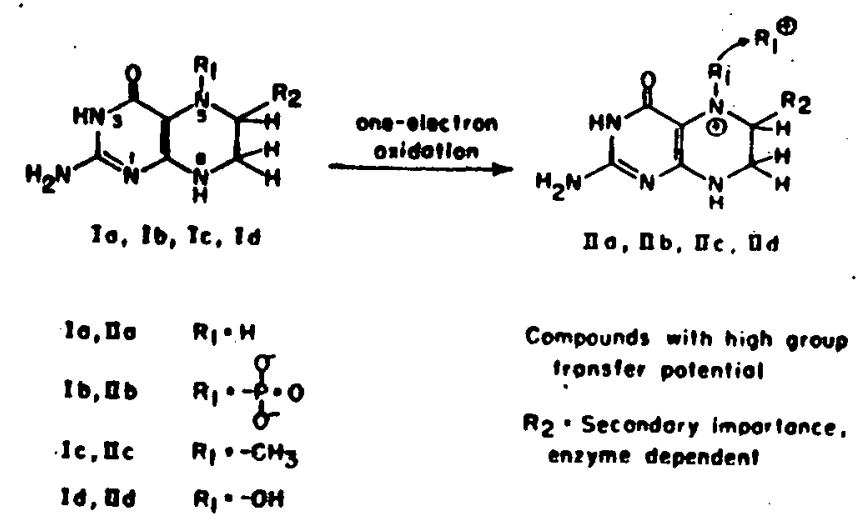

Therefore, it seems a distinct possibility from the above evidence that nicotinamide $\mathrm{N}$-oxide could possible act as an oxygen transfer agent in microsomal hydroxylases. The following scheme presented in Fig. 1 is then proposed as an extension of the general scheme for microsomal hydroxylation proposed above. This scheme incorporates nicotinamide $\mathrm{N}$-oxide as an intermediate formed in "activation" of molecular oxygen. Only cytochrome $P_{450}$ is shown as being reduced by the NADPH. The intervening electron transport chain component is left out for simplicity.

If this proposed scheme is true, two major questions arise: 1) Is nicotinamide $\mathrm{N}$-oxide formed enzymatically. in the liver? and 2) Does nicotinamide $\mathrm{N}$-oxide transfer its oxygen to the substrate? These two 


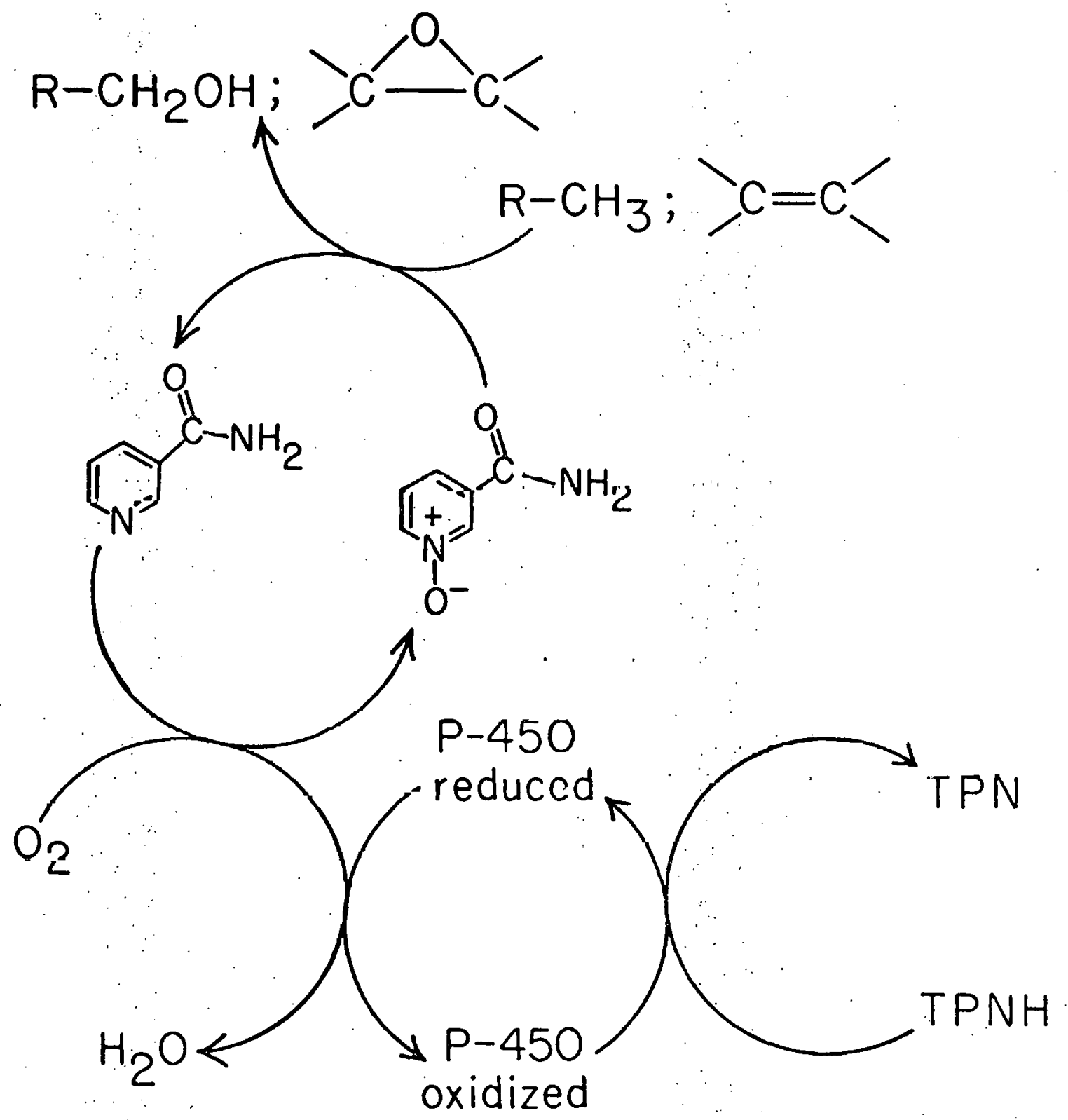

XBL $684-4184$

Figure 1. Proposed scheme for incorporation of nicotinamide $\mathrm{N}$-oxide as an oxygen activating intermediate into microsomal hydroxylations. See text for details. 
questions will be expolored in subsequent sections of the thesis.

Once it is established that nicotinamide $\mathrm{N}$-oxide is formed in the liver, the problem of choosing enzyme systems to test the oxygen transfer scheme arises.

Choosing The Enzyme System

Two enzymes were tried: The squalene oxidase and the free fatty acid hydroxylase. Microsomal hydroxylase systems are only very roughly characterized, and only recently have any of the components been solubilized. It seems that they are very tightly integrated with the membrane structure of the endoplasmic reticulum. Thus in both enzyme systems only the crudest enzyme preparations were attempted, in hope of gaining insight into the mechanism, with subsubsequent exploration into purification of the enzyme. Crude rat liver homogenates were used. The only purification which was done was by centrifugation which will be described in detail. Squalene oxidase was chosen since it closely paralleled the oxygen transfer reaction on the photochemical model system (epoxidation of a double bond): Also there was a very definite increase in oxidase activity with the addition of nicotinamide (see T. Chen and K. Block (1957) and results reported in squalene oxidase section). Laurate hydroxylase was chosen for two reasons: 1) A. Lu and M. Coon (1968) had suceeded in solubalizing some of the components of this hydroxylase systerl. They found that a low molecular weight, heat stable component was needed for hydroxylase activity. This small molecule could possibly be nicotinamide or some other aromatic heterocyclic compound. 2) Lauric acid had a marked effect on the reduction of nicotinamide $\mathrm{N}$-oxide 
(see Fig. 1 in the section under $\mathrm{N}$-oxidase dealing with the reduction of nicotinamide $\mathrm{N}$-oxide).

A third enzyme system was looked at since both of the above enzymes were membrane bound. This third enzyme studied was the p-hydroxybenzoate hydroxylase from psudomonas. This enzyme has been purified and characterized by K. Hosokawa and R. Stanier (1966). Thus this enzyme affords a soluble, pure enzyme for determining if possibly nicotinamide or $i$ ts $\mathrm{N}$-oxide had any effect on such a hydroxylase. The microbial hydroxylase enzymes differ from the microsomal hydroxylases as can be seen in the following brief summary of the mechanism of action. The Microbial Hydroylase: "p-Hydroxybenzoate Hydroxylase

The microbial hydroxylase enzyme seems to be uncomplicated by electron transport components or membranes. The hydroxylation reaction of the benzoate requires NADPH, oxygen, and an FAD on the enzyme. The enzyme seems to be a single protein. The following scheme proposed by B. Hesp, M. Calvin, K. Hosokawa (1969) deliniates the steps in hydroxy=lation.

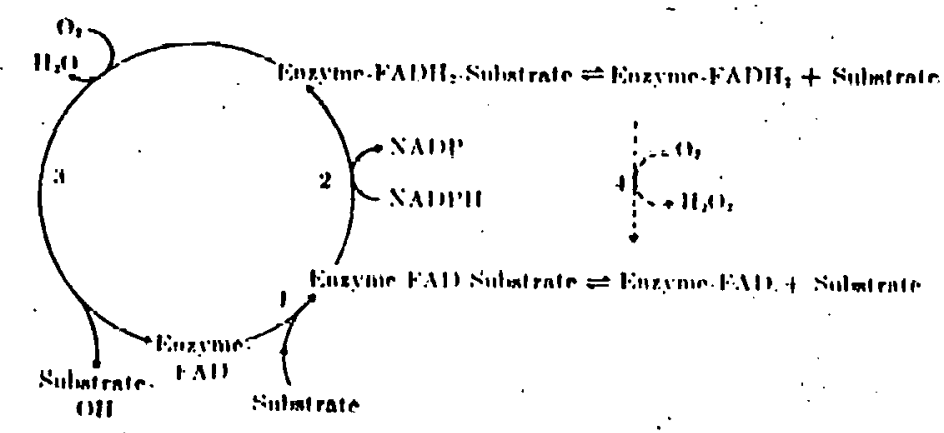

This same scheme has been substantiated by S. Takemoro, et al, (1969). In this scheme too, the activation of molecular oxygen is not explained. 
Nicotinamide is much more difficult to incorporate in any oxygen activation step since there does not exist any evidence in such microbial hydroxylation for nicotinamide participation. However, it was worth a try to see if nicotinamide had any effect on hydroxylase activity or if nicotinamide $\mathrm{N}$-oxide would transfer oxygen to $\mathrm{POB}$ (p-hydroxybenzoate). 
II-2 NICOTINAMIDE N-OXIDASE 


\section{Nicotinamide $\mathrm{N}-0 x i d a s e$}

\section{Introduction}

From the discussion on the possible role of nicotinamide $\mathrm{N}$-oxide in oxygen activation, it can be seen that there must exist a nicotinamide $\mathrm{N}$-oxidase. Such an enzyme was found to exist in the rat liver and brain. The characteristics of this oxidase system were studied, using rat liver homogenates as the source of the enzyme. In the first secion (A), the formation of nicotinamide $\mathrm{N}$-oxide from nicotinamide wi 11 be described. In the second section (B), the reduction of nicotinamide $\mathrm{N}$-oxide will be discussed.

\section{A. Enzymatic Formation of Ni cotinami de $\mathrm{N}$-0xide}

\section{Experimental}

\section{Materials}

Ni cotinamide-7-14C was purchased from New England Nuclear. The specific activity was $48 \mathrm{mC} / \mathrm{mM}$. Nicotinamide, NADP, and glucose-6phosphate (G-6-P) were purchased from Mann Biochemical. G-6-P dehydrogenase $(1,000 \mathrm{IU} / \mathrm{ml})$ was purchased from Cal Biochem. The rats used were Sprague-Dawley, male albino rats.

\section{Enzyme preparation}

Livers from at least two rats were homogenized and pooled. The $0.08 \mathrm{M}$ phosphate buffer $(\mathrm{pH} 7.4)$ contained $1 \mathrm{mM} \mathrm{Mg}{ }^{++}$. The homogenates were then fractionated by centrifugation (see Figure 1 in the squalene oxidase section). The microsomal fraction, or $P_{100}$, is prepared by resuspending the pellet obtained from centrifugation of $S_{25}$ for $1 \mathrm{hr}$ at $10^{5} \mathrm{~g}$ two times in the same volume of buffer and centrifuging at $10^{5} \mathrm{~g}$ again. The pellet is then suspended in buffer using a small 
homogenator. Protein coneentrations were determined in several experiments using the Biuret method. The $\mathrm{S}_{25}$ fraction contained approximately $60 \mathrm{mg}$ protein/ml. The $P_{100}$ fraction contained approximately $40 \mathrm{mg}$ protein/m1. The $S_{100}$ fraction contained approximately $15 \mathrm{mg}$ protein $/ \mathrm{ml}$. These prote in concentrations were not standardized from experiment to experiment, so that there is some variance in the $\mathrm{N}$-oxidase activity. However, the results from a given pooled homogenate are self-cons is tent.

Incubations

A typical incubation contained: $2.0 \mathrm{ml}$ liver homogenate; $0.4 \mathrm{ml}$ NADPH generating system consisting of $0.6 \mathrm{ml}$ of $15 \mathrm{mM} \mathrm{NADP} ; 0.075 \mathrm{ml}$ G-6-P; $0.015 \mathrm{ml} \mathrm{G-6-P}$ dehydrogenase; $0.2 \mathrm{ml}$ nicotinamide ${ }^{14} \mathrm{C}$ solution (final conc. of $5 \mathrm{mM}$ and $5 \mathrm{mC} / \mathrm{mM}$ ). The tubes were incubated at $37^{\circ} \mathrm{C}$ with shaking. The enzymatic reaction was terminated by adding a $0.25 \mathrm{ml}$ aliquot of the reaction mixture to $2 \mathrm{ml}$ methanol. The precipitate was washed an additional three times with $2 \mathrm{ml}$ methanol. The combined methanol washings were evaporated to dryness and $0.5 \mathrm{ml}$ water was added (the flask was scratched with a spatula to suspend the small amount of precipitate). One-tenth $\mathrm{ml}$ of the water solution was spotted on Whatman No. 1 paper, and $100 \mu \mathrm{g}$ nicotinamide $\mathrm{N}$-oxide was added as carrier. The paper was developed in two dimensions. The first dimension was developed with $3 \%$ acetic acid in water saturated n-butanol. The second dimension was developed using n-butanol saturated with $3 \%$ ammoni um hydroxide solution. The nicotinamide $\mathrm{N}$-oxide was visualized by fluorescence under UV light. The radioactive spots 
were visualized by exposure of the paper to film. The radioactive spots were counted using a hand gefger tube. The geiger tube was a flow type utilizing $99.05 \%$ helium and $0.95 \%$ isobutane. The efficiency for carbon-14 was approximately 15\%. Most of the results are reported in counts per minute. Three thousand cpm is equivalent to approximately $1 \%$ conversion of nicotinamide to nicotinamide $\mathrm{N}$-oxide. This figure was checked by eluting the radioactive spots with water and measuring the radioactivity using a liquid scintillation counter. Results.

The production of nicotinamide $\mathrm{N}$-oxide from nicotinamide was verified by extracting the radioactive spot corresponding to nicotinamide $\mathrm{N}$-oxide, adding carrier nicotinamide $\mathrm{N}$-oxide, and measuring the specific activity. The nicotinamide $\mathrm{N}$-Oxide was then recrystallized three times from water, methanol, and water-ethanol. The specific activity for the three recrystallizations wds $966 \mathrm{dpm} / \mathrm{gm}, 998 \mathrm{dpm} / \mathrm{gm}$, $996 \mathrm{dpm} / \mathrm{gm}$.

The quantitative determination of nicotinamide $\mathrm{N}$-oxide is complicated by the fact that during the procedure for extracting, separating, and purifying nicotinamide $\mathrm{N}$-oxide, the $\mathrm{N}$-oxide reverts to some degree to nicotinamide. See Section $B$ nn the reduction of nicolinamlde $\mathrm{N}$-oxide.

Effect of Cofactors on the Formation of Nicotinamide $\mathrm{N}$-Oxide

Figure 1 shows the effect of NADPH (as a NADPH generating system) on the formation of nicotinamide $\mathrm{N}$-oxide. Twenty-five hundredths $\mathrm{ml}$ 


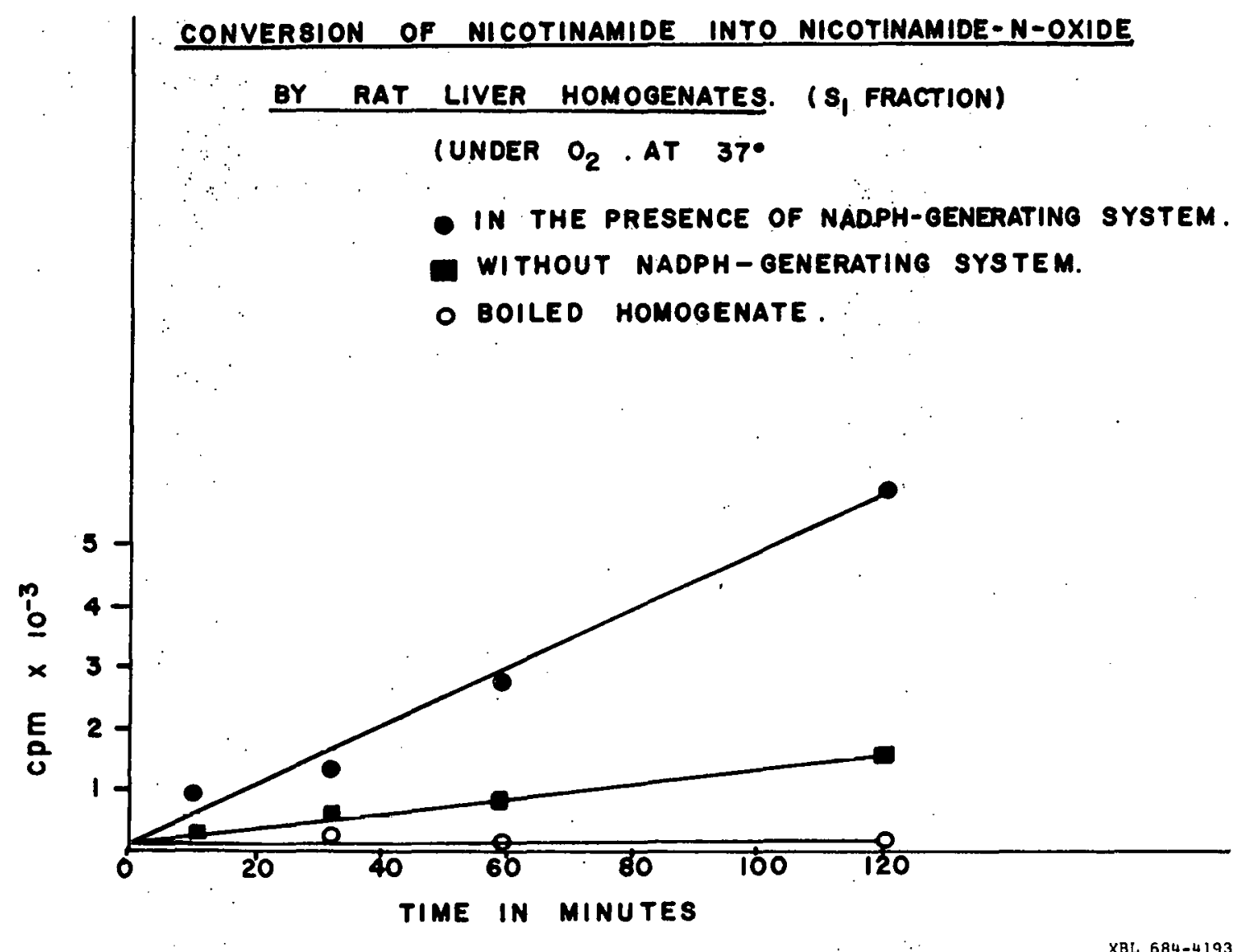

Figure 1. 
aliquots were removed at various times during the course of the incubation and assayed for the nicotinamide $\mathrm{N}$-oxide content.

The formation of nicotinamide $\mathrm{N}$-oxide was examined under aerobic and anaerobic conditions. The results are reported in Figures 2 and 3 . In Figure 2 the formation of nicotinamide $\mathrm{N}$-oxide by the $S_{1}$ fraction of liver homogenates is shown as a function of time. The incubation mixture is the one described under incubations in the experimental section.

0xygen or helium respectively were flushed over the top of the reaction vessel for several minutes and bubbled through the homogenate. A small positive pressure of the gas was maintained over the top of the soluiton. Twenty-five hundredths $\mathrm{ml}$ aliquots were removed at the specified times and assayed for nicotinamide $\mathrm{N}$-oxide.

In another experiment with the $S_{1}$ fraction, using Thunberg tubes and incubation times of $2 \mathrm{hr}$, the $\mathrm{cpm}$ in nicotinamide $\mathrm{N}$-oxide from tubes incubated under helium, air, and oxygen was found to be 5,500, 8,000 , and 9,000 .

In Figure 3 , the formation of nicotinamide $\mathrm{N}$-oxide by the $\mathrm{P}_{100}$ fraction (twice washed) was examined under various atmospheres. In this case, each point on the graph represents a separate reaction vessel which was terminated at the specified time. The reaction vessels were Thunberg tubes which were evacuated and flushed with the specified gas. The homogenate was placed in the top compartment and the nicotinamide with the NADPH generating system was paiced in the bottom compartment. The tubes were tipped and incubated at $37^{\circ} \mathrm{C}$. 


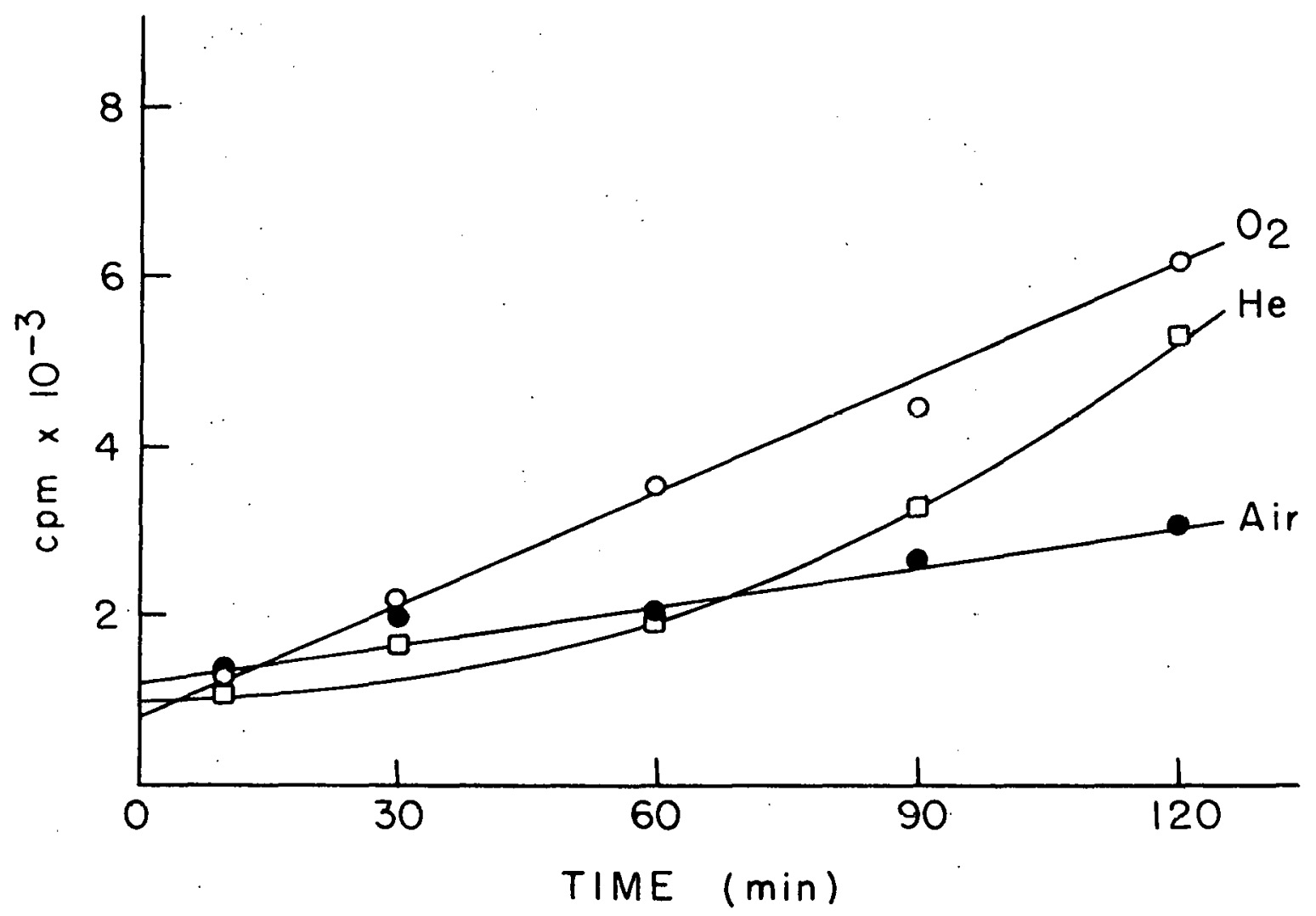

XBL 705-5237

Figure 2. The formation of nicotinamide $\mathrm{N}$-oxide by $\mathrm{l}$ iver homogenates ( $s_{1}$ fraction). Three tubes (described in text) were incubated with $c^{14}$ nicotinamide during the course of incubation and assayed for nicotinamide $\mathrm{N}$-oxide. The ordinate axis is the $\mathrm{cpm}$ in the nicotinamide $\mathrm{N}$-oxide. 


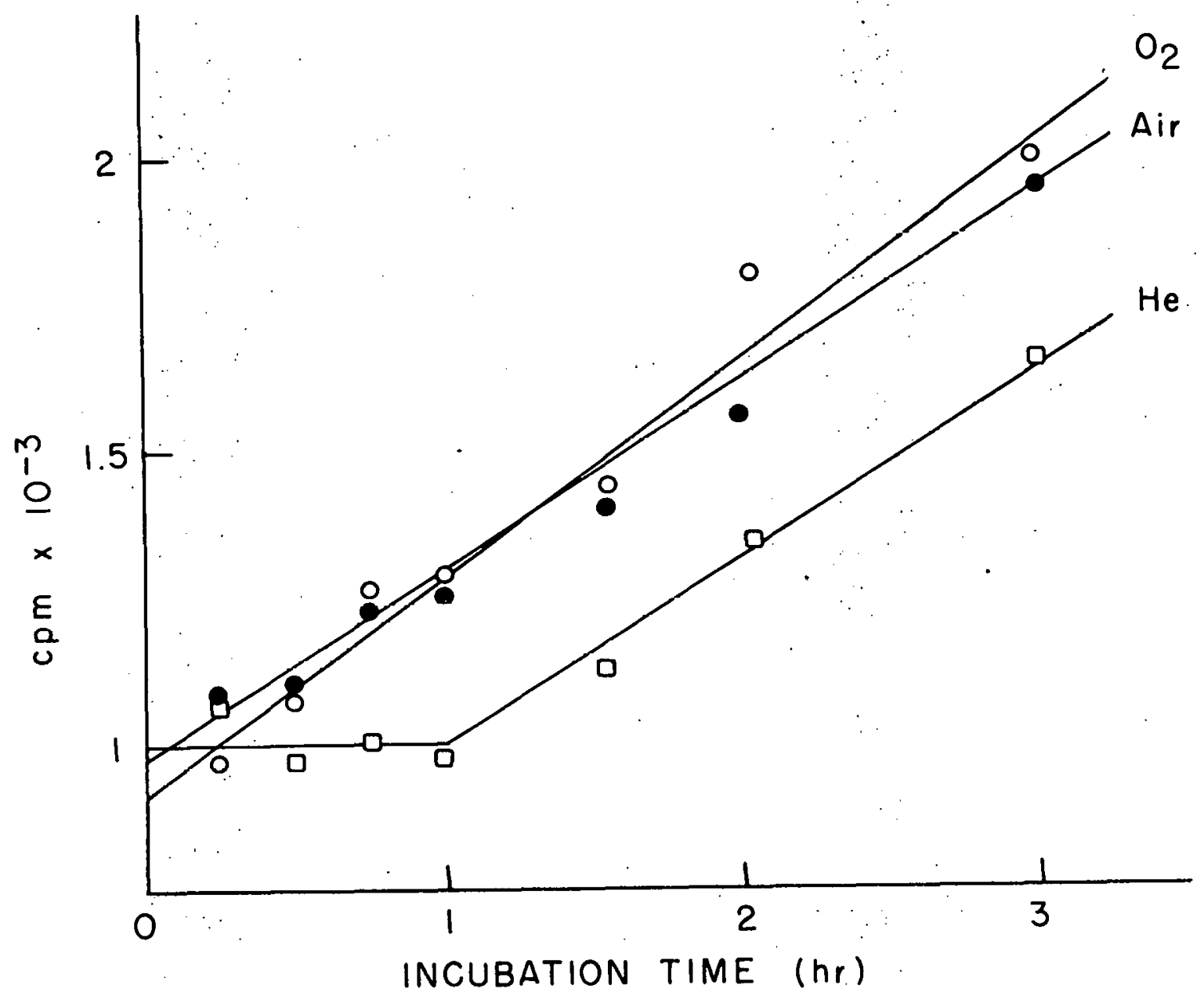

XBL 705-5238

Figure 3. The formation of nicotinamide $\mathrm{N}$-oxide by $\mathrm{liver}$ homogenates $\left(P_{100}\right.$ fraction). Each incubation tube (described in text) was terminated and assayed for nicotinamide $\mathrm{N}$-oxide at the time indicated.

The ordinate axis refers to the cpm in the nicotinamide $\mathrm{N}$-oxide.

The thunberg tubes were flushed with the gasses indicated. 
Purification of the Nicotinamide N-Oxidase

The first purification step was fractionation of the liver homogenate. Table 1 shows the activity of the nicotinamide $\mathrm{N}$ oxidase in various fractions of the homogenate. It is evident from this data that there is a soluble component of the $\mathrm{N}$-oxidase which is a protein. Note that the potentiating effect on $\mathrm{N}$-oxidase activity in $\mathrm{P}_{100}$ by the addition of $\mathrm{S}_{100}$ is destroyed by boiling the $\mathrm{S}_{100}$.

There were a number of attempts to solubilize the $\mathrm{N}$-oxidase from the microsomal fraction. All attempts failed. Freeze-thaw, sonication, and digitonin simply did not solubilize any of the $\mathrm{N}$ oxidase. Deoxycholate $(0.5 \%)$ or Triton $x(1 \%)$ treatment destroyed enzymatic activity. Addition of dithiothreitol $(0.1 \mathrm{M})$ also destroyed the enzymatic activity.

The procedure in attempting to solubilize the $\mathrm{N}$-oxidase is described below. Two methods were tried: 1) adding the detergent or applying the manipulation to the $S_{25}$ fraction, centrifugation at $10^{6} \mathrm{~g}$ and assaying the $S_{100}$ for an increase in activity; and 2) resuspending the pellet $\left(P_{100}\right)$ in the detergent solution, centrifugation at $10^{5} \mathrm{~g}$ and assaying the $S_{100}$ and the $P_{100}$ for activity.

\section{Formation of nicotinamide $\mathrm{N}$-oxide by rat brain}

Four rat brains (total weight $9 \mathrm{~g}$ ) were excised from decapitated rats and homogenated with $22 \mathrm{ml}$ buffer. The fractionation and incubation procedures were the same as those used with rat liver. The incubation time was $2 \mathrm{hr}$. 


\section{Table 1}

NICOTINAMIDE-N-OXIDE FORMATION BY DIFFERENT FRACTIONS OF RAT-LIVER HOMOGENATES

\begin{tabular}{|c|c|c|c|}
\hline \multirow{2}{*}{$\begin{array}{l}\text { Liver Homogenate } \\
\text { fraction }\end{array}$} & \multicolumn{3}{|c|}{ cpm in Nicotinamide- $\mathrm{N}-0 \times$ ide } \\
\hline & $\exp .(i)$ & $\exp (\mathrm{i} i)$ & $\exp (i j i)$ \\
\hline Boiled . $S_{25}$ & 700 & & \\
\hline$s_{\eta}$ & 7,800 & & \\
\hline$S_{25}$ & 8,000 & & 3,600 \\
\hline$s_{100}$ & 700 & 1,500 & 950 \\
\hline$P_{100}$ & 3,600 & 7,000 & 2,000 \\
\hline$P_{100}+S_{100}$ & 6,000 & 16,500 & 4,000 \\
\hline$P_{100}+$ Boiled $S_{100}$ & & 5,000 & 2,100 \\
\hline
\end{tabular}

NOTE: The cpm reported is an average of duplicate runs on the same homogenate. In exp. i ii, 5 volumes/gram liver were used in the homogenation instead of the usual 2.5 volumes buffer/gram liver.

$X B L 705-5236$ 


$\begin{array}{cc}\text { Fraction } & \text { cpm in nicotinamide } \mathrm{N} \text {-oxide } \\ \text { boiled } \mathrm{S}_{1} & 580 \\ \mathrm{~S}_{1} & 950 \\ \mathrm{~S}_{100} & 790 \\ \mathrm{P}_{100} & 1470\end{array}$

- Formation of nicotinamide $\mathrm{N}$-oxide by acetone powder

Acetone powder of rat liver and rat brain were obtained from Mann Biochemical. $0.4 \mathrm{~g}$ were suspended in $10 \mathrm{ml}$ buffer. The incubation procedure was the same as on fresh homogenates. The incubation was terminated at the end of $2 \mathrm{hr}$. The following are the results:

$\begin{array}{cc}\text { Fraction } & \mathrm{cpm} \text { in nicotinamide N-oxide } \\ \text { brain } & 4,300 \\ \text { boiled brain } & 1,000 \\ \text { liver } & 4,400 \\ \text { boiled liver } & 1,000\end{array}$

Check for nicotinamide $\mathrm{N}$-oxidase in other organisms

E. coli, yeast, and spinach leaves were assayed for nicotinamide $\mathrm{N}$-oxidase activity. There was no $\mathrm{N}$-oxidase activity in any of these organisms.

Procedure:

E. coli: $100 \mathrm{ml}$ of E. coli (20 mg protein/ml) was spun down at $3,000 \mathrm{~g}$. The bugs were resuspended in $10 \mathrm{ml}$ buffer medium and put through the french press two times. The incubation procedure was the same as for liver homogenates, except that the temperature was $30^{\circ} \mathrm{C}$. 
Yeast: Two grams frozen yeast was suspended in $10 \mathrm{ml}$ buffer and put through the french press. The assay for $\mathrm{N}$-oxidase was the same as for E. coli.

Spinach leaves: Fresh leaves were picked off a plant, washed, cooled, ribbed. 15 grams were homogenized with $30 \mathrm{ml}$ buffer. The homogenate was fractionated the same as the liver homogenate, and Lhe Incubations were the same. $S_{0}, S_{1}, S_{25}, S_{100}$, and $P_{100}$ were tried.

\section{Discussion}

The important result which is essential to the main question concerning the role of nicotinamide $\mathrm{N}$-oxide in hydroxylase systems is that there is an.enzyme in the microsomes which converts nicotinamide to its $\mathrm{N}$-oxide.

There are a number of interesting questions which arise from the data obtained. However, it must be noted that the enzyme system is very crude and any definitive answers musl walt until the system is solubilized and purified.

There are several factors which implicate the microsomal hydroxylase system in the oxidation of nicotinamide. (A most important fact concerning the source of the source of the oxygen will have to wait for isotopic labelling studies.) The N-oxidase activity is destroyed by detergents. Cytochrome $P_{450}$ is converted to inactive cytochrome $P_{420}$ by the addition of detergents (T. Omura and R. Sato, 1964). J. Schenkman et al. (1967) found that addition of nicotinamide to microsomes in the presence of hydroxylase substrates produced absorption spectra changes. This indicates that the nicotinamide 
binds to the microsomes. In this same paper the authors report that nicotinamide is a competitive inhibitor of aminopyrine demethylase. The significance of this, particularly in light of reported increases in hydroxylase activity with the addition of nicotinamide, is puzzling.

The formation of nicotinamide $\mathrm{N}$-oxide under anaerobic conditions is puzzling. From Figure 3, where each point is a separate tube, no $\mathrm{N}$-oxide is produced for the first hour.. It is possible that there was incomplete deoxygenation, due to the procedure used. Barrie Hesp (from this $1 \mathrm{ab}$ ), in his experiments with deoxygenating enzyme solutions, found that only after extensive bubbling of the solution with helium was the oxygen removed. (Evacuation and flushing with He was not sufficient.) Another possible explanation for the results is that there is an activation of another hydroxylase (possibly dehydrogenase) system under anaerobic conditions. It must be noted that from the experiments of J. Schenkman et al. (1967), it was found that NADPH dependent hydroxylases lost their activity very rapidly with time. (Note that these were aerobic incubations.) Differential inactivation or activation of various enzyme systems or components of these enzyme systems, could possibly explain results as obtained in Figure 2. The conclusion of this little excercise is that it is highly speculative to conclude anything about fine mechanistic details from a crude system of unknown composition and structure. 


\section{Conclusion}

Oxidation of a nitrogen atom to make $\mathrm{N}$-oxides is a general biochemical reaction (M. Bickel, 1969). J. Kirchner and S. Chaykin (1963) reported that nicotinamide $\mathrm{N}$-oxide was formed from nicotinamide in the liver. We have confirmed this finding, extending the scope of the enzyme system.

\section{B. Reduction of Nicotinamide $\mathrm{N}$-Oxide}

There has been much confusion in the literature whether the reduction of $\mathrm{N}$-oxides are enzymatic, non-enzymatic, or require cofactors (M. Bicke1. 1969, p. 341). This same anomalous behavior has been observed in the case of nicotinamide $\mathrm{N}$-oxide, with the microsomal fraction of the liver homogenates... At first the reduction of nicotinamide $\mathrm{N}$-oxide was observed to be affected by various substrates. Then it was discovered that nicotinamide $\mathrm{N}$-oxide was reduced even in the absence of any enzyme. An investigation was undertaken as to the source of this reduction. It was established that reduction occurred during the work-up of the reaction. The particular experiments and the results will be discussed below.

\section{Procedure}

The same incubation procedure was used as with the formation of the nicotinamide $\mathrm{N}-0$. Also the same extraction procedure was used. However, only one-dimensional paper chromatography was employed using the basic solvent to develop the paper. In all the following experiments where $P_{100}$ is roted, a twice washed microsomal fraction of rat liver homogenate was used. (A washing of the microsomal fraction consists of resuspending the pellet $\left(P_{100}\right)$, in buffer, and 
centrifuging again to make washed $P_{100}$ ) In all the incubations ${ }^{14} \mathrm{C}$ nicotinamide $\mathrm{N}$-oxide $(4 \mu \mathrm{C} / \mu \mathrm{M})$ was used in a final concentration of $0.5 \mathrm{mM}$. The results are reported in cpm, since all sample sizes and activities were the same. In the radioautography $3,000 \mathrm{cpm}$ is equivalent to approximately $1 \%$ conversion of nicotinamide $N$-oxide to nicotinamide.

Results

In Table 1 the effect of various substrates of the microsomal hydroxylase system on the reduction of nicotinamide $\mathrm{N}$-oxide are shown. These substrates were present in a concentration of $5 \mathrm{mM}$. In comparing the effect of these various compounds, it seems that lauric acid has the greatest effect. However, it can be noted that the blanks contained a considerable amount of nicotinamide. In Table 2 the effect of lauric acid and cofactors was explored. Here it can be seen that the blanks contained very little nicotinamide. The presence of NADPH seems to increase the amount of nicotinamide formed. In Table 3 further controls were done. It can be seen that the presence of NADPH again increases the amount of nicotinamide formed. The surprising result was that nicotinamide $\mathrm{N}$-oxide alone with buffer was able to be reduced to a substantial degree (approx. $7 \%)$. The degree of reduction seems to be greater than any previous reduction in the presence of liver homogenate.

The control experiments presented in Table 3 indicate that the isolation and separation procedure may yield some reduction of the $\mathrm{N}$-oxide. The chromatographic procedure itself was easily checked by simply spotting a sample of nicotinamide $\mathrm{N}$-oxide directly from 


\section{Table 1}

Incubation of $\mathrm{C}^{14}$ Nicotinamide $\mathrm{N}$-0xide with Liver Microsomes Effect of Drugs

Drug $(5 \mathrm{mM})$

aminopyrine

aniline

caffeine

codeine

squalene

xanthine

lauric acid

blank cpm in nicotinamide

$$
\begin{array}{r}
2,600 \\
2,100 \\
2,900 \\
2,500 \\
3,400 \\
6,900 \\
11,600 \\
8,400
\end{array}
$$

\section{Table 2}

\begin{tabular}{|c|c|c|}
\hline 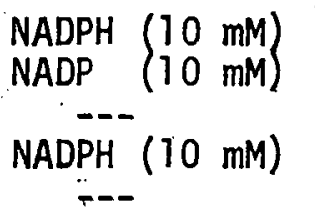 & $\begin{array}{l}P_{1} \\
P_{100} \\
P_{100} \\
100 \\
---\end{array}$ & $\begin{array}{r}10,500 \\
4,200 \\
6,500 \\
26,000 \\
20,000\end{array}$ \\
\hline
\end{tabular}

Incubation of $\mathrm{C}^{14}$ Nicotinamide $\mathrm{N}-0 x i d e$ with Liver Microsomes NADP.H* Laurate $(10 \mathrm{mM})$ He/air $\mathrm{cpm}$ in nicotinamide

$\begin{array}{rrrr}+ & + & \mathrm{He} & 7,400 \\ + & - & \mathrm{He} & 9,700 \\ + & + & \mathrm{He} & 2,400 \\ + & - & \text { He } & 1,200 \\ + & + & \text { Air } & 12,600 \\ + & + & \text { Air } & 5,000 \\ - & + & \text { Air } & 1,500 \\ & + & \text { Air } & 1,600\end{array}$

Table 3

Reduction of Nicotinamide $\mathrm{N}-0 x i d e$

Cofactor Liver homogenate cpm in nicotinamide 
the stock solution, developing the paper, and radioautography. There was 1 ess than $0.5 \%$ nicotinamide formed.

An attempt was made to determine the amount of nicotinamide formed without separating the isolating the products. The first experiment, the reduction of nicotinamide $\mathrm{N}$-oxide by $\mathrm{NADPH}$, was followed using the UV absorption band at 340 to monitor the amount of NADPH. There was no change in the 0.D. at 340 , indicating the MADPH did not reduce the nicotinamide $\mathrm{N}$-oxide. Another method of determining the conversion of nicotinamide $\mathrm{N}$-oxide to nicotinamide in solution was to use a colimetric determination of nicotinamide developed by Mueller and Fox (1951). On incubation of a solution of nicotinamide $\mathrm{N}$-oxide in buffer, with or without added NADPH, NADP, NAD, NADH, no nicotinamide was produced. However, if the extraction procedure was used (i.e., combining methanol fractions and evaporating under reduced vacuum to dryness), nicotinamide was produced in approximately $3 \%$ of the $\mathrm{N}$-oxide added.

Conclusion

The experimental evidence presented here indicates very strongly that there is some reduction of nicotinamide $\mathrm{N}$-oxide by a nonenzymatic process. This non-enzymatic reduction may be caused by NADPH. However, until a procedure is developed which eliminates any reduction during the work-up and separation of nicotinamide $\mathrm{N}$ oxide from nicotinamide, it will be impossible to determine the extent of enzymatic reduction of nicotinamide $\mathrm{N}$-oxide.

Two trends emerge which would need clear definition: 1) The presence of NADPH increases the amount of nfcotinamide formed 
(Figs. 2 and 3); and 2) the presence of microsomal fraction, irrespective of added cofactors, seems to reduce substantially the amount of nicotinamide formed. (Compare especially the 1500-6500 $\mathrm{cpm}$ in nicotinamide when $\mathrm{P}_{100}$ is incubated with nicotinamide $\mathrm{N}$ oxide with the $20,000 \mathrm{cpm}$ in nicotinamide when only nicotinamide. $\mathrm{N}$-oxide is incubated in buffer.)

The possibility remains that the reported enzymatic reduction of aromatic $\mathrm{N}$-oxides may be completely due to xanthine oxidase. K. Murray and S. Chaykin (1966) reported that xanthine oxidase reduces nicotinamide $\mathrm{N}$-oxide. Recently $\mathrm{G}$. Stohrer and G. Brown (1969) found that xanthine oxidase reduces a series of purine $\mathrm{N}-$ oxides. 
II-3 SQUALENE OXIDASE 


\section{Squal lene Oxidáse}

Introduction

In the last section it was shown that nicotinamide $\mathrm{N}$-oxide is indeed a metabolite of nicotinamide. The question that is now posed is whether there is a physiological function for nicotinamide $\mathrm{N}$-oxide, particularly in relation to oxygen activation in hydroxylase systems. One possible role for nicotinamide $\mathrm{N}$-oxide has been outlined in the introduction. (II-I). Whether nicotinamide $\mathrm{N}$-oxide can act as a substitute for molecular oxygen is tested as described in the following sections. The three enzyme systems used are: 1) squalene oxidase, 2) laurate hydroxylase, and 3) p-hydroxybenzoate hydroxylase. The approach is to see if any oxygenated substrates are formed by these enzymes under anaerobic conditions in the presence of nicotinamide $\mathrm{N}$-oxide.

In this section (II-3), squalene oxidase is examined. Squalene acts as the open chain precursor to the sterol structure. The biosynthesis of squalene and its subsequent cyclization to the sterol structure is reviewed by $R$. Clayton (1965). There was very much interest in the oxidation and cyclization of the squalene molecule, both from a chemical and biochemical viewpoint. In 1966, E. Corey et al. (1966) and E. Van Tamelen et al. (1966) independently showed that squalene 2,3-epoxide was the intermediate formed from squalene before cyclization took place. The cofactor requirements for the conversion of squalene to sterols were determined by $T$. Tchen and Bloch (1957) to be the same as those for other "mixed function" oxidases $\left(\mathrm{O}_{2}, \mathrm{NADPH}\right)$. 
It was subsequently shown on a crude enzyme preparation (liver homogenate) by J. D. Willett et al. (1967) and on the purified "oxidosqualene sterol cyclase" (P. Dean et al., 1967), that the cyclization reaction did not require oxygen or NADPH as cofactors. Thus, the conversion of squalene to the epoxide is a mixed function oxidase. T. Tchen and $K$. Bloch (1957) had also shown that nicotinamide incrcased the production of sterols from squalene fourfold over the levels of sterols produced without nicotinamide.

Due to the interest and significance of squalene cyclization, due to the fact that squalene "epoxidase" is a mixed function oxidase, and due to the fact that nicotinamide is implicated in this reaction, squalene oxidase was chosen as one of the enzyme systems to study. Since it was shown that the cyclization of squalene epoxide does not depend on any cofactors and since squalene oxidase is in the microsomes, the squalene oxidase system can be studied by looking at the conversion of squalene to sterols hy liver homogenates.

\section{Experimental}

A crude enzyme preparation was used consisting of fractions of rat liver homogenate. The enzyme was assayed by following the incorporation of radioactive labeled squalene into sterols. The compounds were spearated by thin-layer chromatography (TLC) and gas-liquid chromatography (GLC).

Materials

DL Mevalonic acid-5-3 $\mathrm{H}(50 \mathrm{mC} / \mathrm{mM})$ as DBED salt was obtained from New Engl and Nuclear. ATP, NADP, G-6-P, and G-6-P dehydrogenase were obtained from Cal Biochem. Squalene (Eastman Kodak) was purified by 
gas-liquid chromatography (see assay procedures for conditions). Lanosterol, cholesterol, and dihydrolanosterol were purified according to the procedures employed by Willet, et al. (1967). In the preparation of squalene oxide squalene oxide prepared from the bromohydrin was further purified by column chromatography on silicic acid. The squalene oxide gave the same NMR, elemental analysis, IR, and chromatographic behavior as reported by Willet (1967).

Preparation of Liver Homogenates

The method of homogenation was the same as reported by Bucher and McGarrahan (1956). All work was done at ice temperatures. Male albino rats were decapitated and their livers excised (liver weights averaged $15 \mathrm{~g})$. Each liver was chopped up with a razor blade and homogenized (2.5 ml pH 7.4 phosphate buffer per gram liver) for $30 \mathrm{sec}$ in a Potter-Elvejham homogenizer equipped with a loose fitting teflon pestle (about $5 \mathrm{~mm}$ space between pestle and wall). The crude homogenate was immediately filtered through surgical gauze to remove large particles and fractionated by chetrifugation. The fractionation is described in Figure 1.

Incubation of Homogenates

Reaction vessel: A round-bottom flat ( $15 \mathrm{ml}$ volume) with a Thumberg joint was used. It was found that the shape of the reaction vessel was an essential factor in the incorporation of added squalene into sterols. A round-bottom flask with vigorous shaking gave the best incorporation compared to essentially no incorporation. if a test tube type reaction vessel was used. This is probably due to the 


\section{FRACTIONATION OF LIVER HOMOGENATES}

rat livers ground in Potter-Elve jhem homogenizer (2.5 ml pH 7.4 phosphate buffer $/ \mathrm{g}$ liver).

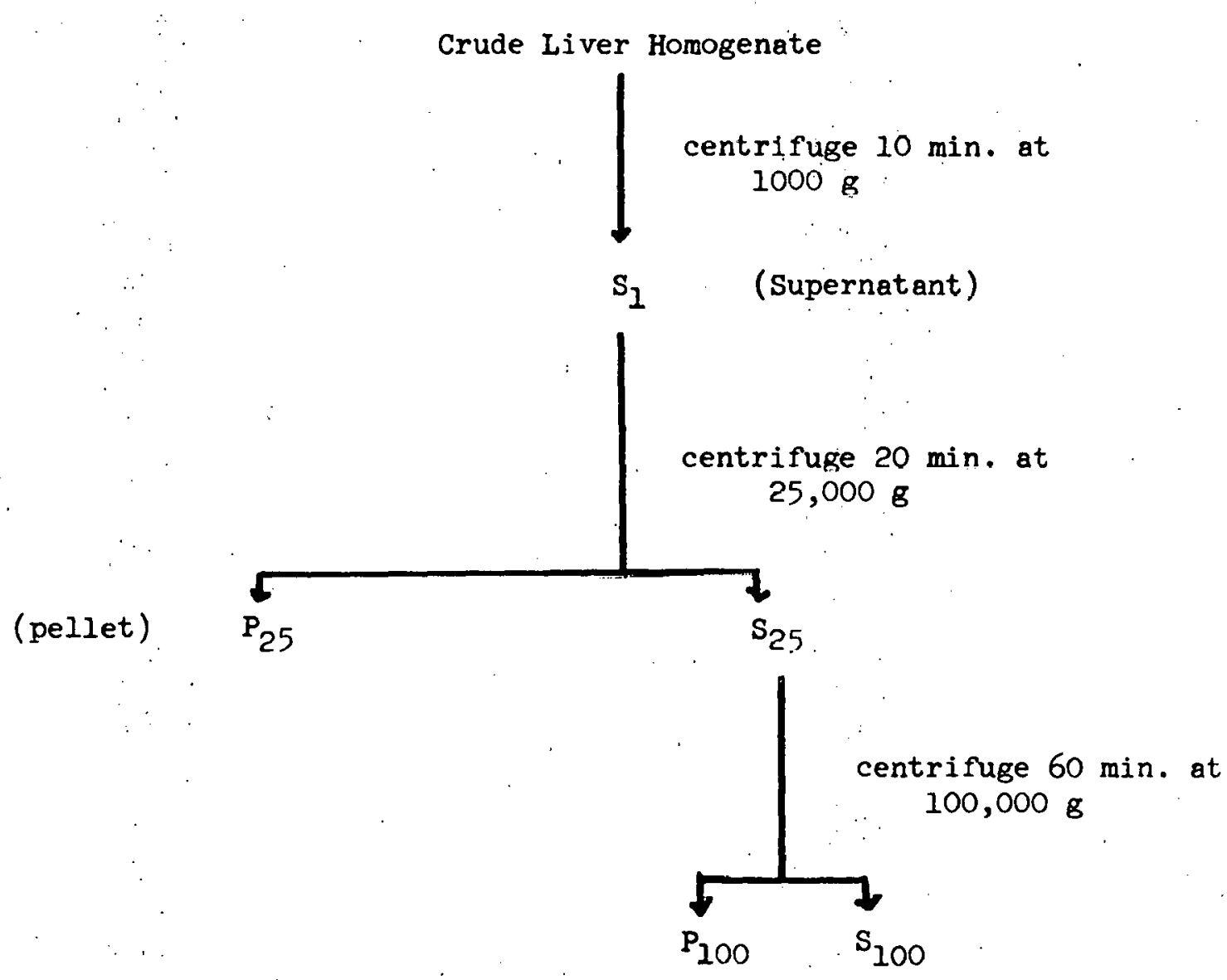

XBL $684-4194$

Figure 1. 
fact that squalene is essentially insoluble and the refore its availability to the enzyme system is due to dispersion of squalene and lipid droplets throughout the homogenate. It was noted that the crude homogenates contained discrete lipid droplets dispersed through the homogenate (possibly the squalene is dissolved in these lipid droplets). If future assays of this type are to be undertaken two possible avenues of overcoming the solubility problem suggest themselves: 1) Add some detergent such as sodium dodecylsulfate (this method would fail if the oxidase is integrally dependent on its structural position in the membranes as many mixed function oxidase systems are); and 2) sonicate the entire incubation mix prior to warming, thus possibly dispersing the squalene in small enough particles so that they will remain suspended.

The Incubation

The incubation is carried out at $37^{\circ}$ with shaking. Squalene is first added in a benzene solution on top of $10 \lambda$ propylene glycol. After the benzene is evaporated the squalene is in a film on the propylene glycol. The liver homogenate fraction is then added. The water soluble components are added in small aliquots. If anaerobic conditions are needed, the NADPH (or NADPH generating system) was placed in the top compartment of the Thunberg tube. The tube is evacuated to $0.4 \mathrm{~mm} \mathrm{Hg}$, then flushed with hëlium (this procedure is repeated three times). After dilaerobic conditions are ostablished, the Thunberg tube is tipped and the reaction initiated. A typical incubati un $1 \mathrm{ir} x$ consists of first adding $165 \mathrm{ig}$ squalene $\left(5 \times 10^{5} \mathrm{dpm}\right)$ and 
$20 \lambda$ propylene glycol. Three $\mathrm{ml} \mathrm{S} \mathrm{S}_{1}$ fraction (combined homogenates of at least two rats) was added, then $0.7 \mathrm{ml}$ of a NADPH generating system $(0.66 \mathrm{ml}) .5 \times 10^{-2} \mathrm{M}$ NADP, $0.1 \mathrm{ml} 0.2 \mathrm{MG}-6-\mathrm{P}, 10 \times \mathrm{G}-6-\mathrm{P}$ dehydrogenase, $2.6 \mathrm{ml}$ buffer). The reaction was terminated by addition of 3 volumes of a 2:1 methanol: $15 \%$ aqueous $\mathrm{KOH}$ solution. Carrier compounds were added in small volumes of acetone. The mixture was sonicated for 1 min and lowed to stand for $15 \mathrm{hr}$. After the completion of this saponification, the mixture was exhaustively extracted with hexane. Greater than $95 \%$ recovery of added radioactivity was achieved (1ess than $1 \%$ of counts remained in the aqueous laver). It was found that the best extraction: procedure was to vigorously stfr the saponification mix with an equal volume of hexane in a large centrifuge tube with a magnetic stirrer for $12 \mathrm{hr}$. After centrifugation, the hexane and aqueous layers were well separated and the hexane layer was drawn off with a pipette. It was found that simple shaking in a separatory flask was unsatisfactory, since after shaking three times with oqual volumes of hexdlle only bU\% of the activity was recovered. The hexane extracts were washed twice with water, dried with sodium sulfate, and the hexane evaporated. A small quantity of benzene was added and the solution was spotted on a TLC sheet or injected tinto GC.

TLC

ChromAR 500 (Mallinckrodt Chemical Co.) prepared TLC sheets were used. The sheets were developed with $2 \%$ ethyl ace tate in $n$-hexane. A spot containing a mixture of pure compounds (squalene, squalene oxide, cholesterol and 1 anosterol) were placed on the edges of the sheet to 
determine the positions. The sheet was cut vertically into strips and the edges visualized with $10 \%$ sulfuric acid. The middle strip (rf: squalene, 0.8 ; squalene oxide, $0.55 ;$ lanosterol, 0.2 ; cholesterol, 0.1$)$ containing the sample spot was cut horizontally, corresponding to the various fractions and shredded directly into scintillation fluid and counted.

$\underline{G L C}$

A glass column was used with on-column injection. The packing was 3\% OV17 on GasChrom Q (Applied Science Lab). A sample of the chromatograph is shown in Figure 2. The fractions corresponding to the various peaks were collected in capillary tubes and washed with benzene into scintillation tubes and counted. Approximately $70 \%$ of the radioactivity injected in the GC was recovered. The collection efficiency was approximately 60 to $80 \%$ as measured by weighing collected fractions of injections of known quantity. The squalene oxide injected was quantitatively converted to two products. This thermal rearrangement will be described below.

Comparison between Results on TLC and GC.

In both cases, the sample containing the radioactive squalene and its products was separated and the individual components counted. The data are presented in relative percent that each fraction had with respect to the total $\mathrm{dpm}$ collected. This method makes the assumption that the collection efficiencies are equal. When a comparison is made by splitting a particular sample in two parts and using the two chromatographic techniques on each part, the GC results are lower in the relative amount of sterols present. This may be due to some decomposition 
GC OF SQUALENE AND STEROLS (Glass column: $3 \%$ OV 17 on gaschrom. Q)

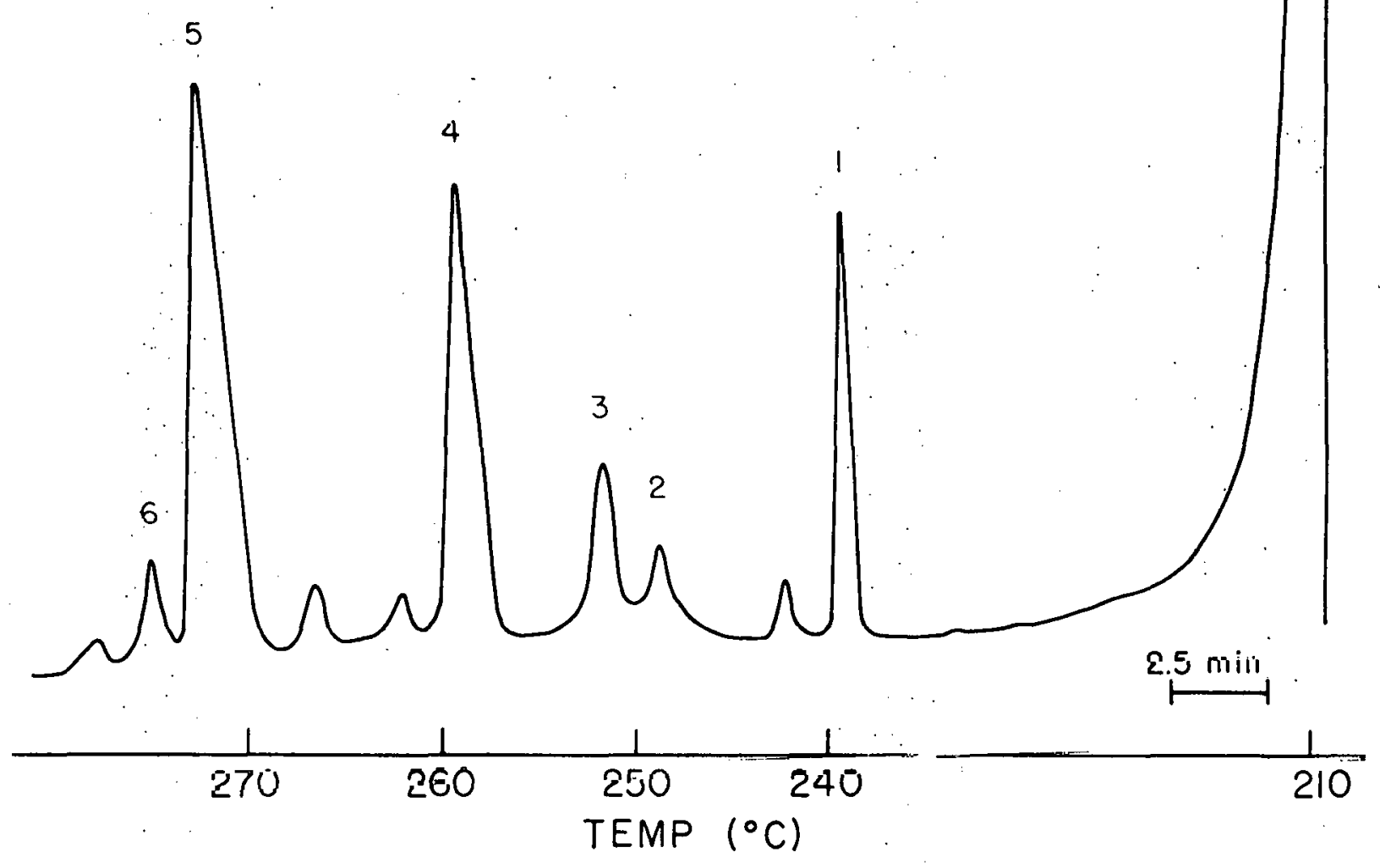

XBL 694-4193

Figure 2. Separation of squalene, squalene oxide and sterols by gas liquid chromatography. Conditions: $6^{\prime} \times 1 / 4^{\prime \prime}$ glass column with oncolumn injection packed with $3 \%$ ov 17 on gaschrom. Q (Applied Science Lab); He gas flow 50 ml/min; inj. temp., $280^{\circ} \mathrm{C}$; detector temp., $280^{\circ} \mathrm{C}$. Peak identification: 1, squalene; 2 and 3, squalene oxide; 4 , cholesterol; 5, dihydrolanosterol; 6,1 anosterol. 
of the sterols on the column, since the collection efficiencies are approximately equal. However, the comparison within one chromatographic procedure leads to the same conclusion for the experiments. Note also that the conversions of squalene to sterols varies widely; however, the results within a set of experiments give the same conclusion.

Thermal Rearrangement of Squalene Oxide

As can be seen in Figure 2, there are two peaks for squalene oxide (peaks numbered 2 and 3 ). These two peaks were each collected and purified by reinjection on the same column. The fact that squalene oxide quantitatively rearranged to these two products was shown in the following manner. A known quantity of squalene oxide was injected, and the areas under the product peaks were measured. These areas were compared to standard mass-area measurements made by injecting known quantities of each of the two purified products. The quantity of squalene oxide calculated from the comparison of areas corresponded closely (within 5\%) to the amount actually injected. The results of the rearrangement are given in Figure 3. Compound $A$ of Figure 3 corresponds to peak number 2 of Figure 2 ; and compound $B$ corresponds to peak 3. The two products are identified by their NMR and IR. Both NMR and IR were taken in $\mathrm{CCl}_{4}$. The NMR data and IR data is tabulated in Tables 1 and 2. The assignments refer to the reaction as shown in Figure 3. In the IR spectra, the absorption maxima reported are those of new bands which are not present in the squalene epoxide IR. 


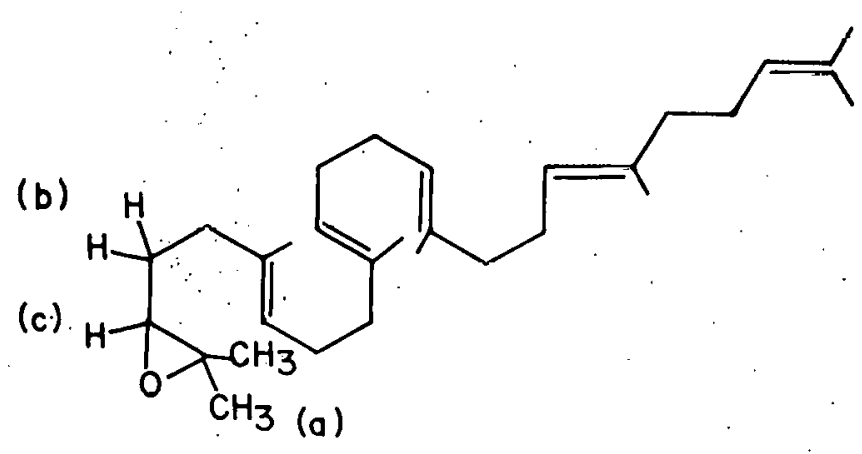

Squalene-2,3-epoxide

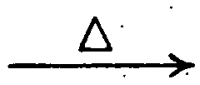

(b)<smiles>CC=C(C)CC1=CCCC(CC(C)C)C1=O</smiles>

A<smiles>CC=C1CC=C(CC(C)C(C)O)CC1</smiles>

(d)

XBL 705-5196

Figure 3. The thermal rearrangement takes place on a GLC column as described in Figure 2. Peaks 2 and 3 of Figure 2 correspond to compounds $A$ and $R$. 


\section{Table 1}

$220 \mathrm{MHz}$ NMR of Products of Squalene Epoxide Rearrangement

Squalene-2,3-epoxide

\begin{tabular}{ccc}
$\begin{array}{c}\text { Spectrum }(\delta) \\
1.18,1.20\end{array}$ & $\begin{array}{c}\text { Integration } \\
6 \mathrm{H}\end{array}$ & $\begin{array}{c}\text { Assignment } \\
\text { methyl H(a) }\end{array}$ \\
$1.57,1.59,1.64$ & $20 \mathrm{H}$ & vinyl methyl $+2 \mathrm{H}(\mathrm{b})$ \\
1.95 & $18 \mathrm{H}$ & allylic H. \\
$2.48(\mathrm{t}, \mathrm{j}=6)$ & $1 \mathrm{H}$ & $\mathrm{H}(\mathrm{c})$ \\
5.05 & $5 \mathrm{H}$ & vinyl H. \\
\hline
\end{tabular}

$j=$ coupling constant

A

Spectrum ( $\delta)$

Integration

Assignment

$1.02,1.07 \quad 6 \mathrm{H}$

$1.57,1.64 .20 \mathrm{H}$

methyl $H(a)$

1.95

$19 \mathrm{H}$

5.05

$5 \mathrm{H}$

vinyl methyl

$+2 \mathrm{H}(\mathrm{b})$

allylic $\mathrm{H}$

$+1 H(c)$

vinyl $H$

$\underline{B}$

\begin{tabular}{|c|c|c|}
\hline Spectrum $(\delta)$ & Integration & Assignment \\
\hline $1.16,1.25$ & $2 \mathrm{H}$ & methylene $H(b)$ \\
\hline $1.57,1.64,1.68$ & $21 \mathrm{H}$ & vinyl methyl $H(a)$ \\
\hline 1.98 & $18 \mathrm{H}$ & allylic H \\
\hline $3.91(t, j=6)$ & I H & $H(c)$ \\
\hline $\begin{array}{l}4.71 \\
4.84\end{array}$ & $\begin{array}{ll}1 & H \\
1 & H\end{array}$ & $\left\{\begin{array}{c}\text { terminal } \\
\text { vinyl } H(d)\end{array}\right.$ \\
\hline 5.05 & $5 \mathrm{H}$ & vinyl $H$ \\
\hline
\end{tabular}


Table 2

IR of Products of Squalene Epoxide Rearrangement

Squalene-2,3-epoxide

A

(new bands appearing) (new bands appearing)

\begin{tabular}{lll} 
IR max & & Assignment \\
2960 & & $v_{\text {as }} \mathrm{CH}_{3}$ \\
2920 & $v_{\text {as }} \mathrm{CH}_{2}$ \\
2815 & & $v_{\text {s }} \mathrm{CH}_{2}$ \\
1450 & & $\delta_{\text {as }} \mathrm{CH}_{3}$ \\
1380 & & $\delta_{\text {s }} \mathrm{CH}_{3}$ \\
1245 & \multicolumn{2}{c}{ epoxide }
\end{tabular}

$\begin{array}{ll}\frac{\text { IR max }}{1725} & \text { Assignment } \\ 1715 & \text { v } \mathrm{C}=0 \\ 1375 & \\ 1380 \\ \text { doublet }\end{array}$

IR max Assignment $3620 \quad 0-H$

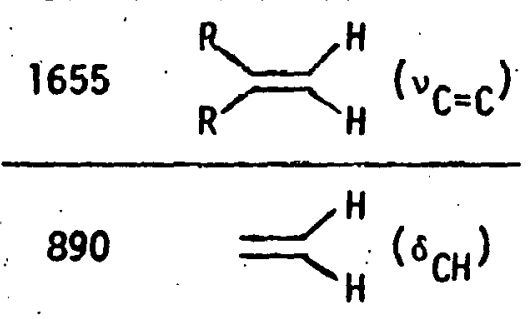

(no 1245) 
89.

\section{Preparation of Squalene $3 \mathrm{H}$}

Three rats were sacrificed, and the livers were homogenated in $0.08 \mathrm{M}$ phosphate buffer $(\mathrm{pH} \mathrm{7.4)}$ containing $4 \mathrm{mM} \mathrm{MgCl} 2$ and $30 \mathrm{mM}$

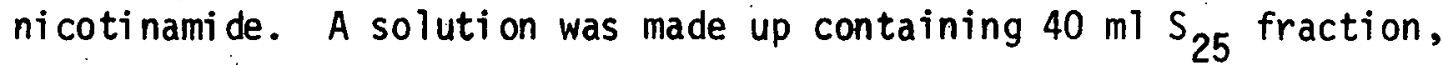
$70 \mathrm{mg}$ mevalonic acid (DBED salt), $0.25 \mathrm{mC} 5-^{3} \mathrm{H}$ mevalonic acid ( $50 \mathrm{mc} / \mathrm{mM}$ ), $10 \mathrm{mg}$ ATP, and $7 \mathrm{ml}$ NADPH generating system $\left(1.33 \mathrm{ml} 1.5 \times 10^{-2} \mathrm{M}\right.$ NADP, $0.2 \mathrm{ml} 0.25 \mathrm{M} \mathrm{G}-6-P, 0.01 \mathrm{ml}$ G-6-P dehydrogenase,; and $5.5 \mathrm{ml}$ buffer).

Ten. Thunberg tubes, each containing $4.8 \mathrm{ml}$ of the stock solution were flushed with he by evacuation four times, and seàled under helium, and incubated at $37^{\circ} \mathrm{C}$ for $2 \mathrm{hr}$. The tubes were combined and the reaction was terminated by the addition of 3 volumes of a 2 to 1 methanol $15 \% \mathrm{KOH}$ solution. The mixture was al lowed to stand approx. $15 \mathrm{hr}$, at which time it was extracted three times with its own volume of hexane. The hexane fraction was washed two times with water and dried over sodium sulfate. The solution was evaporated and placed on an alumina column. The squalene was eluted with hexane. The activity of the eluted fraction containing squalene was $1.1 \times 10^{7} \mathrm{dpm}$. The hexane was evaporated and the squalene was made up to $1 \mathrm{ml}$ with benzene and stored in the freezer.

Results.

The following tables give the experimental results. Much work is not reported here since the experimental procedures were not yet standardized to give good yields of conversion of squalene to sterols. Even when the experimental procedures (note discussion on conflguration of reaclion vessel) were standardized, the conversion of squalene to 


\begin{tabular}{rccc} 
Tube & $\frac{\text { SQ } K}{\text { Atmosphere }}$ & $\frac{\text { Propylene glycol }}{10 \lambda}$ & $\frac{\% \text { Sterols (TLC) }}{17}$ \\
I & $0_{2}$ & $100 \lambda$ & $2 \pi$ \\
II & $0_{2}$ & $300 \lambda$ & 12 \\
III & $0_{2}$ & & 17 \\
\hline
\end{tabular}

Each tube contained: $165 \mu \mathrm{g}$ squalene $\left(10^{6} \mathrm{dpm}\right)$ and $3.7 \mathrm{ml}$ of solution containing $15 \mathrm{ml} \mathrm{S}$ liver homogenate (buffer containec $4 \mathrm{mM} \mathrm{Mg}^{++}$and $30 \mathrm{mM}$ nicotinamide); $0.66 \mathrm{ml}$ $1.5 \times 10^{-2}$ M NADP; $0.1 \mathrm{ml} 0.25 \mathrm{M} \mathrm{G}-6-\mathrm{P} ; 0.01 \mathrm{ml}$ G-6-P dehydrogenase; and $2.6 \mathrm{ml}$ buffer. 
$\underline{S Q-L}$

\begin{tabular}{rccccc} 
Tube & Atmosphere & Nic N-0 & Nic & $\frac{\text { \% Sterols (TLC) }}{4}$ & \% Sterols (GC) \\
I & $0_{2}$ & -- & -- & 4 & 1.9 \\
II & $0_{2}$ & -- & $40 \mathrm{mM}$ & 9.7 & 3.1 \\
III & $0_{2}$ & $40 \mathrm{mM}$ & -- & 5.7 & 2.2 \\
IV & $\mathrm{He}$ & -- & -- & 3.4 & 1.3 \\
VI & $\mathrm{He}$ & $40 \mathrm{mM}$ & -- & 3.4 & 1.2 \\
\hline
\end{tabular}

Each tube contained: $3 \mathrm{ml} \mathrm{S}$ liver homogenate (buffer contained $4 \mathrm{mM} \mathrm{Mg}{ }^{++}$); $0.08 \mathrm{ml}$ propylene glycol; $165 \mathrm{\mu g}$ squalene $\left(10^{6} \mathrm{dpm}\right) ; 0.13 \mathrm{ml} 1.5 \times 10^{-2} \mathrm{M}$ NADP; $0.02 \mathrm{ml} 0.25 \mathrm{M} \mathrm{G-6-P} ; 0.002 \mathrm{ml} \mathrm{G-6-P}$ dehydrogenase; $0.5 \mathrm{ml}$ buffer. 


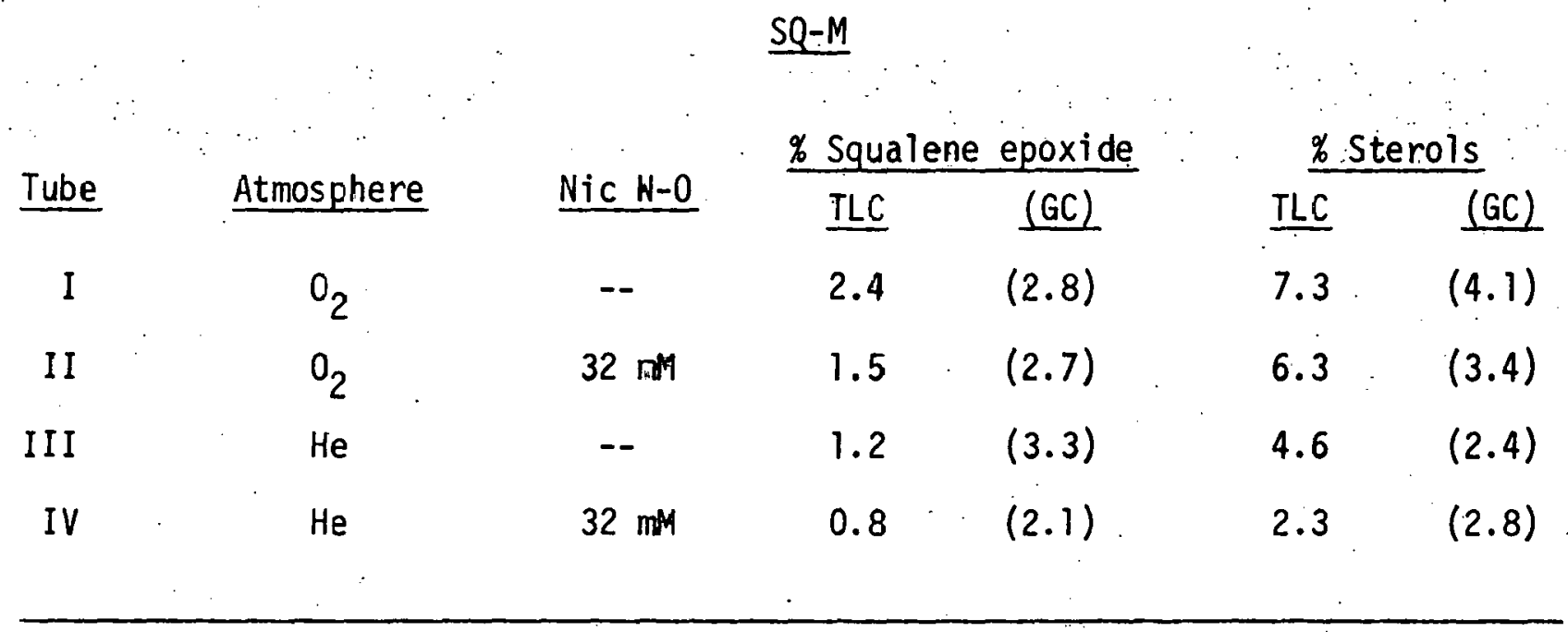

Each tube contained: $4 \mathrm{ml} \mathrm{S}$, liver homogenate (buffer contained $4 \mathrm{mM} \mathrm{Mg}{ }^{+1}$ );

$0.15 \mathrm{ml}$ propylene glycol; $1.65 \mu \mathrm{g}$ squalene. $\left(2 \times 10^{5} \mathrm{dpm}\right)$;

$1 \mathrm{mM}$ NADPH; $0.5 \mathrm{mM}$ NAD. 
$\underline{S Q-N}$

\begin{tabular}{ccc} 
Tube & Atmosphere & \% Sterols (TLC) \\
\hdashline & $\mathrm{O}_{2}$ & 7 \\
I & $\mathrm{He}$ & 2 \\
II & $\mathrm{O}_{2}$ & 15 \\
III & $\mathrm{He}$ & 1
\end{tabular}

Each tube contained: $4 \mathrm{ml} \mathrm{S}$ liver homogenate (buffer contained $4 \mathrm{mM} \mathrm{Mg}{ }^{++}$and $40 \mathrm{mM}$ nicotinamide $\mathrm{N}$-oxide); $0.05 \mathrm{ml}$ propylene glycol; $165 \mu \mathrm{g}$ squalene (see Note) $\left(10^{6} \mathrm{dpm}\right)$; $1 \mathrm{mM} \mathrm{NADPH}$; and $0.5 \mathrm{mM} \mathrm{NAD}$.

Note: Tubes III and IV had squalene ${ }^{3}$ from a different batch than used in SQ-K, L, M and N (I and II). 
SQLO

\begin{tabular}{|c|c|c|c|}
\hline Tube & Nicotinamide (mM) & Squalene (mM) & \% Nicotiramide $\mathrm{N}$-oxide \\
\hline I & 5 & 0.0 & 0.73 \\
\hline II & 5 & 0.1 & 0.81 \\
\hline II I & 5 & 0.5 & 0.82 \\
\hline IV & 5 & 2.0 & 0.85 \\
\hline V & 40 & 0.0 & 0.40 \\
\hline VI & 40 & 0.1 & 0.44 \\
\hline VII & 40 & 0.5 & 0.48 \\
\hline VIII & 40 & 2.0 & 0.48 \\
\hline
\end{tabular}

Each tube contained. (final volume $0.3 \mathrm{ml}$ ): $0.220 \mathrm{ml} \mathrm{s}$ liver homogenate (buffer contained $4 \mathrm{mM} \mathrm{Mg}^{++}$); $0.002 \mathrm{ml}$ propylene glycol; $10 \mathrm{mN} \mathrm{MADPH} ; 5 \times 10^{6} \mathrm{dpm} \mathrm{C}^{14}$ in the nicotinamide. 
sterols varied considerably. This may be due to changes in activity of the enzyme systems or to some uncontrollable variable such as dispersion of squalene in the homogenate. Note that in SQ-N a change in the batch of squalene $3 \mathrm{H}$ made a considerable difference in the sterols produced under $0_{2}$. Note that in $S Q-K$ and $L$ an NADPH generating system was used, whereas in SQ-M and N, NADPH was used. The concentration of NADPH was the same as Scallen et al. (1968). Note that in $\$ Q-N$, the livers were homogenated in buffer containing nicotinamide $\mathrm{N}$-oxide. This experiment was tried since there was a possibility that the site of action of the oxidase was on the inside of the microsomal vesicles and the $\mathrm{N}$-oxide could not pass through the membrane.

In SQ-0, the relationship between the amount of squalene present and the amount of nicotinamide $\mathrm{N}$-oxide formed was studied. This experiment was simply an exploratory one to see if there were any large changes indicating a strong coupling between squalene oxidation and nicotinamide $\mathrm{N}$-oxide formation. Even though there seems to be some slight trend of increasing $\mathrm{N}$-oxide formation with increasing amounts of squalene added, this does not seem to be significant in the light of the errors inherent in the procedure (as discussed in the section on nicotinamide $\mathrm{N}$-axidase). In this experiment the procedures used to determine the amount of nicotinamide $\mathrm{N}$-oxide were similar to those described in Section II-2. 


\section{Conclusion}

The major conclusion that can be drawn from these data is that ni cotinami de $\mathrm{N}$-oxide does not transfer its oxygen to squalene under anaerobic conditions. Thus, nicotinamide $\mathrm{N}$-oxide cannot be a discrete intermediate in activation of oxygen by squalene oxidase. 


\section{II-4 LAURATE HYDROXYLASE.}




\section{Free Fatty Acid Hydroxylase}

Introduction

After the study on squalene oxidase presented in the previous section, a second microsomal mixed function oxidase system was studied. This second system is the hydroxylation of lauric acid. (Peterson et al.; 1969, studied the stoichiometry.) This particular enzyme (or actually substrate for the microsomal enzyme system which may be a single, non-specific hydroxylase) was chosen for several reasons. Lauric acid showed an effect on the reduction of nicotinamide $\mathrm{N}$-oxide in the presence of microsomes (see Table 1 , section (I-2). Hydroxylation in the $\omega$ and $\omega-1$ positions of long chain fatty acids had been demonstrated by B. Preiss and K. Bloch (1964). M. Kusunose et al. (1964) demonstrated w-hydroxylation of lauric acid. A. Lu and M. Coon (1968) succeeded in solubilizing the enzyme system catalyzing w-hydroxylation of lauric acid in rabbit liver microsomes. Three components of the enzyme system were required for activity: cytochrome P-450, TPNH-cytochrome c reductase, and a heat stable factor which was extractable into ether. The possibility that this heat stable factor could be nicotinamide or some heterocyclic aromatic compound supported the investigation of this enzyme system. The same general experimental approach was used as with the squalene oxidase: nicotinamide $\mathrm{N}$-oxide was incubated with liver homogenate, $\mathrm{NADPH}$, and laurate under aerobic and anaerobic conditions and the hydroxylated products were compared. 


\section{Experimental}

A stock solution of $c^{14}$ sodium laurate (purchased from New England Nuclear) was made up so that $20 \mathrm{ml}$ contained $10^{8} \mathrm{dpm}$ and the concentration was $50 \mathrm{mM}$. $0.2 \mathrm{ml}$ of this stock solution was used per $2 \mathrm{ml}$ of the liver homogenate to make a final concentration in the incubation mixture of $0.5 \mathrm{mM}$ of lauric acid. The NADPH generating system was the same one that was used in the squalene oxidase experiments. The homogenations were done as described in the squalene oxidase section.

A typical incubation consisted of $2 \mathrm{ml} \mathrm{S} \mathrm{S}_{25}$ fraction of rat liver homogenate, $0.2 \mathrm{ml}$ laurate stock solution (final conc. of $\left.0.5 \mathrm{mM}, 10^{6} \mathrm{dpm}\right), 0.4 \mathrm{ml} \mathrm{NADPH}$ generating system, and when needed, $3 \mathrm{mg}$ nicotinamide $\mathrm{N}$-oxide in $0.2 \mathrm{ml}$ buffer. If an anaerobic incubation was needed, thunberg tubes were used with the liver homogenate and the NADPH in the bottom compartment and with the nicotinamide $\mathrm{N}$-oxide (when used) ard laurate in the top compartment. The reaction was started by tipping the tube. The incubations were carried out at $37^{\circ} \mathrm{C}$ for one hour. The incubation was terminated by the addition of $1 \mathrm{ml}$ of $10 \%$ sulfuric acid to every $3 \mathrm{ml}$ incubation mixture. The acidic mixture was extracted 7 times with $5 \mathrm{ml}$ of a 9:1 benzene-ether mixture ( $98 \%$ of the added dpm were extracted). The combined extracts were washed with water two times, dried with sodium sulfate, and evaporated to dryness under reduced pressure. The dried extract was dissolved in $0.1 \mathrm{ml}$ methanol and a portion of this was injected into a gas liquid chromatograph (Varian model 204). The peaks were collected in capillary tubes which were 
washed out into scintillation vials and counted. The column for the GC was a $3 \mathrm{ft}, 1 / 4$ inch glass column packed with Chromsorb 101 (Johns Manville). The helium flow was $60 \mathrm{ml} / \mathrm{min}$. The injector, column oven; and detector were maintained at $280^{\circ} \mathrm{C}$. Lauric acid had a retention time of $3.5 \mathrm{~min}$, and the hydroxy acid had a retention time of 8 min.

\section{Results}

The peak corresponding to the hydroxylauric acid (the hydroxylated product being assayed) was determined to be a hydroxy acid by collection of the peak from a preparative run and determined the infrared absorption spectra. The IR showed maxima $\left(\mathrm{cm}^{-4}\right)$ at $3630,3510,3400$ (broad), 3000, 2920, 2850, 1710, 1440, 1380, 1340, $1320,1175,1125,1080$, and 950 . This supports the assignment of the product as a hydroxylauric acid.

Table 1 shows the formation of the hydroxylauric acid under various conditions of incubation. The incubations are as described in the experimental section. It can be seen that under anaerobic conditions very little of the radioactivity added in the lauric acid appears in the hydroxylauric acid peak from the GC of the incubation extracts. There is no increase in the formation of hydroxylauric acid when nicotinamide $\mathrm{N}$-oxide is present.

\section{Conclusion}

Again the conclusion that can be drawn is that nicotinamide $\mathrm{N}$ oxide is not an intermediate in the activation of oxygen by microsomal hydroxylase systems. This confirms the same finding using the squalene oxidase system. 
Table 1

Effect of Nicctinamide $\mathrm{N}-\mathrm{Oxi}$ de on Laurate Hydroxylase

\begin{tabular}{rcccc} 
Tube & Atmosphere & NF.CPH & Nicotinamide N-oxide & \% Hydroxylaurate \\
\cline { 2 - 4 } & air & + & - & 5 \\
II & air & + & $10 \mathrm{mM}$ & 5 \\
III & helium & + & $10 \mathrm{mM}$ & 1.5 \\
IV & helium & - & $10 \mathrm{mM}$ & 2 \\
V & helium & - & - & 1.5
\end{tabular}


II-5 PARAHYDROXYBENZOATE HYDROXYLASE 


\section{P-Hydroxybenzoate Hydroxylase}

\section{Introduction:}

Al though nicotinamide was implicated in microsomal hydroxylase systems, it was shown that nicotinamide $\mathrm{N}$-oxide did not act as a discrete intermediate in the activation of oxygen for squalene oxidase and laurate hydroxylase. The transitory formation of nicotinamide $\mathrm{N}$-oxide by the enzyme with immediate transfer of oxygen to substrate would not be detected by the experimental approach used. Possibly, the potentiation of microsomal hydroxylase systems by nicotinamide could be due to some conformation change brought about by the nicotinamide in the membranes of the microsomes. Thus it seemed reasonable to look at purified, soluble hydroxylase systems.

P-hydroxybenzoate (POB) hydroxylase from psudonomas was studied since the soluble enzyme has been purified, its molecular weight determined $(93,000)$, and some of the mechanistic aspects of the hydroxylation reaction defined (B. Hesp, M. Calvin and K. Hosokawa, 1969). The effect of niçotinamide and nicotinamide $\mathrm{N}$-oxide on this enzyme were studied.

\section{Experimental}

The $\mathrm{POB}$ hydroxylase and the $\mathrm{C}^{14}$ p-hydroxybenzoate were a gift of Dr. Hosokawa. The preparation of the enzyme is given in the paper by K. Hosokawa and R. Stanier (1966). NADPH was purchased from Mann Biochemicals.

In an experiment where anaerobic conditions were necessary, the procedure used was the one described by B. Hesp et al. (1969). Generally buffer, enzyme, and POB were added to a tube and the 
solution was deoxygenated by bubbling with helium. NADPH was then added. At this point nicotinamide $\mathrm{N}$-oxide was added to one tube. The tubes were incubated for two hours at room temperature. The reaction was terminated by heating the samples for ten minutes at $85^{\circ} \mathrm{C}$. The precipitated protein was centrifuged and a known volume of the supernatant was spotted on chromatographic paper. The paper used for paper chronatography was the "Ederol" brand made by J. C. Binzer (Germany). The paper was then developed with a mixture of $100 \mathrm{ml}$ of $69 \%$ butyric acid, $0.85 \% \mathrm{NaOH}$ and $10 \mathrm{ml}$ benzene. The $\mathrm{rf}$ values for the $P O B$ and the product protocathechulic acid (PCA) were 0.8 and 0.6 . The paper was then radioautographed. The spots corresponding to the compounds were cut out, eluted with water, and counted on the liquid scintillation counter.

\section{Rcsults}

The effect of nicotinamide on the formation of PCA

Two tubes were incubated at $4^{\circ} \mathrm{C}$. Tuhe A contained $30 \mathrm{mM}$ nicutinamide. Each tube contained $3 \mathrm{ml} 0.05 \mathrm{M}$ potassium phosphate buffer $\left(\mathrm{pH} \mathrm{7.5)}, 0.075 \mathrm{ml} 2 \times 10^{-7} \mathrm{M} \mathrm{POB}\right.$ hydroxylase, $0.020 \mathrm{ml} 10^{-1} \mathrm{M}$ POB $\left(10^{5} \mathrm{dpm}\right)$, and $0.020 \mathrm{ml} 10^{-1} \mathrm{M} \mathrm{NADPH}$. The contents are added in the order given. At various time intervals $0.3 \mathrm{ml}$ of each tube is removed, placed in a small centrifuge tubc, heated, spun, $0.1 \mathrm{ml}$ is spotted on paper, and POB and PCA determined as described. The re-. sults are given in Figure 1. As can be seen, nicotinamide had a slight inhibitory effect on the formation of PCA. This experiment was repeated at room temperature, and nicotinamide had no effect on the formation of PCA. (At the end of two hours $70 \%$ of the POB had 


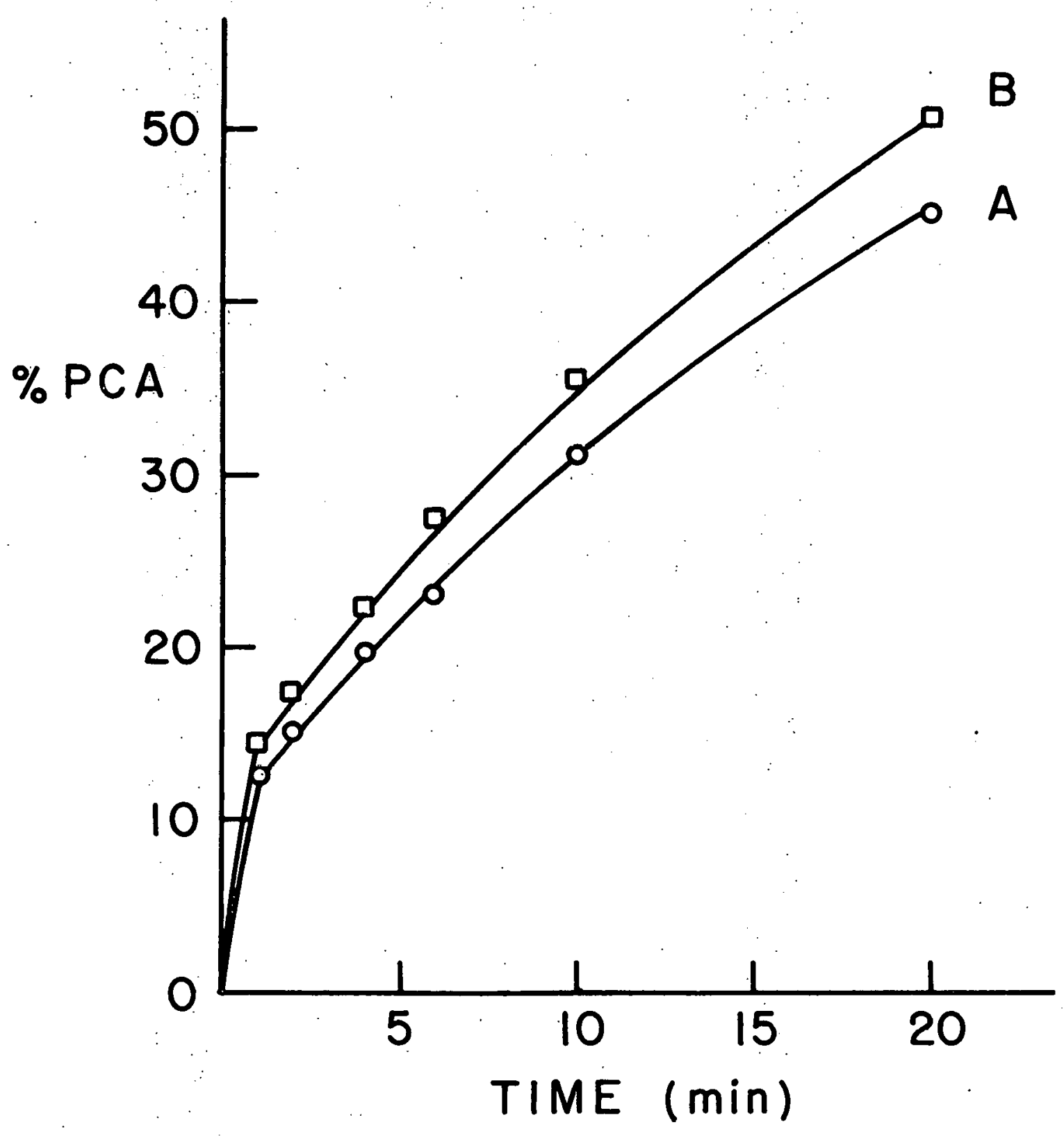

XBL 706-5279

Figure 1. Effect of nicotinamide on the conversion of $p$-hydroxybenzoate $(P O B)$ to protocatechulic acid (PCA) by $P O B$ hydroxylase. A: (0) contains $30 \mathrm{mM}$ nicotinamide; $B:(\square)$ is the control. See text for details on the incubation, 
been converted to PCA with or without nicotinamide present.)

The lack of formation of nicotinamide $\mathrm{N}$-oxide from nicotinamide by POB hydroxylase

Essentially the same experiment was performed as the one for the effect of nicotinamide on PCA formation. In this experiment $\mathrm{C}^{14}$ nicotinamide was added (final conc. of $3 \times 10^{-3} \mathrm{M}$ ), NADPH was $10^{-3} \mathrm{M}$. In a secund tube $\mathrm{POB}$ was added in $10^{-3} \mathrm{M}$ conc. to check if. possible the $\mathrm{N}$-oxide formed during oxidation of $\mathrm{POB}$. A third tube was made up as a control which contained only buffer, NADPH, and the nicotinamide. Aliquots were taken at $30 \mathrm{~min}, 60 \mathrm{~min}$, and $180 \mathrm{~min}$. The reaction was terminated by heating, the tubes were spun, and an aliquot was spotted. The chromatographic procedure was the same as described under the nicotinamide $\mathrm{N}$-oxidase. There was no nicotinamide $\mathrm{N}$-oxide formed.

The lack of oxygen transfer from nicotinamide $\mathrm{N}$-oxide under anaerobic conditions

In this experiment nicotinamide $\mathrm{N}$-oxide was added to the reduced FAD-enzyme-substrate complex in an attempt to replace oxygen by nicotinamide $\mathrm{N}$-oxide. Two tubes were employed in each tube, the procedure was identical except for the addition of nicotinamide $\mathrm{N}$ oxide to one. The other then served as a control. Each tube contained $3 \mathrm{ml}$ buffer, $0.020 \mathrm{ml}$ enzyme $\left(2 \times 10^{-5} \mathrm{M}\right), 0.01 \mathrm{ml} 10^{-1} \mathrm{M}$ $P O B\left(10^{6} \mathrm{dpm}\right)$, some antifoam $C$ above the liquid 1 ine. At this point the tubes were deoxygenated by flushing with extra pure helium. At that point, 1.1 umoles NADPH was added in $0.04 \mathrm{ml}$ buffer. To one tube was then added $5.5 \mu$ moles nicotinamide $\mathrm{N}$-oxide in $0.030 \mathrm{ml}$. 
After allowing the tubes to stand for three hours at room temp. (all above:manipulations were done at ice temp.), the tubes were heated to $85^{\circ} \mathrm{C}$ for $10 \mathrm{~min} .0 .1 \mathrm{ml}$ was then spotted on paper and the amount of PCA formed was determined as described in previous experiments. This experiment was repeated two times. In each case there was no difference between the control and the experimental tubes containing the N-oxide. (13\% PCA formed in each case. This must be due to some slight oxygen leakage or incomplete deoxygenation.)

Conclusion

Neither nicotinamide nor nicotinamide- $\mathrm{N}$-oxide function as cofactors in parahydroxybenzoate hydroxylase. 


\section{CONCLUSION}




\section{Conclusion}

A model system for mi crosomal hydroxylation reactions has been developed. This model system, consisting of a photochemically induced oxygen transfer from pyridine $\mathrm{N}$-oxide to a substrate, has proved to be the best model system to date for enzymatic hydroxylation.

An attempt was made to replace oxygen by nicotinamide $\mathrm{N}$-oxide in microsomal hydroxylase systems and in a microbial hydroxylase. This attempt failed. However, the fact that aromatic $\mathrm{N}$-oxides can form some active intermediate which parallels the "activated" molecular oxygen in hydroxylase systems, and the fact that aromatic $\mathrm{N}$-oxides have been shown to transfer oxygen by xanthine oxidase, indicates that aromatic $\mathrm{N}$-oxides may play a role in enzymatic hydroxylations. The possibility that an aromatic $\mathrm{N}$-oxide is produced "in situ" by the enzymatic system, with subsequent oxygen transfer, will have to wait to be studied until the mi crosomal hydroxylase enzymes have been purified, sequenced, and the active centers determined.

Some of the aspects of these hydroxylase systems which must be kept in mind in further studies are: 1) The enzyme systems must be further purified and characterized; 2) there may be several distinct enzyme systems involved in hydroxylating different substrates; 3) there may be several different mechanisms of action by the same enzyme system for the various substrates. There may be different means of activating molecular oxygen (for example, one electron and two electron transfer centers in the enzyme system) or different cofactor requirements. There is much work being done on these 
hydroxylase systems, and some of these aspects of the problem are being defined.

In Figure 1 is proposed a possible mechanism for the activation of $\mathrm{O}_{2}$ consistent with Bobst's (1968) proposals, using a one-electron transfer center. The scheme shows a generalized aromatic $N$ compound as essential in producing the hydroxylating species $\left(0_{2}^{2-}\right)$. The $\mathrm{N}$ involved could be part of a cofactor molecule (such as FAD, pteridine, nicotinamide) or part of a molecule incorporated in the primary structure of the enzyme itself.

Figure 2 shows a possible two-electron transfer center involving an aromatic $\mathrm{N}$ compound. This scheme is introduced, since $\mathrm{R}-0-\mathrm{O}^{-}$ species have been proposed as possible hydroxylating intermediates. The existence of an aromatic $\mathrm{N}$-dioxide has been described by Edwards and Gillespie (1966). A N-0-0- species may be a more active hydroxylating species than a $\mathrm{C}-0-0^{-}$species. These two schemes are presented only as possible structures to consider as participating in the hydroxylation reaction.

The possibility that other kinds of $\mathrm{N}$-oxides may act as intermediates in the activation of molecular oxygen by hydroxylase systems is still open. H. Schmidt and M. Moeller (1968) report that dimethyl aniline oxide can replace molecular oxygen in some NADPH-dependent oxidations catalyzed by rat liver microsomes. *

Thus the question of $\mathrm{N}$-oxides and activation of molecular oxygen by hydroxylases is still open, and many more questions have been asked.

*The authors have not published their findings yet. This information is from abstracts of papers given at a meeting. It is impossible to assess whether these results have significance to the questions in this thes is. 


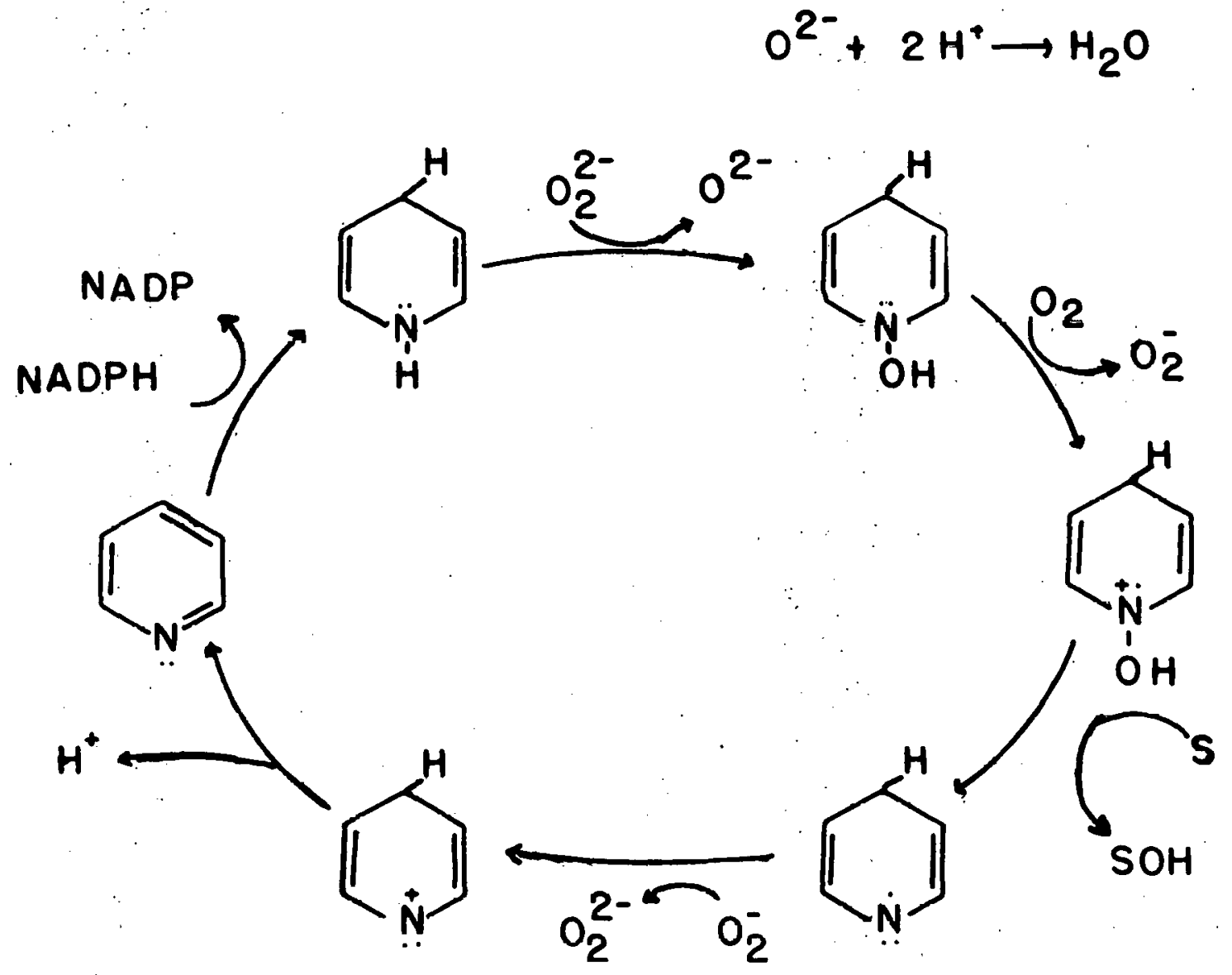

$\mathrm{TPNH}+\mathrm{H}^{+}+\mathrm{O}_{2}+\mathrm{S} \longrightarrow \mathrm{TPN}+\mathrm{H}_{2} \mathrm{O}+\mathrm{SOH}$

Figure 1. Scheme for oxygen activation by hydroxylase $707-5293$ incorporating an aromatic $\mathrm{N}$ compound and a one electron transfer center. 


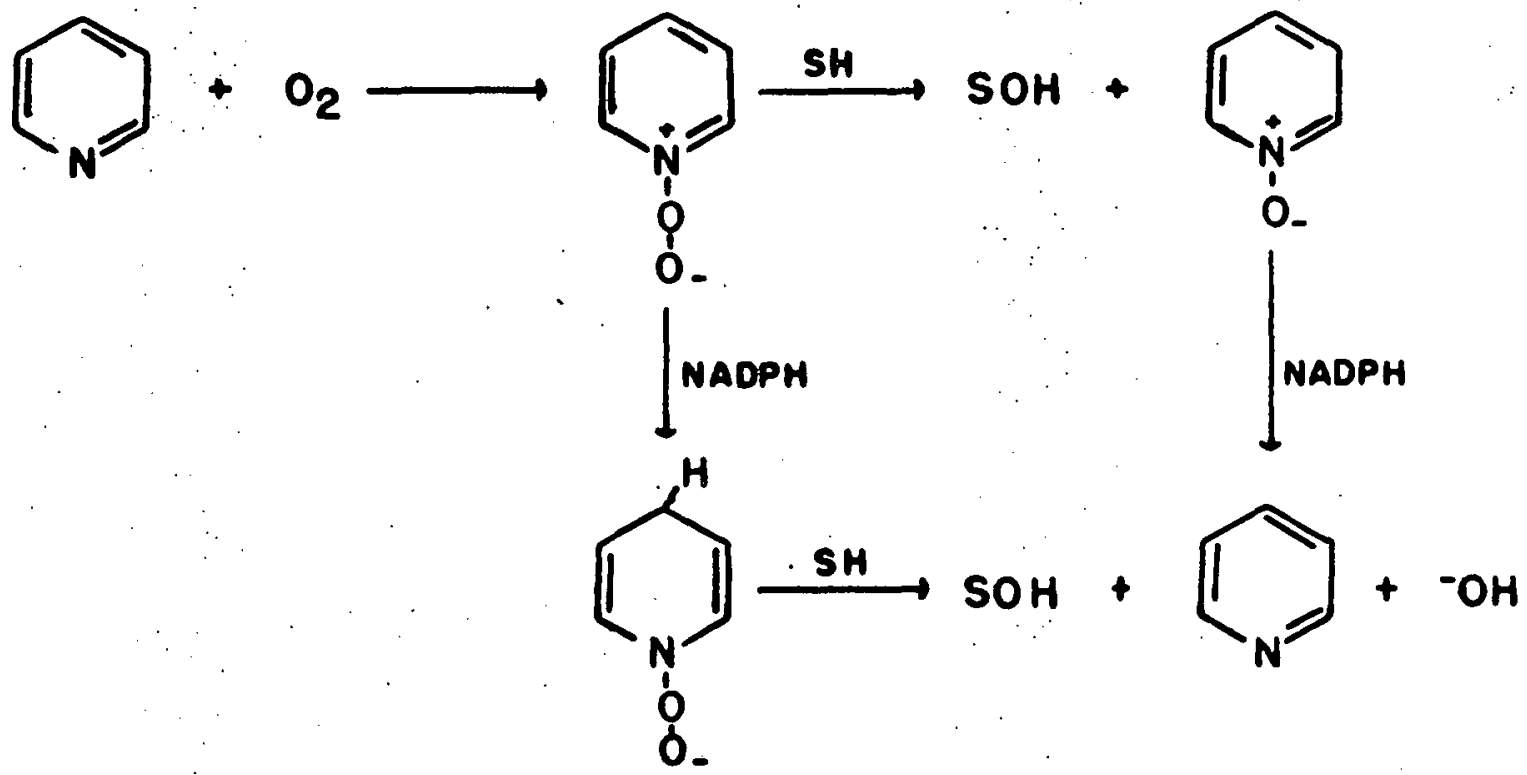

$\mathrm{NADPH}+\mathrm{O}_{2}+\mathrm{S} \stackrel{\text { hydroxylase }}{\longrightarrow} \mathrm{NADP}+{ }^{-} \mathrm{OH}+\mathrm{SOH}$

Fig. 2

Scheme for oxygen activation by hydroxylase incorporating an aromatic $N$ heterocyclyc compound and a two electron transfer center. 


\section{ACKNOWLEDGMENTS}

I thank my wife.

I thank Dr. Melvin Calvin for his constant support. Knowing Dr. Calvin has provided many insights into science and scientific inquiry. His lab reflects his broad interest in the fundamental processes of living systems. My interests and wonder have broadened with each year spent in the laboratory. Dr. Calvin's lab has been the only place I have seen where creativity can flourish. I thank Dr. Richard Lemmon for his support. I thank the many other people in the lab, particularly Dr. Ercole Cavalieri, for the many discussions and technical assistance received. I thank Dr. Henry Chan as a coworker on the nicotinamide work and as a friend. I thank the secretaries and the supporting staff for all the help received in making the work go smoothly. I thank the U. S. Atomic Energy Commission for supporting part of this work. 


\section{References}

Alkaitis, A., and Calvin, M.: The photochemistry of pyridine $\mathrm{N}$-oxide. Chem. Commun., 1968, 292.

Arrhenius, E.: Correlation of $\mathrm{N}$ - and C-oxygenation of aromatic amines with conditions which increase the carcinogenicity of these compounds. Fed. Europ. Biochem. Soc. Symp., 5th Meeting, Vol. 16, (D. Shugar, ed.), Academic Press, New York, 1969, p. 209.

Bickel, M. H.: The pharmacology and biochemistry of $\mathrm{N}$-oxides. Pharmacological Reviews 노, 325 (1969).

Bobst, A. M.: Hydrogenated pteridine derivatives with high group transfer potential. Nature 220, 164 (1968).

Brodie, B. B., Axelrod, J., Cooper, J. R., Gaudette, L., La Du, B., Mitoma, C., and Undenfriend, S.: Detoxification of drugs and other foreign compounds by liver microsomes. Science 121, 603 (1955).

Buchardt, 0.: The photolysis of 2-phenyl substituted quinoline Noxides. A tentative assignment of 4,5-benz-1,3-oxazejplne structures to some of the products. Tetrahedron Letters, 1966, 6221.

Buchardt, 0., Simonsen, 0., and Lohse, C.: Photochemical studies. XVII. The photolys is of 1-phenyl and 1-cyano substituted isoquinoline $\mathrm{N}$-oxides to benz $(f)(1,3)$ oxazepines. (References therein to other $X$-ray studies of oxazepines formed from $\mathrm{N}$-oxides.) Acta Chem. Scand. 24,268 (1970).

Clayton, R. B.: Biosynthesis of sterols, steroids, and terpenoids. Quart. Rev. 19, 201 (1965).

Chaykin (1966): See Murray, K. N., and Chaykin, S. (1966). 
Corey, E. J., Russey, W. E., and Ortiz de Montellano, P. R.: 2,3-0xidosqualene, an intermediate in the biological synthes is of sterols from squalene. J. Amer. Chem. Soc. 88,4750 (1966).

Dean, P.D.G., DeMontellano, P.R.O., Bloch, K., and Corey, E. J.: A soluble 2,3-oxidosqualene sterol cyclase. J. Biol. Chem. 242, 3014 (1967).

Edwards; 0. E., and Gillespie, D. C.: N-dioxides; a new class of amine oxides. Tetrahedron Letters, 1966, 4867.

Emmons, W.: The preparation and properties of oxaziranes. J. Amer. Chem. Soc. $\underline{79}, 5739$ (1957).

Ferris, J. P., Gerwe, D., and Gapski, G. R.: Detoxification mechanisms. III. The scope and mechanism of the iron-catalyzed dealkylation of tertiary amine oxides. J. Org. Chem. $\underline{33}, 349: 3$ (1968).

Fersht, A. W., and Jencks, W. P.: The acylpyridinium ion intermediate in pyridine catalyzed acyl transfer. J. Amer. Chem. Soc. 91, 2125 (1969).

Gelboin, H, V.: A microsome-dependent binding of benzo(a)pyrene to DNA. Cancer Res. 29, 1272 (1969).

Grover, P. L., and Sims, P.: Enzyme-catalyzed reactions of polycyclic hydrocarbons with deoxyribonucleic acid and protein in vitro. Biochem. J. 110, 159 (1968).

Hata, N., and Tanaka, T.: Chemical processes subsequent to the $n-\pi$ and $\pi-\pi$ transitions of pyridine $\mathrm{N}$-oxide and 2-picoline $\mathrm{N}$-oxide. $\mathrm{J}$. Chem. Phys. 36, 2072 (1962).

Hayaishi, 0., and Nozaki, M.: Nature and mechanisms of oxygenases. Science 164, 389 (1969). 
Hayaishi, 0.: Enzymatic hydroxylations. Ann. Rev. Biochem. 28, 21 (1969).

Heinz, E., Tulloch, A. P., Spencer, J.F.T.: Stereospecific hydroxylation of long chain compounds by species of Torulops is. J. Biol. Chem. 244, 882 (1969).

Hesp, B., Calvin, M., and Hosokawa, K.: Studies on p-hydroxybenzoate hydroxyl ase from Pseudomonas putida. J. Biol. Chem. 244, 5644 (1969).

Hill, H.A.O., Roder, A., and Williams, R.J.P.: Cytochrome P-450. Suggestions as to the structure and mechanism of action. Naturwissenschaften $\underline{57}, 69$ (1970).

Holtzman, J. L.: Effect of 4,4-dideuteration of reduced nicotinamideadenine dinucleotide phosphate on the mixed function oxidases of hepatic mi crosomes. Biochemis try 9 , 995 (1970).

Hosokawa, K., and Stanier, R. Y.: Crystallization and properties of p-hydroxybenzoate hydroxylase from peeudomonas putida. J. B101. Chem. 241, 2453 (1966).

I chikawa, Y., and Yamano, T.: Preparation and phys icochemical properties of functional hemoprote in P-450 from mammalian tissue mi crosomes. Bioch im. Biophys. Acta 200, 220 (1970).

Jerina, D. M.: Discussion, p. 231. Microsomes and Drug Oxidations, (J. R. Gillette, et al., eds.), Academic Press, New York, 1969. Jerina, D. M., Boyd, D. R., and Daly, J. W.: Photolysis of pyridine $\mathrm{N}$-oxide: An oxygen transfer model for enzymatic oxygenation, arene epoxide formation, and the NIH shift. Tetrahedron Letters, 1970, 457. 
Jerina, D. M., Daly, J. W., and Witkop, B.: The role of arene oxideoxepine systems in the metabolism of aromatic substrates. II. Synthesis of $3 ; 4-$ toluene- $4-{ }^{2} \mathrm{H}$ oxide and subsequent "NIH shift" to 4-hydroxytoluene-3-2H. J. Amer. Chem. Soc. 90, 6523 (1968). Jerina, D. M., Daly, J. W., Witkop, B., Zaltzman-Nirenberg, P., and Undenfriend, S.: The role of arene oxide-oxepine systems in the metabolism of aromatic substrates. III. Formation of 1,2-naphthalene by liver mi crosomes. J. Amer. Chem. Soc. 90, 6525 (1968).

Jerina, D. M., Daly, J. W., Witkop, B., Zaltzman-Nirenberg, P., and Undenfriend, S.: 1,2-Naphthalene oxide as an intermediate in the mi crosomal hydroxylation of naphthalene. Biochemistry $\underline{9}, 147$ (1970). Jones, D. F.: Microbial oxidation of long-chain aliphatic compounds. Part V. Mechanism of hydroxylation. J. Chem. Soc. (C), 1968, 2827. Kaneko, C., Yamada, S., and Yokoe, I.: Reactions of 1 aH-oxazi rino$(2,3 a) q u i n o l i n e s$ and laH-oxazirino $(2,3 a)$ isoquinolines via 7 -membered oxazepine intermediates. Tetrahedron Letters, 1966, 4701. Kenney, F. T., Holten, D., and Albritton, W. L.: Hormonal regulation of liver enzyme synthesis. National Cancer Institute Monograph 27, 1967.

Kirchner, J., and Chaykin, S.: The biosynthesis of nicotinamide $\mathrm{N}$-oxide. Fed. Proc. 22, 296 (1963).

Kusunose, M., Kusunose, E., and Coon, M. J.: Enzymatic oxidation of fatty acids. I. Products of octonoate, decanoate, and laurate oxidation. J. Biol. Chem. 239, 1374 (1964). 
Leibman, K. C., and Oritz, E.: Oxidation of indene in liver microsomes. Mol. Pharmacol: 4, 201 (1968).

Lu, A.Y.H., and Coon; M. J.: Role of hemoprotein P-450 in fatty acid w-hydroxylation in a soluble enzyme system from liver microsomes.

J. Bior. Chem. 243, 1331 (1968).

Mainwaring, W.I.P.: The effect of age on protein synthesis in mouse liver. Biochem. J. 113, 869 (1969).

Mason, H. S.: Mechanisms of oxygen metabolism. Science 125, 1185 (1957).

McMahon, R. E., and Sullivan, H. R.: The mi crosomal hydroxylation of ethylbenzene stereochemical, induction and isotopic studies. "Microsomes and Drug 0xidations," (J. R. Gillette, et al., eds.), Academic Press, New York, 1969, p. 239.

Murray, K. N., and Chaykin, S.:: The reduction of nicotinamide $\mathrm{N}$-uxide by xanthine oxidase. J. Biol. Chem. 241, 3468 (1966).

Murray, K. N., Watson, J. G., and Chaykin, S.: Catalysis of the direct transfer of oxygen from nicotinamide $\mathrm{N}$-oxide to xanthine by xanthine oxidase. J. Biol. Chem. 241, 4798 (1966).

Ochiai, E.: Recent Japanese work on the chemistry of pyridine 1-oxide and related compounds.. J. Org. Chem. 18, 534 (1953).

Ochiai, E.: Aromatic Amine Oxides. Elsevier Publishing Co., New York, 1967.

Omura, T., Sato, R., Cooper, D. Y., Rosenthal, O., and Estabrook, R. W.: Function of cytochrom P-450 of mi crosomes. Fed. Proc. 24, 1181 (1965). 
Ono, H. K.: Diaryl and triaryl oxaziridines. Ph.D. Thesis, University California, Berkeley, 1969.

Orrenius, S., Gnosspelius, Y., Das, M. L., and Ernster, L.: The hydroxylating enzyme system of liver endoplasmic reticulum. Proc. Fourth Meeting Fed. Europ. Biochem. Soc. 6 , 81 (1967). Peterson, J. A., McKenna, E. J., Estabrook, R. W., and Coon, M. J.: Enzymatic $\omega$-oxidation: Stoichiometry of the $\omega$-oxidation of fatty acids. Arch. Biochem. Biophys. 131, 245 (1969).

Preiss, B., and Bloch, K.: w-Oxidation of long chain fatty acids in rat liver. J. Biol. Chem. 239, 85 (1964).

Putochin, N.: Uber enige verbindungen der pyrrol- und indol-reihe und uber isomerisationen in diesen reihen. Ber. 59, 1987 (1926). Splitter, J. S., and Calvin, M.: 0xaziridines. I. The irradiation products of several nitrones. J. Org. Chem. 30, 3427 (1965). Streith, J., Danner, B., and Sigwalt, C.: Photochemistry of pyridine $\mathrm{N}$-oxides: Atomic oxýgen transfer in solution; a new synthesis of phenol. Chem. Commun., 979 (1967):

Spence, G. G., Taylor, E. C., and Buchardt, 0.: The photochemical reactions of azoxy compounds, nitrones, and aromatic $\mathrm{N}$-oxides. Chem. Rev. 70, 231 (1970).

Strittmatter, P.: Microsomal electron transport. "Biological 0xidations," (T. P. Singer, ed.), Interscience Publishers, New York, 1968, p. $1 \%$.

Stohrer, G., and Brown, G. B.: Purine N-oxides. XXVII. The reduction of purine $\mathrm{N}$-oxides by xanthine oxidase. J. Biol. Chem. 244, 2498 (1969). 
Schenkman, J. B., Ball, J. A., and Estabrook, R. W.: On the use of nicotinamide in assays for microsomal mixed-function oxidase activity. Biochem. Pharmacol. 16, 1071 (1967).

Scallen; T. J., Dean, W. J., and Schuster, M. W.: Enzymatic conversion of squalene to cholesterol by an acetone powder of rat liver microsomes. Biochem. Biophys. Res. Commun. 31, 287 (1968).

Schmidt, H. L., and Moeller, M.: Hydroxylation with dimethylaniline oxide by liver microsomes. Fed. Europ. Biochem. Soc. Meeting, Abstr. 5, 94, 1968.

Stohrer, G.: Reduction of hydroxylamine derivatives by xanthine oxidase. Israe 1 J. Chem. $\underline{6}, 845$ (1968).

Takemori, S., Yasuda, H., Mihara, K., Suzuki, K., and Katagiri, M.: Mechanism of the salicylate hydroxylase reaction. Biochim. Biophys. Acta 191, 58, 69 (1969).

Taylor, E. C., and Crovetti, A. J.: Pyridine-1-oxides. I. Synthesis of some nicotinic acid derivatives. J. Org. Chem. 19, 1633 (1954).

Tchen, T. T., and Bloch, K.: On the conversion of squalene to 1 anosterol in vitro. J. Biol. Chem. 226, 921 (1957).

Tchen, T. T., and Bloch, K.: On the mechanism. of enzymatic cyclization of squalene. J. Biol. Chem. 226, 931 (1957).

Tenhunen, R., Marver, H. S., and Schmid, R.: Microsomal heme oxygenase. J. Biol. Chem. 244, 6386 (1969).

Tsuchiya, T., Arai, H., and Igeta, H.: Photo-induced oxygenation by pyridazine $\mathrm{N}$-oxides. II. Formation of epoxides from ethylenic compounds. Tetrahedron Letters, 1969, 2747. 
Ullrich, $V_{.}$, and Staudinger, $H_{0}:$ Oxygen reactions in model systems. "Mi crosomes and Drug Oxidations," (J. R. Gillette et al., eds.), Academi c Press, New York, 1969, p. 199.

Undenfriend, S., Daly, J. W., Guroff, G., Jerina, D. M., ZaltzmanNirenberg, P., and Witkop, B.: Significance of the NIH shift with respect to liver microsome hydroxylations. "Microsomes and Drug Oxidations," (J. R. Gillette et al., eds.), Academic Press, New York, 1969, p. 225.

Van Tamlen, E. E., Willett, J. D., Clayton, R. B., and Lord, K. E.: Enzymatic conversion of squalene 2,3-oxide to lanosterol and cholesterol. J. Amer. Chem. Soc. 88,4752 (1966). Willett, J. D., Sharpless, K. B., Lord, K. E., Van Tamlen, E. E., and Clayton, R. B.: Squalene-2,3-oxide, and intermediate in the enzymatic conversion of squalene to lanosterol and cholesterol. J. Biol. Chem. 242, 4182 (1967).

Williams, R. J.: Electron transfer and energy conservation, in "Current Topics in Bioenergetics," (R. Sanadi, ed.), Academic Press, New York, Vol. 3, 1969, p. 79. 


\section{LEGAL NOTICE}

This report was prepared as an account of Government sponsored work. Neither the United States, nor the Commission, nor any person acting on behalf of the Commission:

A. Makes any warranty or representation, expressed or implied, with respect to the accuracy, completeness, or usefulness of the information contained in this report, or that the use of any information, apparatus, method, or process disclosed in this report may not infringe privately owned rights; or

B. Assumes any liabilities with respect to the use of, or for damages resulting from the use of any information, apparatus, method, or process disclosed in this report.

As used in the above, "person acting on behalf of the Commission" includes any employee or contractor of the Commission, or employee of such contractor, to the extent that such employee or contractor of the Commission, or employee of such contractor prepares, disseminates, or provides access to, any information pursuant to his employment or contract with the Commission, or his employment with such contractor. 
